Illinois State University

ISU ReD: Research and eData

Theses and Dissertations

$6-15-2020$

\title{
Landscape Performance Of Annual Bedding Plants Following Foliar Application Of Silicon And Titanium
}

Vania Maria Pereira

Illinois State University, vaniapereira1820@gmail.com

Follow this and additional works at: https://ir.library.illinoisstate.edu/etd

Part of the Agriculture Commons

\section{Recommended Citation}

Pereira, Vania Maria, "Landscape Performance Of Annual Bedding Plants Following Foliar Application Of Silicon And Titanium" (2020). Theses and Dissertations. 1304.

https://ir.library.illinoisstate.edu/etd/1304

This Thesis is brought to you for free and open access by ISU ReD: Research and eData. It has been accepted for inclusion in Theses and Dissertations by an authorized administrator of ISU ReD: Research and eData. For more information, please contact ISUReD@ilstu.edu. 


\section{LANDSCAPE PERFORMANCE OF ANNUAL BEDDING PLANTS FOLLOWING FOLIAR APPLICATION OF SILICON AND TITANIUM}

\section{VÂNIA MARIA PEREIRA}

\section{Pages}

The U.S. floriculture industry was estimated at $\$ 4.77$ billion in 2018 with annual bedding plants representing the main segment valued at $\$ 1.46$ billion dollars. Silicon $(\mathrm{Si})$ and titanium (Ti) are beneficial nutrients which can improve growth and quality of greenhouse horticultural crops when applied exogenously. Information is lacking as to whether $\mathrm{Si}$ and Ti enhancement during greenhouse production increases bedding plant performance in the outdoor landscape. Therefore, this study examined landscape performance of four annual bedding plant species treated with foliar applications of $\mathrm{Si}$ and Ti during greenhouse production over two growing seasons. Plant species were selected based on U.S. consumer popularity and included 'Black Velvet Rose F1' geranium (Pelargonium zonale), 'Mega Bloom Pink Halo F1' vinca (Catharanthus roseus), 'Double Hot Cherry' zinnia (Zinnia hybrid) and 'Accent White Hybrid' impatiens (Impatiens walleriana). Silicon treatments were supplied as foliar sodium silicate $\left(\mathrm{NaSiO}_{3}\right)$ treatments at rates of $0,50,150$ and $250 \mathrm{mg} \mathrm{Si} \cdot \mathrm{L}^{-1}$ in a randomized block design. In a similar separate experiment, Ti treatments were supplied as foliar Ti-ascorbate $\left(\right.$ Tytanit $\left.^{\circledR}\right)$ at rates of $0,50,100$ and $150 \mathrm{mg} \mathrm{Ti} \cdot \mathrm{L}^{-1}$. Each study was conducted during the 2018 and 2019 growing seasons. Treatment applications were applied weekly for 4 weeks for impatiens, vinca, and zinnias, and 7 weeks for geraniums. Once plants reached marketable size, they were transplanted into the field in a randomized block design, mulched, and irrigated as needed. Growth and 
quality trait (plant height, number of leaves and flowers/inflorescences, basal stem and flower/inflorescence diameter, SPAD chlorophyll content, and growth index) data were collected before and during treatment application under greenhouse culture and every 15 days in the field starting 30 days after transplanting up until frost. Silicon treatments had a significant impact on the landscape performance of zinnia for the number of inflorescences $(P=0.016)$ and growth index $(P=0.071)$ in 2019 . The $50 \mathrm{mg} \mathrm{Si} \cdot \mathrm{L}^{-1}$ treatment produced the highest number of inflorescences $(P=0.019)$ and highest growth index $(P=0.056)$. Titanium treatments also had a significant effect over time for geranium for plant height $(P=0.013)$ in 2019 and chlorophyll content $(P=0.011)$ for impatiens in 2018 . The $100 \mathrm{mg} \mathrm{Ti} \cdot \mathrm{L}^{-1}$ and $150 \mathrm{mg} \mathrm{Ti} \cdot \mathrm{L}^{-1}$ treatments had a significant effect on plant height $(P=0.016)$ for geraniums. The $50 \mathrm{mg} \mathrm{Ti} \cdot \mathrm{L}^{-1}$ and $100 \mathrm{mg} \mathrm{Ti} \cdot \mathrm{L}^{-1}$ treatments had a significant effect for chlorophyll content $(P=0.012)$ for impatiens. Overall, $\mathrm{Si}$ and Ti supplementation affected the quality and performance of annual bedding plants in the landscape. However, this response was species, concentration amount applied, and year specific. KEYWORDS: beneficial nutrients, landscape performance, quality traits, silicon, titanium, ornamentals 


\title{
LANDSCAPE PERFORMANCE OF ANNUAL BEDDING PLANTS FOLLOWING FOLIAR APPLICATION OF SILICON AND TITANIUM
}

\author{
VÂNIA MARIA PEREIRA
}

\author{
A Thesis Submitted in Partial \\ Fulfillment of the Requirements \\ for the Degree of \\ MASTER OF SCIENCE \\ Department of Agriculture \\ ILLINOIS STATE UNIVERSITY
}


Copyright 2020 Vânia Maria Pereira 


\title{
LANDSCAPE PERFORMANCE OF ANNUAL BEDDING PLANTS FOLLOWING FOLIAR APPLICATION OF SILICON AND TITANIUM
}

\author{
VÂNIA MARIA PEREIRA
}

COMMITTEE MEMBERS:

David E. Kopsell, Chair

Dean A. Kopsell

Robert L. Rhykerd 


\section{ACKNOWLEDGMENTS}

This research project would not have been possible without the assistance of numerous people. I want to start thanking the College of Applied Sciences and Technology (CAST) and Department of Agriculture at Illinois State University (ISU) for the financial support that allowed me to pursue my master's degree.

This thesis would not have been possible without the guidance of my advisor and committee chair Dr. David Kopsell. Thank you for the support and dedication, being always available to answer my questions and help me throughout the research years. I also want to thank my committee members Dr. Robert Rhykerd and Dr. Dean Kopsell, without whose knowledge and assistance this study would not be possible.

I would like also to show my gratitude to the ISU Horticulture Center staff and volunteers, special Nicholas Pershey, Jaci Dixon, Kent Seymour and Kevin Wiand for all help, encouragement and support among these years. I will never forget the moments shared, friendships made, and personal and professional development these interactions have provided me. My earnest thanks to Jessica Chambers for all encouragement and support in all years I spent at ISU. I am forever grateful for all the opportunities she allowed me at the Horticulture Center, the professional development trips and our friendship. I could not have done this without her support.

My most sincere appreciation for my family of friends Andreza Leite, Andre Ferraz, Anderson Ferraz, Tamara Rocha and my boyfriend Derek Ruszkowski for all help during my experiment, emotional support, understanding, and endless love through the duration of my studies. Finally, my sincere and deepest thankfulness for my family, to my parents Eremar Serafim Pereira and Aparecida Maria de Lima Pereira, my brothers Edimar and Ederson Pereira, 
and to my cousins Ana Lima and Adriana Alves. This would not have been possible without them, thank you for believing in me, for the encouragement, utmost support and kindness.

V.M.P 


\section{CONTENTS}

Page

ACKNOWLEDGMENTS $\quad$ i

TABLES

CHAPTER I: THE PROBLEM AND ITS BACKGROUND 1

CHAPTER II: REVIEW OF RELATED LITERATURE 4

Global Floriculture Industry $\quad 4$

United States Floriculture Industry

Overview of the Bedding and Garden Plants Market $\quad 7$

Greenhouse Systems $\quad 8$

$\begin{array}{ll}\text { Structure } & 8\end{array}$

Temperature Control $\quad 9$

$\begin{array}{ll}\text { Light Supplementation } & 10\end{array}$

$\begin{array}{ll}\text { Environmental Control Systems } & 11\end{array}$

$\begin{array}{ll}\text { Irrigation } & 11\end{array}$

$\begin{array}{ll}\text { Root Media } & 12\end{array}$

$\begin{array}{ll}\text { Fertilization } & 12\end{array}$

Pathogens and Insects Management 13

$\begin{array}{ll}\text { Annual Bedding Plants } & 13\end{array}$

$\begin{array}{ll}\text { Greenhouse Production } & 13\end{array}$

$\begin{array}{ll}\text { Consumers Expectations } & 16\end{array}$

$\begin{array}{ll}\text { Consumers Practices } & 17\end{array}$

$\begin{array}{ll}\text { Soilless Media } & 19\end{array}$ 
$\begin{array}{ll}\text { Plant Nutrition } & 21\end{array}$

$\begin{array}{ll}\text { Plant Nutrition History } & 21\end{array}$

$\begin{array}{ll}\text { Essential Elements } & 22\end{array}$

$\begin{array}{ll}\text { Foliar Fertilization } & 26\end{array}$

$\begin{array}{ll}\text { Beneficial Nutrients } & 28\end{array}$

$\begin{array}{ll}\text { Silicon } & 29\end{array}$

$\begin{array}{ll}\text { Introduction to Silicon } & 29\end{array}$

Plant Accumulation and Essentiality 31

Plant Uptake and Metabolism 32

Beneficial Effects for Plant Growth 34

Beneficial Effects for Ornamental Species 36

Silicon Supplementation $\quad 41$

$\begin{array}{ll}\text { Titanium } & 42\end{array}$

Introduction to Titanium $\quad 42$

Plant Uptake and Metabolism 43

Beneficial Effects on Plant Growth 45

Beneficial Effects for Ornamental Species $\quad 52$

Titanium Supplementation 53

CHAPTER III: LANDSCAPE PERFORMANCE OF ANNUAL BEDDING PLANTS FOLLOWING FOLIAR APPLICATION OF SILICON AND TITANIUM 54

$\begin{array}{ll}\text { Abstract } & 54\end{array}$

$\begin{array}{ll}\text { Introduction } & 56\end{array}$

$\begin{array}{ll}\text { Material and Methods } & 60\end{array}$ 
$\begin{array}{ll}\text { Annual Bedding Plant Selection } & 60\end{array}$

$\begin{array}{ll}\text { Greenhouse Culture } & 60\end{array}$

Experiment 1: Silicon Supplementation $\quad 62$

Experiment 2: Titanium Supplementation $\quad 62$

Data Collection on Greenhouse $\quad 63$

$\begin{array}{ll}\text { Landscape Culture } & 63\end{array}$

$\begin{array}{ll}\text { Data Collection on Landscape } & 65\end{array}$

$\begin{array}{ll}\text { Data Analysis } & 65\end{array}$

Results and Discussion $\quad 66$

Experiment 1: Silicon Supplementation $\quad 66$

Experiment 2: Titanium Supplementation 76

CHAPTER IV: CONCLUSION AND RECOMMENDATIONS 84

$\begin{array}{ll}\text { REFERENCES } & 118\end{array}$ 


\section{TABLES}

Table

Page

1. Product analysis for Peter's Professional 20N-10P-20K water soluble fertilizer

2. 'Black Velvet Rose F1' geranium (Pelargonium zonale), 'Mega Bloom Pink Halo F1' vinca (Catharanthus roseus), 'Double Hot Cherry' zinnia (Zinnia hybrid) and 'Accent White Hybrid' impatiens (Impatiens walleriana) landscape data collection (by days after transplanting-DAT) schedule for 2018 and 2019 growing season for Si and Ti experiment at the Horticulture Center, Illinois State University, Normal, IL

3. Soil testing results for 2018 and 2019 growing season at the Horticulture Center at Illinois State University, Normal, IL

4. Yard Waste Compost Analysis for 2018 (08/20/2018).

5. Yard Waste Compost Analysis for 2019 (07/05/2019).

6. Results for multivariate analysis of variance for silicon supplementation effect on overall quality traits for 'Black Velvet Rose F1' geranium (Pelargonium zonale), 'Mega Bloom Pink Halo F1' vinca (Catharanthus roseus), 'Double Hot Cherry' zinnia (Zinnia hybrid) and 'Accent White Hybrid' impatiens (Impatiens walleriana) growing under greenhouse conditions at Illinois State University, Normal, IL for silicon treatments varying from $0,50,150$, and $250 \mathrm{mg} \mathrm{Si} \cdot \mathrm{L}^{-1}$

7. Mean values ${ }^{\mathrm{a}}$ of 'Black Velvet Rose' geranium (Pelargonium zonale) growth parameters after plants reached marketable size under greenhouse conditions at Illinois State University for 2019 growing season, Normal, IL with silicon treatments (Si Concentration) varying from $0 \mathrm{mg} \mathrm{Si} \cdot \mathrm{L}^{-1}$ to $250 \mathrm{mg} \mathrm{Si} \cdot \mathrm{L}^{-1}$ 
8. Mean values ${ }^{\mathrm{a}}$ of 'Double Hot Cherry' zinnia (Zinnia hybrid) growth parameters after plants reached marketable size under greenhouse conditions at Illinois State University for 2019 growing season, Normal, IL with silicon treatments ( $\mathrm{Si}$ Concentration) varying from $0 \mathrm{mg} \mathrm{Si} \cdot \mathrm{L}^{-1}$ to $250 \mathrm{mg} \mathrm{Si} \cdot \mathrm{L}^{-1}$

9. Results for repeated measurements multivariate analysis of covariance for chlorophyll content over time through plant development on landscape conditions for 'Black Velvet Rose F1' geranium (Pelargonium zonale), 'Mega Bloom Pink Halo F1' vinca (Catharanthus roseus), 'Double Hot Cherry' zinnia (Zinnia hybrid) and 'Accent White Hybrid' impatiens (Impatiens walleriana) at the Horticulture Center at Illinois State University, Normal, IL in response to silicon treatments varying from $0,50,150$, and $250 \mathrm{mg} \mathrm{Si \cdot \textrm {L } ^ { - 1 }}$

10. Mean values ${ }^{\mathrm{a}}$ of chlorophyll content (SPAD) for 'Accent White' impatiens (Impatiens walleriana) on landscape culture at the Horticulture Center at Illinois State University for 2018 growing season, Normal, IL by silicon treatments ( $\mathrm{Si}$ Concentration) varying from $0 \mathrm{mg} \mathrm{Si} \cdot \mathrm{L}^{-1}$ to $250 \mathrm{mg} \mathrm{Si} \cdot \mathrm{L}^{-1}$

11. Mean values ${ }^{\mathrm{a}}$ of chlorophyll content (SPAD) for 'Double Hot Cherry' zinnia (Zinnia hybrid) on landscape culture at the Horticulture Center at Illinois State University for 2018 growing season, Normal, IL by silicon treatments ( $\mathrm{Si}$ Concentration) varying from $0 \mathrm{mg} \mathrm{Si} \cdot \mathrm{L}^{-1}$ to $250 \mathrm{mg} \mathrm{Si} \cdot \mathrm{L}^{-1}$

12. Results for repeated measurements multivariate analysis of covariance for the number of flowers and inflorescences over time through plant development on landscape conditions for 'Black Velvet Rose F1' geranium (Pelargonium zonale), 'Mega Bloom Pink Halo F1' vinca (Catharanthus roseus), 'Double Hot Cherry' 
zinnia (Zinnia hybrid) and 'Accent White Hybrid' impatiens (Impatiens walleriana) at the Horticulture Center at Illinois State University, Normal, IL in response to silicon treatments varying from $0,50,150$, and $250 \mathrm{mg} \mathrm{Si} \cdot \mathrm{L}^{-1}$

13. Mean values ${ }^{\mathrm{a}}$ of number of inflorescences for 'Black Velvet Rose F1' geranium (Pelargonium zonale) on landscape culture at the Horticulture Center at Illinois State University for 2019 growing season, Normal, IL by silicon treatments ( $\mathrm{Si}$ Concentration) varying from $0 \mathrm{mg} \mathrm{Si} \cdot \mathrm{L}^{-1}$ to $250 \mathrm{mg} \mathrm{Si} \cdot \mathrm{L}^{-1}$

14. Mean values ${ }^{\mathrm{a}}$ of number of flowers for 'Mega Bloom Pink Halo F1' vinca (Catharanthus roseus) on landscape culture at the Horticulture Center at Illinois State University for 2019 growing season, Normal, IL by silicon treatments ( $\mathrm{Si}$ Concentration) varying from $0 \mathrm{mg} \mathrm{Si} \cdot \mathrm{L}^{-1}$ to $250 \mathrm{mg} \mathrm{Si} \cdot \mathrm{L}^{-1}$

15. Mean values ${ }^{\mathrm{a}}$ of number of inflorescences for 'Double Hot Cherry' zinnia (Zinnia hybrid) on landscape culture at the Horticulture Center at Illinois State University for 2019 growing season, Normal, IL by silicon treatments (Si Concentration) varying from $0 \mathrm{mg} \mathrm{Si} \cdot \mathrm{L}^{-1}$ to $250 \mathrm{mg} \mathrm{Si} \cdot \mathrm{L}^{-1}$.

16. Results for repeated measurements multivariate analysis of covariance for growth index over time through plant development on landscape conditions for 'Black Velvet Rose F1' geranium (Pelargonium zonale), 'Mega Bloom Pink Halo F1' vinca (Catharanthus roseus), 'Double Hot Cherry' zinnia (Zinnia hybrid) and 'Accent White Hybrid' impatiens (Impatiens walleriana) at the Horticulture Center at Illinois State University, Normal, IL in response to silicon treatments varying from $0,50,150$, and $250 \mathrm{mg} \mathrm{Si \cdot \textrm {L } ^ { - 1 }}$ 
17. Mean values ${ }^{\mathrm{a}}$ of growth index for 'Double Hot Cherry' zinnia (Zinnia hybrid) on landscape culture at the Horticulture Center at Illinois State University for 2019 growing season, Normal, IL by silicon treatments (Si Concentration) varying from $0 \mathrm{mg} \mathrm{Si} \cdot \mathrm{L}^{-1}$ to $250 \mathrm{mg} \mathrm{Si} \cdot \mathrm{L}^{-1}$

18. Mean values ${ }^{\mathrm{a}}$ of fresh mass on landscape culture for 'Mega Bloom Pink Halo F1' vinca (Catharanthus roseus) and 'Double Hot Cherry' zinnia (Zinnia hybrid) at the Horticulture Center at Illinois State University for 2019 growing season, Normal, IL by silicon treatments (Si Concentration) varying from $0 \mathrm{mg} \mathrm{Si} \cdot \mathrm{L}^{-1}$ to $250 \mathrm{mg}$ $\mathrm{Si} \cdot \mathrm{L}^{-1}$

19. Mean values ${ }^{\mathrm{a}}$ of dry mass on landscape culture for 'Mega Bloom Pink Halo F1' vinca (Catharanthus roseus) and 'Double Hot Cherry' zinnia (Zinnia hybrid) at the Horticulture Center at Illinois State University for 2019 growing season, Normal,

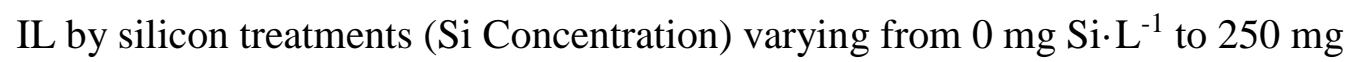
$\mathrm{Si} \cdot \mathrm{L}^{-1}$

20. Results for multivariate analysis of variance for titanium supplementation effect on overall quality traits for 'Black Velvet Rose F1' geranium (Pelargonium zonale), 'Mega Bloom Pink Halo F1' vinca (Catharanthus roseus), 'Double Hot Cherry' zinnia (Zinnia hybrid) and 'Accent White Hybrid' impatiens (Impatiens walleriana) growing under greenhouse conditions at Illinois State University, Normal, IL for titanium treatments varying from $0,50,100$, and $150 \mathrm{mg} \mathrm{Ti} \cdot \mathrm{L}^{-1}$

21. Mean values ${ }^{\mathrm{a}}$ of 'Black Velvet Rose F1' geranium (Pelargonium zonale) growth parameters after plants reached marketable size under greenhouse conditions at 
Illinois State University for 2018 growing season, Normal, IL with titanium treatments (Ti Concentration) varying from $0 \mathrm{mg} \mathrm{Ti} \cdot \mathrm{L}^{-1}$ to $150 \mathrm{mg} \mathrm{Ti} \cdot \mathrm{L}^{-1}$

22. Mean values ${ }^{\mathrm{a}}$ of 'Mega Bloom Pink Halo F1' vinca (Catharanthus roseus) growth parameters after plants reached marketable size under greenhouse conditions at Illinois State University for 2018 growing season, Normal, IL with titanium treatments (Ti Concentration) varying from $0 \mathrm{mg} \mathrm{Ti} \cdot \mathrm{L}^{-1}$ to $150 \mathrm{mg} \mathrm{Ti} \cdot \mathrm{L}^{-1}$

23. Results for repeated measurements multivariate analysis of covariance for plant height over time through plant development on landscape conditions for 'Black Velvet Rose F1' geranium (Pelargonium zonale), 'Mega Bloom Pink Halo F1' vinca (Catharanthus roseus), 'Double Hot Cherry' zinnia (Zinnia hybrid) and 'Accent White Hybrid' impatiens (Impatiens walleriana) at the Horticulture Center at Illinois State University, Normal, IL in response to titanium treatments varying from $0,50,100$, and $150 \mathrm{mg} \mathrm{Ti} \cdot \mathrm{L}^{-1}$

24. Mean values ${ }^{\mathrm{a}}$ of plant height for 'Black Velvet Rose F1' geranium (Pelargonium zonale) on landscape culture at the Horticulture Center at Illinois State University for 2019 growing season, Normal, IL by titanium treatments (Ti Concentration) of $0,50,100$ and $150 \mathrm{mg} \mathrm{Ti} \cdot \mathrm{L}^{-1}$.

25. Results for repeated measurements multivariate analysis of covariance for chlorophyll content over time through plant development on landscape conditions for 'Black Velvet Rose F1' geranium (Pelargonium zonale), 'Mega Bloom Pink Halo F1' vinca (Catharanthus roseus), 'Double Hot Cherry' zinnia (Zinnia hybrid) and 'Accent White Hybrid' impatiens (Impatiens walleriana) at the Horticulture 
Center at Illinois State University, Normal, IL in response to titanium treatments varying from $0,50,100$, and $150 \mathrm{mg} \mathrm{Ti} \cdot \mathrm{L}^{-1}$

26. Mean values ${ }^{\mathrm{a}}$ of SPAD chlorophyll content for 'Accent White Hybrid' impatiens (Impatiens walleriana) on landscape culture at the Horticulture Center at Illinois State University for 2018 growing season, Normal, IL by titanium treatments (Ti Concentration) of $0,50,100$ and $150 \mathrm{mg} \mathrm{Ti} \cdot \mathrm{L}^{-1}$

27. Results for repeated measurements multivariate analysis of number of flowers and inflorescences over time through plant development on landscape conditions for 'Black Velvet Rose F1' geranium (Pelargonium zonale), 'Mega Bloom Pink Halo F1' vinca (Catharanthus roseus), 'Double Hot Cherry' zinnia (Zinnia hybrid) and 'Accent White Hybrid' impatiens (Impatiens walleriana) at the Horticulture Center at Illinois State University, Normal, IL in response to titanium treatments varying from $0,50,100$, and $150 \mathrm{mg} \mathrm{Ti} \cdot \mathrm{L}^{-1}$

28. Mean values a of number of inflorescences for 'Black Velvet Rose F1' geranium (Pelargonium zonale) on landscape culture at the Horticulture Center at Illinois State University for 2019 growing season, Normal, IL by titanium treatments (Ti Concentration) of $0,50,100$ and $150 \mathrm{mg} \mathrm{Ti} \cdot \mathrm{L}^{-1}$

29. Mean values ${ }^{\mathrm{a}}$ of fresh mass on landscape culture for 'Black Velvet Rose F1' geranium (Pelargonium zonale) and 'Mega Bloom Pink Halo F1' vinca (Catharanthus roseus) at the Horticulture Center at Illinois State University for 2019 growing season, Normal, IL by titanium treatments (Ti Concentration) of 0 , 50, 100 and $150 \mathrm{mg} \mathrm{Ti} \cdot \mathrm{L}^{-1}$ 
30. Mean values ${ }^{\mathrm{a}}$ of 'Black Velvet Rose F1' geranium (Pelargonium zonale) dry mass on landscape culture at the Horticulture Center at Illinois State University for 2019 growing season, Normal, IL by titanium treatments (Ti Concentration) of $0,50,100$ and $150 \mathrm{mg} \mathrm{Ti \cdot} \cdot \mathrm{L}^{-1}$ 


\section{CHAPTER I: THE PROBLEM AND ITS BACKGROUND}

Floriculture is a very broad market, including the production of floral crops such as cut flowers and foliage, flower bulbs, potted flowers, foliage plants, and bedding plants (National Agricultural Statistics Service [NASS], 2019) The floriculture market represents an important share of U.S. economy. The U.S. ranks fourth globally in per capita consumption of flowering plants and related goods, spending an estimated \$95.70 per person in 2016 (International Association of Horticultural Producers [AIPH] \& Union Fleurs, 2019). The personal consumption expenditures on flowers, seed, and potted plants have been increasing since 2008, achieving almost $\$ 35$ billion in the last quarter of 2019 (Bureau of Economic Analysis [BEA], 2020). Annual bedding and garden plants represents a large share of U.S. floriculture market, being responsible for $31.6 \%$ of the total wholesale value of all floriculture crops, accounting for \$1.46 billion in 2018, a growing market up 13\% from 2015 (NASS, 2019).

The annual bedding and garden plants section of floriculture refers to any herbaceous plants produced and sold for landscape use, garden beds, or patio containers. These plants can include ornamental and vegetable species (Kaiser and Ernst, 2019). The production of annual bedding plants occurs mainly in greenhouse systems (Link and Ross, 1978). Several important practices take place in a greenhouse environment to facilitate growing operations, the most important of which is the use of soilless growing media. Soilless growing media is commonly composed of lightweight organic and mineral components, providing the plant with support, aeration, and nutrient and water supply (Hamrick, 2003). However, when compared to natural soil, soilless growing media has a low nutrient content, so for adequate plant quality and development, fertilization and nutritional management is required (Reed, 1996). Nutritional deficiency in plants can delay crop development, decrease plant quality and reduce cost 
efficiency (Hamrick, 2003). Providing adequate nutrition is especially important for ornamental plant species where visual quality is highly desired by the consumer (Veatch-Blohm et al., 2012).

Besides essential elements required for primary growth of plants, plant performance can be enhanced by the presence of other elements that do not meet essential criteria. These elements are described as beneficial nutrients, able to stimulate growth by promoting physiological functions in certain plants, in different taxa, and under specific growing conditions. Some examples of beneficial mineral elements are aluminum ( $\mathrm{Al}$ ), selenium $(\mathrm{Se})$, sodium $(\mathrm{Na})$, cobalt $(\mathrm{Cu})$, silicon (Si), and titanium (Ti) (Pilon-Smits et al., 2009). Since the effects of beneficial nutrients are specific to certain growing conditions and plant species and taxa, more studies are required to determine the extent of beneficial effects in the plant ecology (Pilon-Smits et al., 2009).

Silicon is the second most abundant element in the Earth's crust, existing as silicate minerals, a key component to soil composition (Emsley, 2001). In the soil solution, $\mathrm{Si}$ is present as monosilicic acid $\left[\mathrm{Si}(\mathrm{OH})_{4}\right]$ in concentrations that vary from 14 to $20 \mathrm{mg} \mathrm{Si} \cdot \mathrm{L}^{-1}$, with lower concentrations present at high $\mathrm{pH}(\mathrm{pH}>7)$ (Marschner, 1995). Besides having expressive quantities in the soil, Si has not been as extensively studied as well as other nutrients (Sommer et al., 2006). Previous research has shown several benefits from Si supplementation especially under stress conditions, where it can alleviate biotic and abiotic effects. Silicon can decrease the susceptibility of plants to insect and pathogen attacks by inducing plant defense reactions, mitigate abiotic stresses such as freezing and salinity, stimulate mechanisms that reduce excessive loss of water in transpiration under drought circumstances, and reduce heavy metal toxicity (Ma, 1991; Liang et al., 2015; Ma, 2015; Pilon-Smits et al., 2009). 
Titanium is the ninth most abundant element in the Earth's crust (Emsley, 2001). Across plant species, Ti tissue content can vary from 1 to $578 \mathrm{mg} \cdot \mathrm{kg}^{-1}$, averaging $33.4 \mathrm{mg} \cdot \mathrm{kg}^{-1}$. Titanium can be applied to plants as a dry soil application, as a dissolved element in hydroponic culture, or as a foliar application, which is the most effective form of delivery for most plants (Lyu et al., 2017). Some of the improvements in plant quality after Ti fertilization are visualized in seed germination, protein and chlorophyll synthesis, activity of antioxidant enzymes, yield biomass, uptake of nutrients (overall nutritional status of the plant), photosynthesis, carbohydrate production, growth, control of plant diseases, fruit and vegetable quality, and strengthening stress tolerance (Carvajal and Alcaraz, 1998; Lyu et al., 2017). However, reports on Ti are vague and rare (Marschner, 1995). The mechanisms behind the potential beneficial effect of Ti remain unclear and there is need for more research to specifically address of its effect on different plant species (Lyu et al., 2017).

Silicon and Ti have the potential to impact the growth and quality traits of annual bedding plants grown in soilless media when applied during greenhouse production (WhittedHaag et al., 2014). Previous research examining the potential effects from Si and Ti application reported differing results depending on plant species, plant stage, and tissue concentration of nutrients (Mills and Jones, 1996). Due to promising results from previous research of $\mathrm{Si}$ and $\mathrm{Ti}$ supplementation on greenhouse production of annual bedding plants presenting a potential enhance of growth and quality traits. Additional research is essential to determine if $\mathrm{Si}$ and $\mathrm{Ti}$ have effects on the landscape performance of greenhouse-grown annual bedding plants. 


\section{CHAPTER II: REVIEW OF RELATED LITERATURE}

\section{Global Floriculture Industry}

The floriculture market is a specialized branch of horticulture industry which includes the commercial production of floral crops such as annual bedding and garden plants, potted herbaceous perennials, potted flowering plants for indoor and patio use, foliage plants for indoor or patio use, cut flowers, cut cultivated greens, and propagative floriculture materials (NASS, 2019). The global floriculture market is composed of a very integrated and complex supplydemand chain where key producers and consumers are widely spread around the world (AIPH and Union Fleurs, 2019).

The global floriculture market is projected to reach $\$ 96.39$ billion by 2021 (Technavio, 2018). Developed countries represent the biggest share of the market for floricultural products, being concentrated on the United States (U.S.), Canada, Western Europe, and Japan (Nelson, 2012). Likewise, these developed countries hold the higher per capita consumption of flowers, plants and related goods. The U.S. is ranked fourth for the highest expenditure on flowers and related goods in the world, with a consumption of $\$ 97.15$ per capita (AIPH and Union Fleurs, 2019).

Growth in emerging markets and developing economies is projected to reach $4.7 \%$ in 2019 and 2020, increasing from 4.5\% in 2018 (AIPH and Union Fleurs, 2019). Cut flowers and cut foliage are the main products for the developing countries in South and Central America, Africa, the Middle East, and Asia. These products are exported to developed countries, traded on a global scale (Nelson, 2012; van Rijswick, 2016). The supply and demand chain for the sector of live plants, including potted, bedding plants, and nursery products are produced and traded 
regionally (van Rijswick, 2016). Production capacity is proportionally based to the size of the urban area around local or regional growers (Nelson, 2012).

The floriculture industry expands with the economic progress, increase of population and tendency towards urbanization of a nation (Nelson, 2012). Global tendencies for the market are an increase in urban green spaces, online sales, and sustainability with a boost in regional production (Technavio, 2018; van Horen, 2017). The increase of the world's population and metropolitan area concentration escalate the value of green spaces, opening a wide range of new markets for floriculture products (van Horen, 2017). In 2015, the share of online cut flower sales in Europe varied from $4 \%$ in Russia to $10 \%$ in the United Kingdom. The online market is also important to potted indoor plants, accounting for $12 \%$ of sales in France and the Netherlands (van Rijswick, 2016). The European market has been orientating to an increase of demand in perennials, potted and garden plants, with a possible decrease in the cut flower market. Consumers are choosing in-country or on-continent production to decrease the $\mathrm{CO}_{2}$ footprint of the products they purchase and promote sustainable regional floriculture production (van Horen, 2017).

\section{United States Floriculture Industry}

The horticulture industry in the U.S is one of the fastest growing segments on the national agricultural economy, which has experienced growth and expansion even under recession periods (Hall et al., 2006). The floriculture market is a very important sector for the U.S. horticulture economy. In 2019, the per capita consumption of flowers plants and related goods was \$105.70, increasing 8\% from 2016 (BEA, 2020). The overall U.S. personal consumption of flowers, seeds, and potted plants reached \$35 million dollars in the last quarter of 2019 (BEA, 2020). Aging of American population is expected to increase the use of bedding plants for 
outdoor gardening as a recreation lifestyle activity (Hamrick, 2003). As predicted by the 2019 National Gardening Association's annual survey, the interest in gardening from the young population is increasing, 18 to 34 year-olds accounted for a quarter of overall consumption in lawn and garden in 2018 and for 2019 38\% of this age group plan to spend more in garden activities (The National Gardening Association [NGA], 2019).

In 2018, the expanded wholesale value for all crop production in the floriculture industry for growers with $\$ 10,000$ or more in sales, was $\$ 4.77$ billion, a nine percent increase from the prior census taken in 2015. The number of producers and area used for production also increased from 2015. In 2018, floriculture production accounted for 6,386 producers covering an area of approximately 80 million square meters. The total wholesale value of floriculture crops sold on operations with $\$ 100,000$ or more sales for 2018 was $\$ 4.6$ billion, representing most sales and producers for the U.S. (NASS, 2019).

The consumer trends for the 2015 floriculture market were divided into $46 \%$ for outdoor bedding and garden plants, 34\% for fresh flowers, and 20\% for flowering and green houseplants (Agriculture Marketing Resource Center [AgMRC], 2018). Annual bedding and garden plants represent a large share of the U.S. floriculture market, the most important finished crop produced (Hamrick, 2003). Likewise, in 2018 the segment of bedding and garden plants (including herbaceous perennials) was responsible for $47 \%$ of the wholesale value of all reported crops, being the largest single category on the floriculture market with $\$ 2.16$ billion value. Annual bedding and garden plants comprise $\$ 1.46$ billion of the bedding and garden plants segment, representing 67\% of it and increasing 13\% from 2015 (NASS, 2019). 


\section{Overview of the Bedding and Garden Plants Market}

The bedding and garden plant category of the floriculture industry refers to any

herbaceous plants produced and sold for landscape use in garden beds or patio containers (Kaiser and Ernst, 2019). The term bedding plant is not a botanical classification, it defines plants that share common procedures of greenhouse production and retail marketing (Kessler, 2013). Crops in this category include annuals, biennials, perennials, and vegetables, raised in a greenhouse by seeds or cuttings and planted in the gardens as a temporary colorful display (Hessayon, 2004). In the U.S. the bedding garden plant segment of the Floriculture Industry in 2018 represented $47 \%$ of the wholesale value of all floriculture crops (NASS, 2019). The largest contributor inside this category was the annual bedding and garden plants segment, with a wholesale value of $\$ 1,457$ million, representing 67\% of the total bedding and garden market sector (NASS, 2019).

The top five production states in this category are California, Michigan, Florida, North Carolina, and Texas, accounting for $51 \%$ of the total bedding and garden value. Illinois ranks fifteenth in annual/garden plant wholesale value, with a total of $\$ 40.6$ million, almost $40 \%$ of the total wholesale value of all plant categories in the Illinois floriculture industry. The floriculture industry in Illinois covers an area of 1,196 hectare in protected culture and 127 hectare in open ground (NASS, 2019). The increase in bedding and garden annuals production by growers in the Midwest-Illinois region is supported by higher overall prices (Hall et al., 2006).

The most commonly commercialized annual bedding plant species in the U.S. based in the National Agriculture Statistics Survey, Floriculture Crops 2018 Summary are begonia (Begonia spp.), geranium (Pelargonium spp.), impatiens (Impatiens spp.), marigold (Tagetes spp.), pansy (Viola spp.), and petunia (Petunia $x$ hybrid) (NASS, 2019). Bedding plants are grown and marketed in different containers, such as hanging baskets, flats, trays and pots 
(Hamrick, 2003). Consumers of bedding plants seek species to provide instant color to their gardens, easy maintenance, and blooming for all season long (Kessler, 2004). Growers in northern latitudes $\left(\geq 40^{\circ} \mathrm{N}\right)$ start their greenhouse production of annual bedding plants from midwinter to spring to have plants at marketable size (field-grown stage is characterized by a plant with at least one open flower and filling out the container) and blooming at the peak market demand (Olberg and Lopez, 2016). Greenhouse production allows growers of bedding and garden plants to produce a variety of plants all year long (Hamrick, 2003). Usually, the start of production of crops to Spring sales is initiated in January, followed by the production of coldhardy annuals in the Fall season and growth of poinsettia crop for Christmas sales (Aggie Horticulture, 2020).

\section{Greenhouse Systems}

A greenhouse is a protected structure covered with a transparent material to allow light to penetrate through for plant growth. The three purposes of a greenhouse are to: (1) provide a controlled growing environment for economically viable crops; (2) enable plant production in regions that outdoor conditions would not allow; and (3) extend the growing season during times of unfavorable field conditions (Ingels, 1994). The greenhouse production system is considered “intensive" agricultural production. It requires large inputs of capital and labor per unit area to produce crops of high value. Differing from "extensive" production systems, which require large inputs of land area per capital and labor to produce a crop of low value, common to field production (Beytes, 2003).

\section{Structure}

The most common shapes for a greenhouse are A-shaped, Quonset, and gutter connected types. The choice of shape of greenhouses is determined by wind and winter snow loads as well 
as cost and availability. The covering, or glazing materials, include glass, film plastics, fiberglass-reinforced plastic, acrylic panels and polycarbonate sheets and panels (Nelson, 2012). Plant growth in a greenhouse structure can be regulated by chemical and non-chemical process, as water stress, nutritional stress, light, root restriction, and temperatures (Nelson, 2012).

\section{Temperature Control}

The wide range of chemical reactions that occurs in plants and regulates their plant growth are controlled by the environmental temperature (Ingels, 1994). Plants raised in less than ideal temperature conditions can present alterations in crop growth, timing, and blooming (Hamrick, 2003). Under higher temperatures, plant growth rate is increased which reduces stem strength. Flowering can be affected by a premature or delay in blooming, color fade, reduction of flower size, and bud abortion (Hamrick, 2003; Prasad and Kumar, 2005). Warmer temperatures can influence plant timing by a shift of 1 or 2 days to a week in the crop production schedule (Ingels, 1994). Cold temperatures can slow growth rates and decrease the uptake of nutrients (Hamrick, 2003). Different species can present preferences in ideal temperatures for growth, being classified as cool-season and warm-season crops (Ingels, 1994).

Heating is essential in a greenhouse system to keep the temperatures on an optimum range for plant growth (Prasad and Kumar, 2005). The heat required in a greenhouse is defined by the quantity of heat lost, mostly caused by the conduction through the covering material of the greenhouse (Prasad and Kumar, 2005). Additionally, loss can be caused by infiltration of cold air and loss of warm air, and radiation from warmer materials inside of the greenhouse to colder materials outside (Nelson, 2012). Types of greenhouse heating systems include: (1) unit heater: self-contained fireboxes to heat a specific area - also called forced-air heaters; (2) central heat: central boiler of hot water or steam with a radiant system to dissipate the heat; or (3) radiant heat: 
by gas being burned in pipes on the overhead of the greenhouse radiating heat to the plants. Solar heating is a possibility but comes with higher costs (Nelson, 2012).

Cooling systems are required in summer as well as winter. The summer heat can be controlled by evaporating cooling systems such as fan-and-pad and fog, in these systems heat is absorbed by water during evaporation (Prasad and Kumar, 2005). In winter, cooling is commonly used to reduce uneven temperatures inside of the greenhouse, where cold and/or hot spots can lead to irregular crop timing and quality. Two cooling systems for winter include convection-tube and horizontal airflow (HAF) (Nelson, 2012). Ventilation is also essential for uniform plant growth and diseases reduction (Ingels, 1994).

\section{Light Supplementation}

In Northern regions of the U.S., the winter is marked by low light quantities, with short day length duration and periods of cloudy weather (Beytes, 2003). Light influences overall plant growth and quality, as root growth, shoot development, branching and leaf size, and flowering by initiation, size, and quantity (Hamrick, 2003). To overcome the lack of light, supplemental lighting can be used to increase plant growth and manipulate photoperiod lighting, facilitating the promotion of blooming in different periods of the year to growers (Beytes, 2003). Plant growth is influenced by the characteristics of light, quality, intensity, daily light integral (DLI) and daily duration (Nelson, 2012). The options available for growers include High Pressure Sodium (HPS), the most frequent type used due to high efficiency and light spectrum, metal halide, more often for research or crops growing without any natural lightening, and incandescent and fluorescent bulbs, which are still used for photoperiod control (Beytes, 2003). Increasing in popularity is the use of light-emitting diodes (LED) which allow the possibility to control the spectral output from the lights to the plants, maximizing their photosynthetic efficacy, 
also providing high light intensity by low radiant heat, and a using capability that is safe and at a lower power usage (Morrow, 2008).

\section{Environmental Control Systems}

The environmental control system of greenhouses has progressed over the years, starting as manual systems, on and off switches (thermostats and timeclocks), staged controllers to integrated-control computers and model-based computers (Nelson, 2012). Computer-controlled, automated growing systems increase grower's productivity and crop quality (Prasad and Kumar, 2005). The benefits provided are the uniformity of crops, better timing, higher quality, disease control, conservation of energy, decreased labor and increased profit (Nelson, 2012).

\section{Irrigation}

Watering issues is the process that accounts for the highest loss in plant quality in greenhouse production. Underwatering induces wilting and slows growth in plants due to the reduction of photosynthesis, also causes a hardened appearance of the plants, burning or dropping lower leaves. In bedding plants, a controlled underwatering practice can provide a control over plant height without damaging the quality of the crop. Overwatering can cause a rapid expansion of soft new growth, which is susceptible to dry periods and wilting easily, making the shipping process difficult. Plant root systems can be injured by the excess of water causing wilting, hardened growth, overall stunning and nutrient deficiency symptoms (Nelson, 2012). Irrigation can be provided by overhead systems, surface systems, and subsurface systems (Ingels, 1994). Proper watering begins with the choice of a well-drained substrate, performing irrigation when initial moisture stress is visible, and watering the whole substrate thoroughly (Nelson, 2012). 


\section{Root Media}

The main purposes of root media are to provide support for plant growth, a reservoir of water and nutrients, and gas exchanges between roots and the atmosphere (Prasad \& Kumar, 2005). Soilless media is used as the main root substrate for greenhouse production because it provides a mixture of uniform composition, it is free of pathogens, and it is lightweight, which facilitates handling and shipping (Nelson, 2012). The composition materials and concentrations of a mix can vary regionally according to the available resources, moreover, special mixes are also formulated for specific crops and/or specific container sizes (Hamrick, 2003). Soilless media formulation is based on two or more major ingredients that will determine the main physical characteristics of the media. Common main ingredients include sphagnum peat moss, pine bark, core, and vermiculite. In addition to the main ingredients, other materials added to provide specific qualities to the media as amendments, for example, liming material, calcium sulfate, inorganic fertilizer, wetting agents, and sand (Jones, 2012).

\section{Fertilization}

In comparison to all other production factors, fertilization has the greatest effect on plant quality and longevity (Hamrick, 2003). There are fourteen elements commonly defined as essential to plant growth, grouped into the two categories of macronutrients and micronutrients, depending on the amount required by the plant (Marschner, 1995). Macronutrients are absorbed in relatively large quantities, being present in dry plant tissue on concentrations of $0.2 \%(2 \mathrm{~g} / \mathrm{kg})$ to $7 \%(70 \mathrm{~g} / \mathrm{kg})$. Nitrogen $(\mathrm{N})$, potassium $(\mathrm{K})$ and phosphorus $(\mathrm{P})$ are considered primary macronutrients and are included in most complete fertilizers. Calcium $(\mathrm{Ca})$, magnesium $(\mathrm{Mg})$, and sulfur (S) are considered secondary macronutrients, which may or may not be present in the greenhouse fertilizer mixes. Micronutrients are required in lesser quantities and their 
concentration in dry plant tissue ranges from $0.0001 \%(0.001 \mathrm{~g} / \mathrm{kg})$ to $0.06 \%(0.06 \mathrm{~g} / \mathrm{kg})$. Iron $(\mathrm{Fe})$, manganese $(\mathrm{Mn})$, zinc $(\mathrm{Zn})$, copper $(\mathrm{Cu})$, boron $(\mathrm{B})$, and molybdenum $(\mathrm{Mo})$ are essential micronutrients and are mainly supplied by commercial growing media or exogenous fertilizers. The two other essential micronutrients nickel $(\mathrm{Ni})$ and chlorine $(\mathrm{Cl})$ are not supplied by fertilization due to their occurrence in media and fertilizers (Ingels, 1994).

Greenhouse fertilization is essential due to increased plant growth which occurs in a short period of time (Prasad and Kumar, 2005). The fertilization program can be performed by mixing dry fertilizers into the growing media substrate prior to planting or by adding liquid fertilizers in the irrigation system, termed fertigation, post planting (Ingels, 1994; Prasad and Kumar, 2005).

\section{Pathogens and Insects Management}

Diseases and insects are a great concern to greenhouse production. They can affect the crop's aesthetic value by decreasing quality, and if present by the marketing time can generate apprehension by consumers diminishing purchase (Prasad and Kumar, 2005). An integrated approach to insect and disease management involves precise scouting and monitoring and proper control decision making to avoid spreading (Kaiser and Ernst, 2019). Most pathogens, insects, and mites have short life cycles, so epidemics are likely to occur in unmonitored controlled environment systems (Hamrick, 2003).

\section{Annual Bedding Plants}

\section{Greenhouse Production}

The term annual bedding plant applies to garden plants that complete their life cycle in one growing season (Grupp, 2020). Greenhouse production of annual bedding plants involves the growth of a heterogeneous group of species sharing similar production methods (Kessler, 2004). Automated environmental control systems in greenhouses provide adequate control over 
ventilation, heating, cooling, irrigation, photoperiod, light intensity, and fertilization. Improving of grower's profit by increasing the control over plant timing and production and offering a better-quality product to consumers (Beytes, 2003).

The main objective when planning the production of annual bedding plants is to determine the production schedule. Correct timing for plant development to reach a marketable size at the peak market demand is essential for greenhouse grower profitability and minimizing shrinkage or profit loss due to unsalable plants (Njue, 2018; Kaiser and Ernst, 2019; Nelson, 2012; Ingels, 1994). Scheduling also benefits the greenhouse management of time, labor, bench space and increase crop quality (Njue, 2018). The production schedule has to consider the species specifications and greenhouse growing system structures such as container size, temperatures, photoperiods, irrigation, fertilization, and plant growth regulators (Kessler, 2004; Njue, 2018).

Monitoring temperatures inside of a greenhouse is extremely important to keep cooling, heating and ventilation systems working properly. The thermostat should be placed by the height of the plant's growth, in case of potted plants 15 to $30 \mathrm{~cm}$ above the pot rim (Nelson, 2012). The optimum temperature for bedding plants during the day is $15^{\circ} \mathrm{C}$ to $18{ }^{\circ} \mathrm{C}$ and during the night temperatures can vary depending on the expected result: $21{ }^{\circ} \mathrm{C}$ to reduce stretching and $4{ }^{\circ} \mathrm{C}$ to 7 ${ }^{\circ} \mathrm{C}$ to harden plants off for sale (Ingels, 1994).

Each species has a specific container size requirement it is optimally produced in.

Oversized or undersized container sizes can produce plants that are not aesthetically pleasant. If the pot is too small plants can lose lower foliage before blooming. If the pot is too large plants can start to bloom before filling all container area with foliage. Market tendencies are for commercialization of small containers where plants reach marketable size faster (Kessler, 2004). 
The use of plug production for plant starters is a common practice, providing plants that have enhanced quality and conformance in a shorter time. With the use of mechanical transplanting methods, labor is decreased, which can lower the price of products to the consumer (Nelson, 2012).

A wide range of growing media can be used to produce bedding plants. Soilless media is the most common substrate used coming in a broad combination of materials (Kessler, 2004; Kaiser and Ernst, 2019). The choice of a media is guided by the cost, the volume required, the irrigation system used, and the grower's preference (Kaiser and Ernst, 2019).

Annual bedding plant quality can be increased by providing fertilization until the last weeks before the plant achieves marketable size. Annual bedding plant containers have a small amount of substrate and per se little reservoir of nutrients. Moreover, plants are usually watered regularly, which increases nutrient leaching (Nelson, 2012). Micronutrient deficiency can also occur due to leaching and continuous production (Prasad and Kumar, 2005).

The production of annual bedding plant is a high-risk business with large start-up costs and demanding labor and management (Kaiser and Ernst, 2019). The initial investment depends on the greenhouse system and equipment choices. The costs can start at $\$ 3.00$ per square foot (0.09 square meter) on a polyethylene greenhouse or $\$ 4.00$ per square foot $(0.09$ square meter) of a low-profile glass greenhouse. However, adding automated equipment such as heating, cooling, screening or coverings, among others can raise the price until around $\$ 26.50$ per square foot (0.09 square meter) on a set of high technology equipment (Nelson, 2012). The profits in the long term in gross sales can achieve as high as \$20 per square foot (0.09 square meter) (Kaiser and Ernst, 2019; Aggie Horticulture, 2020). 
The bedding plant market is usually limited regionally due to shipping weight and perishability, with most product shipped within 500 miles $(800 \mathrm{~km})$ distance. Direct marketing from growers to retail centers, such as garden centers, big box stores, and general retailers also occurs, occasionally passing through a wholesaler, a broker or in auctions. A new trend for small growers is the direct sale to consumers as in farmer's market or roadside stands (Nelson, 2012). In direct marketing, a main consideration before choosing cultivars to be produced is their popularity and consumer appreciation for their performance in the garden (Kessler, 2004).

\section{Consumers Expectations}

While planning market strategies of their products, growers should consider two points before choosing the cultivars to be produced: 1) their popularity; and 2) postharvest life (Kessler, 2004). Quality of bedding plants is extremely important to keep a loyal consumer. Plants that do not present good quality traits at the point of purchase may never recover in the landscape, never achieving their full potential (Black, 2006). The landscape performance of a plant will determine consumer's choice for future purchases. Plants that last longer, achieve their full potential and are free of diseases and pests will induce the thought of a healthy plant and good landscape performance, stimulating further purchases (Hamrick, 2003).

The definition of plant quality differs between growers' and consumers' points of view. For growers, plant quality is reached when plants within a species meet standards of uniform physical dimensions and appearance. For consumers, the quality definition is built by their socioeconomic background, income level, and mental state. They are driven by the emotional factors related to floriculture crops, which improve their living space and act as an expression of mood (Hamrick, 2003). The fact that annual bedding plants must be replanted every season allows the opportunity for consumers to try new plant species, colors and new designs for 
landscape areas (Kessler, 2013). Common quality traits required are a sturdy and compact plant, short and thick stems, lateral branches, healthy dark green leaves, few open flowers, and free of damages, pests, and diseases (Kessler, 2013; Black, 2006).

\section{Consumers Practices}

Plant installation and maintenance in the homeowner landscape should follow proper planting practices to achieve plant maximum performance. The correct placement of a plant in the landscape is the primary factor for growth success, so plants must be well-suited to the site selected (Grupp, 2020). Moreover, the display in bed should account for the spacing considering the mature plant size (Ingels, 1994).

Landscape bed preparation is frequently based on the incorporation of soil amendments such as organic matter and fertilizers. Organic matter when added to soils improve their texture, aeration, and drainage. Applying a 7 to $10 \mathrm{~cm}$ layer in the bed and incorporating it into the soil with 15 to $20 \mathrm{~cm}$ of topsoil is recommended (Grupp, 2020). Bed preparation should be done at least a week before plant purchase (Ingels, 1994). Fertilization is fundamental to urban areas where the topsoil has been disturbed and essential elements may be lacking. Annuals and herbaceous perennials have an immediate requirement for nutrients after transplanting. The best fertilization method is applying slow-release fertilizer placed under the plant while planting. Providing nutrients direct to the plant root system (Wade and Sparks, 2016). With correct fertilization prior to planting, most annuals would behave well throughout the season. Some annuals can be fertilized in midsummer, 6 to 8 weeks after planting, with a low concentration fertilizer if required by plants (Ingels, 1994; Grupp, 2020).

Annual bedding plants can create a pot-bound root system during greenhouse growth that needs to be broken and untangled before plant installation in the field. This process will 
encourage root growth out into the surrounding soil (Ingels, 1994; Grupp, 2020). Planting the plants too shallow or too deep can also cause problems (Wade and Sparks, 2016). The top of the rootball should be placed at the same level as the surrounding soil grade. Tall plants can be pruned to increase branching, removing the terminal shoot to impulse the development of lateral shoots, a practice also called pinching (Ingels, 1994).

Watering is dependent on soil type, sunlight, temperatures and season of the year (Ingels, 1994). The irrigation should be provided at night or early morning to avoid loss by evaporation. Irrigate plants as needed, as soon as plants start to show wilting or exhibit a pale grayish-green. It is recommended to provide infrequent irrigation at a slow velocity to reach greater soil depth, promoting deeper root growth (Grupp, 2020). Weed control should start as soon as weeds appear, to avoid plant and weed competition for moisture, nutrients, and space (Grupp, 2020). Weeds can be controlled mechanically by hand, mulch and landscape fabric, or chemically with pre- and post-emergence herbicides (Wade and Sparks, 2016).

Mulching is the application of loose aggregate materials, organic or inorganic, to the surface of a bed planting (Ingels, 1994). The best form of mulch is an organic material with a fine texture which does not mat into layers (Wade and Sparks, 2016). Organic materials can be worked into the soil in fall to boost organic matter and ameliorate soil structure (Grupp, 2020). When choosing organic materials, if possible, give preference to leaf mulch instead of wood chips (Illinois Landscape Contractors Association [ILCA] 2016). The benefits of mulching, besides the prevention of weed growth, are the retention of water around the root system, minimization of soil temperature fluctuations, and enhancement of the overall aesthetic appearance of the landscape (Ingels, 1994; Grupp, 2020). Mulch should be applied at a thickness of 5 to $7 \mathrm{~cm}$ to provide these benefits (Black, 2006; Ingels, 1994; Grupp, 2020). 
Plants in the landscape are exposed to a complex range of insects and diseases. The best defense for a plant is their health and natural resistance to pests. Healthy and actively growing plants can tolerate some insect and disease damages without long term effects (Wade and Sparks, 2016). Furthermore, placing plants in sites that are not suitable for the species can weaken the plant and render it susceptible to insects and disease infestations, similar to the effect from poor cultural practices (Wade and Sparks, 2016).

Some annuals require more maintenance actions to keep plants in full potential. Deadheading is the practice of removing old blooms from the plants to encourage them to rebloom, keeping the plant attractive to the landscape. A few species that require this practice are geranium (Pelargonium spp.) and marigold (Tagetes spp.). Annuals that do not require this practice are called "self-cleaning', dropping their old flowers naturally, such as begonia (Begonia spp.), impatiens (Impatiens spp.), and vinca (Catharanthus spp.) (Grupp, 2020).

\section{Soilless Media}

The rapid economic, scientific and technological development of societies around the world, plus an increase in population and standard living, has created a demand for a high value of food and ornamentals of high quality. The increase in standards living have also expended the demand for floricultural crops, such as bedding plants, potted plants, and cut flowers while boosting the use of protected cultivation systems (Raviv et al., 2019). Greenhouse systems provide a near-optimal growing condition for plants. One obstacle of the system is the use of containers providing relatively limited space for root growth. To maximize this space, the use of soilless media is essential, providing better control over crucial production factors and improving plant quality (Raviv et al., 2019). 
Annual bedding plant growers mostly use soilless growing media to their production systems (Kessler, 2004). The advantages of using soilless media include a uniform composition, predictable responses on holding and releasing water, air, and nutrients to the roots, and lighter weight, facilitating handling in the greenhouse and product shipping (Ingels, 1994). Several different formulations of growing media are available for bedding plants, with no one single best formulation (Kaiser and Ernst, 2019). Soilless mixes can range from general, all-purpose formulations to formulations developed to meet a specific production demand, such as seedling production, short term production, and long-term growth (Jones, 2012). The media must provide an adaptable biological and chemical environment to facilitate plant absorption of nutrients in a limited area. Moreover, being affordable for growers and easy to purchase and manage (Barrett et al., 2016).

The ingredients and rates used for the formulation of soilless media are determined by the crop type, the objective of production such as seed germination and seedling production, and the duration of crop growth, either short-term or long-term. Germination and seedlings mix consist of fine particles to provide good seed-to-soil contact and moisture between soil and roots. The short-term mix should hold a moderate amount of water and contain some essential elements to support plant growth until transplant. Long-term mixes have a coarse texture, with moderate water holding and good air capacity to keep roots able to exchange gases (Jones, 2012).

The physical characteristics of a growing media affect aspects of plant growth in a container by the determining the level of porosity for water, air and nutrient availability (Hamrick, 2003). Soilless media formulation is based on two or more major ingredients that will determine the main physical characteristics of the media (Jones, 2012). The most common components to provide water and nutrient retention are sphagnum peat moss, bark $(0$ to $3 / 8$ in; 0 
to $9.52 \mathrm{~mm}$ ), coir, sawdust, manure compost, vermiculite, and calcined clay. Aeration is supplied by small bark ( $3 / 8$ to $3 / 4$ in; 9.52 to $19.05 \mathrm{~mm})$, sand at concrete grade, perlite, and rice (Oryza sativa) hulls. Light weight is available by the insertion of vermiculite and perlite into the mix. Some amendments to root substrate are limestone to achieve the desired $\mathrm{pH}$ for the mix, wetting agents, and nutrients as micronutrients mix and phosphate, nitrogen, and potassium (Nelson, 2012). The basic nutrient starter package stimulates a flush in initial growth and last around 2 weeks before leaching by irrigation (Hamrick, 2003).

Fertilization is required to achieve optimum plant growth due to the low concentration of nutrients in the media and the leaching process caused by frequent irrigation (Link and Ross, 1978). The demand for fertilization is specific to each species, determining the kind, amount, frequency, and application form of the fertilizer (Jones, 2012).

\section{Plant Nutrition}

Plant nutrition describes the process where chemical compounds are supplied and absorbed by plants to sustain their growth and development. Those compounds are referred to as nutrients and are necessary for plant growth and metabolism, where plants convert nutrients into cellular material or use them for energetic purposes (Mengel and Kirkby, 1987).

\section{Plant Nutrition History}

The first notes about plant nutrition observations date back to Greek philosophers who documented the basics characteristics of plant growth. Some of the main advances over time started around the $16^{\text {th }}$ and $17^{\text {th }}$ centuries. Theodore de Saussure (1767-1845) described what may be called the first explanation of selectivity in the plant absorption of solutes, laying out the principle of essentiality. His conclusions were supported by German researches C.S. Sprengel (1787-1859) and A.F. Wiegmann (1771-1853). Sprengel was the first to write that soil can be 
unproductive because is deficient in one single element that is necessary to plants. A clear statement of the "law of the minimum" which is wrongly credited to Liebig. In the middle of the $19^{\text {th }}$ century, Jean-Baptiste Boussingault (1802-1887) revolutionized research by focusing on the balance of elements absorbed by the crop and amount subtracted from the soil and fertilized medium (Epstein, 1972).

Justus von Liebig (1803-1873) in 1840 compiled and summarized all information scattered by the time about certain elements importance in plant growth, publishing it into the book "Organic Chemistry in its Applications to Agriculture and Physiology" which established mineral nutrition of plants as a scientific discipline and encouraged research on the field (Marschner, 2012). In early 1860, Julius von Sachs and W. Knop started the use of the nutrient solution for growing plants (Epstein E. , 1972). Dennis R. Hoagland (1884-1949), who was a professor at the University of California-Berkeley, is considered a pioneer in modern research in plant nutrition (Epstein and Bloom, 2005). Hoagland and Broyer (1936) formulated nutrient solutions that with some modifications have been widely used in plant nutrition experiments. Research in plant nutrition is a constantly evolving process, advances in technology are essential to provide the ability to study nutrients effects in plant metabolism in very low concentrations.

\section{Essential Elements}

Plants can absorb and accumulate a wide range of elements from the growing media. Watanabe et al. (2007) analyzed 670 species of terrestrial plants that compiled a general leaf composition of 42 elements. From these 42 elements encountered in plant composition, some were essential for plant growth and some were not (Watanabe et al., 2007). The formal description of element essentiality was described by Arnon and Stout (1939), determining three criteria that the element must meet to be considered an essential nutrient for plant growth. The 
first criteria of essentiality is that when the nutrient element is deficient, plants cannot complete their vegetative or reproductive life cycle stages. The second criteria is that the prevention or correction of the deficiency only occurs by the supply of the specific element. The third criteria for essentiality is that the element is directly involved in plant metabolism (Marschner, 2012). Epstein and Bloom (2005) presented drawbacks in using these three criteria to define what is an essential element. For some elements, even in severe deficiency, plants can still complete their life cycle, contrasting the first criteria by Arnon and Stout. Moreover, not all elements have been proven in their function in plant metabolism, such as for boron essentiality (Epstein and Bloom, 2005).

Considering those factors Epstein and Bloom (2005) proposed a new definition of the requirements for an element to be determined essential to plant growth. Establishing two criteria, where the element must attend to one or both. The first criteria is the element must be part of a molecule that is elemental in the constitution of a structure or metabolism in the plant. The second criteria is the deficiency of the element can decrease plant performance causing plant abnormalities in its growth, development, or reproduction (Epstein and Bloom, 2005).

The list of essential elements has been updated over the years, presenting mineral and non-mineral elements. The non-mineral essential elements are supplied by air and water, being carbon $(\mathrm{C})$, oxygen $(\mathrm{O})$, and hydrogen $(\mathrm{H})$. As mineral elements, six are required in relatively large quantities by plants, classifying the group as macronutrients (Epstein, 1972). Macronutrients are present in higher concentrations in the plant structure due to being constituents of organic compounds (proteins or nucleic acid) or acting as osmotica (Marschner, 2012). By the 1860s, the macronutrients list was composed of N, P, K, S, Ca, and Mg. Iron was also added to this list, but was the only element required in lesser quantities. In 1905, G. 
Bertrand concluded that manganese (Mn) was essential to plant growth, and similar to iron, required in lesser quantities. This finding created a new classification of the essential elements, the micronutrients group, first composed of $\mathrm{Fe}$ and $\mathrm{Mn}$, to distinguish them from the other elements (Epstein, 1972). Micronutrients are mostly constituents of enzymes molecules, being present and required for plants in low concentrations due to their different functions (Marschner, 2012).

At the beginning of 1914, the experiments of P. Mazé with solution cultures pointed out the possible existence of other essential nutrients. These experiment enlightened plant nutrition research for the essentiality of other elements. By 1931, three more nutrients were added to the list of micronutrients, B, Zn, and $\mathrm{Cu}$, researched by K. Warrington, A.L. Sommer, C.B. Lipman and J.S. McHargue, respectively (Epstein, 1972). In 1939, Mo was added to the micronutrient list by P.R. Stout and D.I. Arnon working in the laboratory of D.R. Hoagland at the University of California-Berkeley. The experiment exposed the issue with contamination in nutrient solutions. Molybdenum is required in very low concentration by plants and even when present in at concentration of $0.1 \mathrm{umol} / \mathrm{L}$ (10 ppb), no deficiency symptoms were observed, indicating the need of rigorous exclusion of nutrients in the solution for the research of micronutrients requirements. In 1954 chlorine $(\mathrm{Cl})$ was added to the list of micronutrients by T.C. Broyer. Nickel (Ni) was the latest addition to micronutrients group in the 1980s, required in few quantities and their deficiency in the field have just been show for pecan trees, Carya illinoensis, by Wood, Reily and Nyczepin (2003) growing on the Gulf Coast Plain of the U.S (Epstein and Bloom, 2005).

Considering plant physiological requirements, the division into the macro- and micronutrient categories is difficult. Due to this fact, Mengel and Kirkby (1987), proposed 
another classification of nutrients into four groups based on elements with similar biochemical behavior and physiological functions. The first group is formed by major constituents of plant material, components of amino acids, enzymes, proteins, and acid nucleic $(\mathrm{C}, \mathrm{H}, \mathrm{O}, \mathrm{N}$, and $\mathrm{S})$. The second group is part of energy transfer reactions into the plant, as inorganic acids or anions, or bound with hydroxyl groups $(\mathrm{P}, \mathrm{B}$, and $\mathrm{Si})$. Third, acting in enzyme activation, bridging reaction partners, balance anions and control membrane permeability and electro-potentials $(\mathrm{K}$, $\mathrm{Na}, \mathrm{Mg}, \mathrm{Ca}, \mathrm{Mn}$, and $\mathrm{Cl})$. The fourth group facilitates electron transport by valency change (Fe, $\mathrm{Cu}, \mathrm{Zn}$, and Mo) (Marschner, 2012; Mengel and Kirkby, 1987).

The element concentration in plant tissue can vary by plant species and age, and the concentration of all other mineral elements (Marschner, 2012). The current list of essential elements may not be a permanent list. More elements still can be found as essentials to higher plant growth as research techniques evolve (Mengel and Kirkby, 1987). Certain species can utilize additional elements that do not meet the essentiality criteria determined by Arnon and Stout (1939) but can be beneficial to plant performance. To refer to those beneficial elements Epstein (1972) suggest the terms of "apparently nonessential" and "not known to be essential". Stating that it is incorrect to call such elements "nonessential" due to the difficulty of having a highly purified solution and that even in very small quantities of the nutrient plants do not show a deficiency (Epstein, 1972). As experimental techniques become more sensitive with higher purity on the control solution, new elements have been found as beneficial for plants (Barker and Pilbeam, 2015).

The lack of or poor availability of an essential element can cause negative effects on plant metabolism, where plants will express this as growth disturbances such as damage on leaves and flowers among other abnormalities. The deficiency symptoms vary according to the 
nutrient, level of deficiency, plant species and other environmental factors (Epstein, 1972).

Nutritional deficiencies or toxicities can cause a delay in crop development, reduce plant quality, lower cost-efficiency, and decreases profitability (Hamrick, 2003).

Compared to other cultures in the agricultural field, floriculture is relatively new, thus research related to fertilization on ornamentals is a new area (Furtini et al., 2015). The return of popularity of farmer's markets in the U.S. has demonstrated a trend of consumers being willing to pay more for a locally-grown product of higher quality (Epstein and Bloom, 2005). Quality standards are not easily defined and they depend on the purpose of the plant being used (Mengel and Kirkby, 1987). Plant quality is provided by the combination of physical and chemical proprieties in a plant to achieve the standards of commercialization (Marschner, 2012).

\section{Foliar Fertilization}

Foliar application of fertilizers is becoming widely used in agricultural production, due to the benefits of a more targeted-orientated and sustainable production practices. The efficacy of foliar application relies on several aspects related to the nutrient solution applied, plant condition, and environmental circumstances. The nutrient solution needs to provide adequate wetting, spreading, adherence, and absorption into the leaves (Marschner, 2012). Environmental conditions can affect the efficacy of application by temperature, humidity and windy rates, also the time of the day when the application takes place (Jones, 2012). Rain can cause washing off the fertilizer solution (Marschner, 2012). The physiology of the plant determines the rate of penetration and distribution of the solution, by the leaf nature (leaf size, maturity and surface aspects) and stage of plant growth (Jones, 2012). Furthermore, the leaf can suffer damages by toxic levels and the application may facilitate the entrance of pathogens (Marschner, 2012). 
Plants have two structures to control matter exchange between aerial parts and the environment. Those structures are the cuticle, a nonliving hydrophobic layer that covers the leaf with low permeability to water, solutes, and gases, and the stomata, apertures in the leaf specialized in the $\mathrm{CO}_{2}$ uptake and water exchange. Further, these structures allow the intake of solutes and gases into the plant, resulting in foliar uptake of solutes from atmospheric deposition or foliar fertilization. The process of solutes penetration is passive, driven by the concentration difference among the leaf surface and leaf interior (Marschner, 2012).

Leaf composition and permeability to solutes are influenced by the plant stage and conditions, plus environmental circumstances (Marschner, 2012). In general, higher penetration rates are achieved in young and partially expanded leaves (Sargent and Blackman, 1962). The absorption of solution trough the leaf tissue is maximized by increasing the time the solution remains in the leaf surface. Applying fertilizers in cool temperatures and low concentrations will avoid quick evaporation of the solution and prevent possible leaf damaging by burning (Mengel and Kirkby, 1987). Moreover, the use of a surface-active agent in the solution increases plant absorption (Sargent and Blackman, 1962). Referred as adjuvants, they are chemicals that optimize the contact of solution applied and leaf surface increasing the stomata penetration (Marschner, 2012).

Focusing in increase plant quality and profit and reducing environmental impacts, an advancement in studies of foliar fertilization is expected to better understand the several aspects that can influence the effectiveness of this technique. Enlightening correct concentrations for a specific nutrient-species relationship, timing, and conditions of application. (Fernandez \& Eichert, 2009). 


\section{Beneficial Nutrients}

Analyzing 138 families of terrestrial plants have yielded leaf composition of 42 different elements. Plant family is responsible for over $25 \%$ of the variation in the composition for 21 of these elements. The other $75 \%$ is correlated with differences between species within families, between locations of sampling as soil and environment, and sampling techniques (Watanabe et al., 2007). Certain species can utilize additional elements that do not meet the criteria for essentiality but can be beneficial to plant performance under determined conditions, referred as beneficial elements (Marschner, 2012). Advances in analytical chemistry to produce highly purified solutions without element contamination even in very low concentrations will lead to a shift of elements from the beneficial category to the micronutrient group (Marschner, 2012). Facilitating the process for researches to define beneficial elements roles in plant development (Mills and Jones, 1996).

The function and concentration in plant tissue of beneficial elements depends on the element and the plant species. Elements functions in plant tissues can be suggested by concentration. Higher concentrations imply a structural or osmotic role. Lower concentrations indicate a function as a cofactor for specific enzymes (Pilon-Smits et al., 2009). The five most studied beneficial elements are aluminum ( $\mathrm{Al})$, cobalt (Co), sodium $(\mathrm{Na})$, selenium $(\mathrm{Se})$, and silicon $(\mathrm{Si})$. Sodium is required for certain halophytes, plants indigenous of saline soils which tolerate and require high levels of salt (Epstein, 1972). Silicon is essential for certain groups of plants and rice, beneficiating also other gramineous (Epstein,1999). Aluminum and selenium are essential to hyperaccumulator species. Cobalt is essential for the functionality of nitrogen microbial partners of plants. Thus, these nutrients may not be essential, but plants can benefit from their supplementation by fertilization (Pilon-Smits et al., 2009). Other elements that have 
been shown to produce beneficial effects on plant growth are iodine (I), cerium (Ce), lanthanum (La), titanium (Ti), and vanadium (V) (Marschner, 2012).

Plant requirements for beneficial elements are usually minimal quantities (Morgan, 2016). However, $\mathrm{Si}, \mathrm{Ti}$, and $\mathrm{Al}$ can occur in plant biomass at high concentrations. Their level in plant tissues depends on the plant species and the concentration of the element in the soil and their availability, ranging according to the soil $\mathrm{pH}$, organic matter, $\mathrm{P}$ concentration and cation exchange capacity (Jones, 2012).

Beneficial nutrients can have a direct effect on the enhancement of plant growth or substitute an essential nutrient. Substitution is a process that still unclear but is active when the essential nutrient is in marginal concentrations (Jones, 2012). Some examples of substitution, $\mathrm{Na}$ can replace K role as an osmoticum, Si can substitute B in cell stability, acting by bridging polyuronides and stimulating lignin, Co effect in nodulation affecting $\mathrm{N}_{2}$ fixation rates, and $\mathrm{Se}$ can be a replacement of $\mathrm{S}$ in proteins (Marschner, 2012). Replacements are synergistic at low concentrations, however at high concentrations it can turn to be antagonistic (Lyu et al., 2017).

\section{Silicon}

\section{Introduction to Silicon}

Silicon ( $\mathrm{Si}$ ) is the second most abundant element in the Earth's crust, a key component to soil composition present as silicate minerals (Emsley, 2001). In the soil solution, Si is present as monosilicic acid $\left[\mathrm{Si}(\mathrm{OH})_{4}\right]$ in concentrations that vary from 3.5 to $40 \mathrm{mg} \cdot \mathrm{L}^{-1} \mathrm{Si}$. (Marschner, 2012). The solubility of $\mathrm{Si}$ in soils even in higher concentrations of the element is extremely low (Ma, 2015), having a solubility of $\sim 2 \mathrm{~mm}$ and on $\mathrm{pH}>7.0$ the solubility is decreased (Prasad and Kumar, 2005). Silicon has a strong affinity with oxygen (O), forming silica (Si dioxide) or silicates. Silicon dioxide comprises $60 \%$ of the earth's crust and more than $50 \%$ of the soil (Ma 
and Takahashi, 2002). Even in excessive amounts, Si cannot cause serious injuries to plants (Ma et al., 2001).

As a result of the high quantity in most soils, $\mathrm{Si}$ is present in the tissue of all soil-based grown plants (Ma, 2015). The concentration of $\mathrm{Si}$ in the soil and plant composition varies greatly, depending on the soil environment, plant species, uptake, among other factors (Epstein and Bloom, 2005). From all beneficial elements known, Si is the only that is consistently present in soils at concentrations that are similar to some macronutrient elements (Epstein, 1994). However, this element has not received much scientific attention since Si deficiency is not easy visualized in plants and it is abundant in most soils (Ma and Takahashi, 2002).

Silicon is not considered an essential nutrient for plant growth but the beneficial effects on growth, development, yield, biotic and abiotic stress resistance is present in a wide range of plant species (Ma, 2004). In a world where population and the demand for food is constantly increasing, and the land for food production has a finite area with increasing environmental stresses, Si appears as an important element for plant nutrition (Epstein, 2009).

The beneficial effects of Si are maximized by stress conditions, under biotic stress (disease or insect damage) or abiotic stress (climate stress, water deficiency, and mineral stress) (Epstein E. , 1994; Epstein, 2009; Ma et al., 2001). The function of Si in plants is more mechanical than physiological and this characteristic explains why the effects of Si are more visible under stress situations (Ma et al., 2001).

The first studies in Si uptake and accumulation by plants suggested that the element was only effective for a few monocots species. Research over the years has demonstrated a potential use of Si on several plant species, such as in ornamental crops (Frantz et al., 2005). It has been noted that "Si is a "ubiquitous contaminant". It is present as an impurity in the macronutrient 
salts used in making up nutrient solutions, in the water even if distilled or demineralized, in containers (glass, of course, must be avoided), and as dust (Werner and Roth, 1983)" (Epstein, 1994). Complete exclusion of Si from a nutrient solution is difficult to achieve, even on plants that did not receive $\mathrm{Si}$ as supplementation it can be found in trace amounts in the dry matter composition (Epstein, 1994).

\section{Plant Accumulation and Essentiality}

Silicon plays an important role in plants when exposed to stressful conditions, due to this fact Epstein (1999) refers to this element as a 'quasi-essential', attending to the second part of the essentiality requirements from Epstein and Bloom (2005). The essentiality of Si varies according to plant species and conditions. It is considered essential for algae species of diatoms, yellow-brown or golden algae (phylum Chrysophyta), and horsetails (Equisetum spp.). The range of $\mathrm{Si}$ on a dry-weight basis of plants is approximately $0.1 \%$ to $10 \%$, a spectrum that can be higher or at the same levels of some macronutrients (Epstein and Bloom, 2005).

Plants can be classified into Si accumulator and non-accumulator species based on $\mathrm{Si}$ content and $\mathrm{Si} / \mathrm{Ca}$ ratio. The $\mathrm{Si} / \mathrm{Ca}$ ratio criteria was first reported in a study by Striegel (1912) where he demonstrated that monocots and dicots differ in $\mathrm{Si}$ and calcium (Ca) content. Monocots have a higher concentration of $\mathrm{Si}$ and low $\mathrm{Ca}$, while dicots have a higher concentration of $\mathrm{Ca}$ and low Si (Ma and Takahashi, 2002). The standards for plant accumulation of Si was determined by $0.5 \%$ of $\mathrm{Si}$ in the dry matter content of plants and $1.0 \mathrm{Si} / \mathrm{Ca}$ ratio. The value of $0.5 \%$ was determined according to $\mathrm{Si}$ average concentration in the soil solution (10 ppm) and the average water requirement for a plant $(500 \mathrm{ml})$. The Si uptake level by the plant on passive transport is $0.5 \%$ on dry weight biomass. Accumulator plants have a Si concentration and $\mathrm{Si} / \mathrm{Ca}$ ratio double of the critical value, higher than $1.0 \% \mathrm{Si}$ and $1.0 \mathrm{Si} / \mathrm{Ca}$ ratio. Non-accumulating plants have a $\mathrm{Si}$ 
content and $\mathrm{Si} / \mathrm{Ca}$ ratio lower than $0.5 \%$ and 0.5 , respectively. Plants that have values between these contents are considered intermediates (Ma and Takahashi, 2002).

Ma and Takahashi (2002) analyzed 175 species from the Nippon Shinyaku Botanical gardens classifying them into the three groups of Si accumulation. High accumulators are present in Bryophyta, Pteridophyta on Lycopsida, Equisetopsida, and in part of Filicopsida, which present accumulators and non-accumulators according to the family level. Cyperaceae family is formed by accumulators and excluders. All species on the Gramineae family present a degree of accumulation differing between subfamilies. Intermediate levels are found in Angiospermae species in the family Commelinaceae and orders Cucurbitale and Urticales. Most of the other species demonstrated a low accumulation (Ma and Takahashi, 2002). The variation between plant species is associated with the capacity of the plant's uptake Si by the roots, Si contents can also vary into the same species by each variety (Ma, 2015). Accumulators species found in wetlands can accumulate $10 \%$ to $15 \%$ of $\mathrm{SiO}_{2}$ in the dry matter, such as for paddy rice and horsetails (Equisetum arvense). In drylands, cereals and sugar cane (Saccharum officinarum) can compile $1 \%$ to $3 \%$ of $\mathrm{SiO}_{2}$ in their biomass. Non-accumulators are represented for most dicots including legumes that have $\mathrm{SiO}_{2}$ concentrations of less than 0.5\% (Mengel and Kirkby, 1987).

\section{Plant Uptake and Metabolism}

Plants that have different Si accumulation also differ in the mode of plant nutrient uptake. The uptake process can be active, passive, and rejective. Active uptake is characterized by the incorporation of $\mathrm{Si}$ in a velocity faster than water exhausting Si from the solution, common for rice species. The passive process occurs in plants where the assimilation of $\mathrm{Si}$ is at a similar rate as water, does not have significant changes in the solution concentration, as for cucumber (Cucumis sativus). The rejective mode is present when some species exclude $\mathrm{Si}$, increasing $\mathrm{Si}$ 
concentration in the solution, present in tomatoes (Lycopersicon esculentum) (Barker and Pilbeam, 2015). The mechanism used in rejective or active uptake still unknown (Ma et al., 2001).

Silicon is metabolized in plant tissue as silicic acid $\left[\mathrm{Si}(\mathrm{OH})_{4}\right]$ which is similar to B metabolized as boric acid $\left[\mathrm{B}(\mathrm{OH})_{3}\right]$. Both are weak acids in solutions, located mainly in cell walls interacting with pectin and polyphenols. Silicon effects in plant metabolism are similar to the B. In general, Si affects cell wall stability, promotes plant and leaf erectness, and enhances water use and resistance to insects and diseases (Marschner, 2012). After absorption Si is transported to shoots, where it is concentrated due to loss of water and polymerized into colloidal acid, and then to silica gel with the increase in silicic acid contents (Ma et al., 2001).

The metabolism of Si inside of the plants still unknown. It is hypothesized that the element takes an active role in the plant defenses by bioactivation of molecules to respond to biotic and abiotic attacks. The defense to abiotic factors occurs in a passive role, with the deposit of Si between the cuticle and cell wall on leaves forming a hydrated silica layer that acts as a physical barrier (Leatherwood and Mattson, 2015). This structural form is associated with the cell wall, providing strength and rigidity to it, are hydrated silica $\left(\mathrm{SiO}_{2} * \mathrm{nH}_{2} \mathrm{O}\right)$ called 'opal' or 'opal phytoliths'. This process increases plant resistance to lodging and damage from pests and diseases. When in solution within the plant Si can increase resistance by a synthesis of defense compounds (Epstein and Bloom, 2005). Moreover, Si responses are related to the plant growth environment, greenhouses systems that try to achieve optimum growth conditions may visualize less Si results than plants growing in stress conditions (Epstein, 2009).

Silicon can form two types of silicified cells on rice depending on how much of $\mathrm{Si}$ is accumulated. The first one to be formed is silica cells, located in vascular bundles on a bell 
shape. The continuous increase of Si levels in the plant, silica bodies are formed present in bulliform cells. Those structures are present in the plant leaves, epidermis and vascular tissues of the stem, leaf sheath, and hull (Ma et al., 2001). Silica incorporation into cell walls have an effect analogous to lignin by a compression of resistant structural effect. Providing leaf erectness and higher light interception, thus increasing photosynthesis levels in a lower energetical expense (Epstein, 1994).

Deficiency symptoms vary according to the plant species. In rice, which is an accumulator of $\mathrm{Si}$, symptoms showed are necrosis in older leaves, wilting, and lodging. Nonaccumulators as tomatoes demonstrate a malformation in leaves and failure on pollination and fruit formation (Mengel and Kirkby, 1987).

\section{Beneficial Effects for Plant Growth}

General effects of Si include their essentiality for Diatoms and Equisetaceae, prevention of lodging of rice and wheat (Triticum spp.), enhance photosynthesis, resistance of biotic stresses (bacterial and fungal diseases and to physical damage of herbivorous), abiotic stresses (lodging, drought, low temperatures, salinity, heavy metals and aluminum toxicity), also influencing the mineral composition of the plants to other nutrients such as nitrogen, phosphorus and others (Epstein, 2001; Epstein and Bloom, 2005). In rice, Si is deposited on the leaf blade keeping their stature and maximizing plant canopy to light exposition, which increase the photosynthesis rate in the plant (Ma and Takahashi, 2002). Silicon can mitigate toxic effects from metals high concentrations, such as aluminum and manganese (Epstein and Bloom, 2005). Moreover, Si increase yields and disease resistance of solution-culture production of high value crops like as flowers (Epstein and Bloom, 2005). 
In conditions of water stress and low humidity, Si has influenced rice growth by reducing the transpiration rate by $30 \%$ less than non-supplied Si plants, presenting more results under stressed conditions than non-stressed (Ma, 1991). Silicon is deposited under a cuticle forming a double layer, which acts in decreasing the transpiration rate (Ma and Takahashi, 2002).

Mineral stress is caused by the deficiency of essential elements or toxicity by the excess of essential nutrients and other elements (Ma et al., 2001). Silicon has the capacity to alleviate essential nutrients imbalances effects on plants (Epstein, 1994). Ma and Takahashi (1993) analyzed $\mathrm{Ca}$ and $\mathrm{Si}$ interaction in wetland production of rice (Oryza sativa L. cv. Akebono) and concluded that $\mathrm{Si}(1.66 \mathrm{mM} \mathrm{Si})$ decreased the Ca uptake and content in the shoot which might be a result of Si decrease in transpiration rate. Silicon concentration in the leaf blade seems to determine the formation of silica bodies (Ma and Takahashi, 1993).

Silicon has a beneficial effect on the balance of $\mathrm{Zn}$ and $\mathrm{P}$ absorption in cucumber (Cucumis sativus) plants. In high $\mathrm{P}$ and low $\mathrm{Zn}$ without the presence of $\mathrm{Si}$ visual abnormalities in the growth and chlorosis symptoms can be identified. Symptoms that are not visualized when $\mathrm{Si}$ is present in the solution, however, the mechanism behind it still unknown (Marschner et al., 1990). Silicon demonstrates more beneficial effects when $P$ is at low or high concentrations, decreasing Fe and Mn uptake when $\mathrm{P}$ is in deficient levels to increase $\mathrm{P}$ availability in plants, and at high concentrations of P, Si acts in reducing P uptake (Ma and Takahashi, 1990; Ma, 2004). As noted by Nagaoka in 1998 "This is supported by the fact that Si supply increased the rate of $\mathrm{P}$ translocation to the panicles in rice" (Ma, 2004).

Silicon adds to the growth medium alleviates $\mathrm{Mn}$ and Fe toxicity on plants. Reducing necrotic browning in barely (Hordeum vulgare) and decrease the uptake of Fe and $\mathrm{Mn}$ on rice (Prasad and Kumar, 2005). Silicon effect in Mn was first described by Williams \& Vlamis in 
1957. Studying Mn toxic effects in barley, they found that $\mathrm{Si}$ does not decrease the amounts of Mn uptake by the plant, but prevents the Mn accumulation in specific spots in the leaves, redistributing Mn into leaf tissue and preventing necrotic points due to Mn toxicity (Williams \& Vlamis, 1957).

Over application of $\mathrm{N}$ is common for Japanese rice fields, causing a decrease in leaf erectness which leads to a lower light interception and photosynthesis rate, and increases susceptibility to blast disease (Magnaporthe grisea). Silicon supplementation in this situation had increase leaf erectness, resulting in enhance light interception and photosynthesis rate, and decrease the occurrence of blast disease (Ma et al., 2001).

Silicon effect in $\mathrm{Al}$ toxicity is suggested to occurs in the solution and plants by forming Si-Al complexes (Ma et al., 2001). Si have ameliorated the effects of $\mathrm{Cu}$ toxicity for bedding plants that are Si accumulator zinnia (Zinnia elegans), and non-accumulator snapdragon (Antirrhinum majus), being responsive to Si, but in different ways (Frantz et al., 2011). Silicon effects over salt stress are related to the decrease in transpiration and sodium $(\mathrm{Na})$ concentration in the shoot, reducing Na influx in the plant (Ma et al., 2001).

Zinnia (Zinnia elegans) is the specie that most accumulate Si from all dicot plants studied until nowadays, accumulating nearly $1.3 \% \mathrm{Si}$ of their dry weight $\left(13,000 \mathrm{mg} \cdot \mathrm{kg}^{-1}\right)$. Silicon fertigation in zinnias has influenced the control of powdery mildew (Golovinomyces cichoracearum), delaying symptoms for a week, and colony spread for two weeks, beneficiating growers with a longer time to manage the disease (Frantz et al., 2010).

\section{Beneficial Effects for Ornamental Species}

Ma and Yamaji (2006) present that $\mathrm{Si}$ accumulation differs greatly among species due to the differences in Si uptake by plants associating the fact that higher rates of accumulation would 
promote better responses in plant strength and rigidity. Hogendorp et al. (2012) quantified Si accumulation for ten common horticulture crops, meadow sage (Salvia $\times$ sylvestris), tickseed (Coreopsis verticillata), garden phlox (Phlox paniculata), New England aster (Symphyotrichum novae-angliae), Chinese astilbe (Astilbe chinensis), coral flower (Heuchera hybrid), garden zinnia (Zinnia elegans), French marigold (Tagetes patula), sweet basil (Basil spp.), and rosemary (Rosmarinus officinalis). Zinnia and aster accumulated expressive amount of 5,365 and 4,797 $\mathrm{mg} \cdot \mathrm{kg}^{-1} \mathrm{Si}$, respectively from irrigation water and growing medium. Leading to the hypothesis that this natural Si accumulation indicate that they can be beneficiated by Si fertilizations (Hogendorp et al., 2012). However, Mattson and Leatherwood (2010) research refutes that hypothesis.

Mattson and Leatherwood (2010) analyzing 21 species of bedding and potted plants on Si supplementation by potassium silicate applied as drenches, they concluded that plant accumulation of $\mathrm{Si}$ is not a prerequisite to plant morphological responses. Species that accumulated significant amounts of Si did not show a significant morphological improvement, while some species that did not accumulate Si presented significant morphological benefits. The morphological effects were dependent on species and parameter measured. Control plants in certain species still able to absorb Si available in the irrigation water and peat substrate, being responsive to $\mathrm{Si}$ at a lower rate when compared to $\mathrm{Si}$-supplied treatments. Demonstrating that $\mathrm{Si}$ can be supplied by water and growing substrate, however, Si fertilization is essential to enhance crop growth and quality traits.

Frantz et al. (2005) made the first description of Si uptake and accumulation in species of the Balsaminaceae family. Analyzing New Guinea Impatiens (Impatiens hawkeri W. Bull, cv. 'Pure Beauty Purple'), plants that received Si treatments were stiffer to touch presenting a 
serrated edge on leaf margin, provided by Si deposition in this leaf surface area. The structures on this edging were called 'scales' presenting a high concentration of Si.

Silicon determination by three methods was compared by Frantz et al. (2008) measuring Si contents in plant tissue for 14 floriculture species. Si deposition on most species was around trichomes bases and along leaf margins. The method EBA- Electron Beam Analysis (scanning electron microscopy coupled with energy dispersive X-ray analysis), was the most responsive to lowers concentrations of $\mathrm{Si}$, with a detection limit of $300 \mathrm{mg} \cdot \mathrm{kg}^{-1}$ dry weight of Si. Zinnia (Zinnia elegans L. 'Oklahoma white') was the highest accumulator, acquiring more than 1\% of Si in the dry weight. Verbena (Verbena $\times$ hybrida Voss 'Tukana white'), impatiens (Impatiens wallerana Hook.f 'Super elfin white'), New Guinea impatiens (Impatiens hawkeri Bull. 'Sonic light lavendar'), and calibrachoa (Calibrachoa $\times$ hybrida 'Colorburst violet') accumulated in the range of $0.2 \%$ to $0.8 \%$ (Frantz et al., 2008).

Frantz et al. (2010) detected Si in 46 horticultural crops, deposited mainly in leaf margins and trichomes with quantities varying by each specific species. More than 20 species presented concentrations above $1,000 \mathrm{mg} \cdot \mathrm{kg}^{-1}(0.1 \%)$, with the lower quantities of $\mathrm{Si}$ in roots and stems (Frantz et al., 2010). Si fertilization has a great potential for ornamental production. Greenhouse systems are widely used to produce ornamentals, based on the use of soilless growing media, which lack $\mathrm{Si}$ in their formulation. Indicating a requirement of $\mathrm{Si}$ as supplementation to produce higher quality bedding plants (Frantz et al., 2004).

Studies from Poland have demonstrated a positive effect of Si in ornamental plants. The first part of the study analyzed Sanvitalia speciosa 'Sunbini', Verbena 'Patio Blue' and Portulaca umbraticola 'Duna Red'. In contrast with control, the highest dose of Si applied as Actsil of $0.3 \% \mathrm{Si}\left(180 \mathrm{mg} \mathrm{Si} \cdot \mathrm{dm}^{-3}\right)$ increased the number of shoots by approximately 2.5 times to 
all species. The highest concentration also enhanced the number of buds, number of flowers or inflorescences, and flower diameter for all species. Chlorophyll content for Sanvitalia was superior with Actisil in higher concentrations (Dębicz and Wróblewska, 2011).

Wróblewska and Dębicz (2011) researched four other ornamental species, Argyranthemum frutescens 'Blazer Rose', Xerochrysum bracteatum 'Gold', Osteospermum ecklonis 'Grande Pink Blush' and Gaura lindheimeri 'Corinas Choice'. The number of lateral shoots was also increase to all species. Strawflower (Xerochrysum bracteatum 'Gold') had all characteristics positively affected by Si in overall plant growth and flowering. The number of buds and flowers or inflorescences, was increased to Xerochrysum bracteatum 'Gold', Osteospermum ecklonis 'Grande Pink Blush' for $0.3 \%$ of Si treatment and for Gaura lindheimeri 'Corinas Choice' and Argyranthemum frutescens 'Blazer Rose' by the $0.2 \%$ treatment (Wróblewska and Dębicz, 2011).

In greenhouse zinnia (Zinnia elegans 'Oklahoma formula Mix') production, the specie presented effects of $\mathrm{Si}$ dependent to the $\mathrm{Si}$ form and rate applied. Application of potassium silicate in drenches on concentrations of 100 and $200 \mathrm{mg} \mathrm{Si} \cdot \mathrm{L}^{-1}$ have resulted in compact plants with straight and thicker stems. Flower diameter was affected by Si incorporation in different sources and concentrations. Si foliar applications moderately increased the leaf resistance, which reduce transpiration and can be associated with the increase in flower diameter. The moderate increase in leaf resistance can indicate a benefit in quality and shelf-live for cutting flowers. Silicon concentration in zinnia where higher in leaves, flower and stem. Indicating an Si deposition as trough passive accumulators (Kamenidou et al., 2009).

Silicon have affected the greenhouse production of ornamental sunflowers (Helianthus annuиs L. 'Ring of Fire'). The effects were dependent of Si source and concentration applied. 
Plants had a better overall quality with Si treatments over control plants, influencing the quality traits of plant height, stem diameter, and flower diameter. Higher doses of Si (100 and $200 \mathrm{mg} \cdot \mathrm{L}^{-}$

${ }^{1}$ ) by substrate drenches application of $\mathrm{KSiO}_{3}$, have cause deformed flowers and delay in blooming (Kamenidou et al., 2008). Silicon effects on zinnia and ornamental sunflower are dependent on form, source and concentration of Si supplementation (Kamenidou et al., 2008; Kamenidou et al., 2009).

Gerbera (Gerbera hybrid L. 'Acapela') have demonstrated positive effects when Si is supplemented by diverse sources and applications rate. More expressive results were visualized for foliar fertilizations of $\mathrm{NaSiO}_{3}$. Producing thicker flower peduncles, increasing flower diameter and plant height, and promoting early blooming on plants supplement with Si over control plants. However, high rates of $\mathrm{Si}$ applied by foliar spray $\left(150 \mathrm{mg} \mathrm{Si} \cdot \mathrm{L}^{-1}\right.$ of $\left.\mathrm{NaSiO}_{3}\right)$ damaged plants by stem shortening and flower deformation. This effect may be associated with sodium toxicity or leaf antitranspirant effect (Kamenidou et al., 2010).

Kamenidou and Cavins (2005) studying Si supplementation by different sources and concentrations to three species of cut flowers (ornamental sunflowers, Helianthus annuus L. 'Ring of Fire'; zinnia, Zinnia elegans 'Oklahoma formula Mix'; and gerbera, Gerbera hybrid L. 'Acapella') demonstrated that Si effects varies according to the source, concentration and plant species. Plant accumulation of Si follow the pattern leaves $>$ flowers $>$ stems, at any rate of $\mathrm{Si}$ applied. Silicon beneficiated flower production, by thicker and straight stems, increase in flower diameter, and promoting early blooming. Enhancing cut flower quality and marketable value. (Kamenidou and Cavins, 2005).

Silicon influenced quality traits in the greenhouse production of the ornamentals of Gazania rigens 'Kiss yellow', Salvia farinacea 'Fairy queen' and Verbena 'Obsession lilac'. 
Plants exhibited the best responses to higher doses of 120 and $180 \mathrm{mg} \mathrm{Si} \cdot \mathrm{dm}^{-3}$, improving growth and flowering. For Gazania, $120 \mathrm{mg} \mathrm{Si} \cdot \mathrm{dm}^{-3}$ have increased the number of leaves by $83 \%$ in comparison with control. The highest dose increased the number of inflorescences for all species, compared to control, the number of inflorescence increased by $96 \%$ to Salvia (Dębicz et al., 2017).

The supplement of potassium silicate, by fertigation or foliar spray, increases plant resistance in Poinsettia (Euphorbia pulcherrima) production. Reducing root rot and improving plant strength and post-harvest life (Leatherwood and Mattson, 2015). Silicon have increase strength of the stems lower part for gerbera (Gerbera jamesonii Bolus), improving cut flower quality (Babalar et al., 2016).

Silicon affected the plant height for different ornamental species, geranium (Pelargonium $\times$ hortorum 'Elite Cherry'), impatiens (Impatiens walleriana 'Accent White'), pansy (Viola $\times$ wittrockiana 'Delta Premium Marina'), petunia (Petunia $\times$ hybrid 'Celebrity White') and snapdragon (Antirrhinum majus 'Montego Purple') when applied as sodium silicate $\left(\mathrm{NaSiO}_{3}\right)$. For the number of days to flower impatiens exhibited a linear increase and chlorophyll content (SPAD index) have a linear decrease for geranium. Silicon seems to have species-specific beneficial results when related to annual bedding plant species, requiring more research on the field (Whitted-Haag et al., 2014).

\section{Silicon Supplementation}

Silicon fertilization has great potential for ornamental production. Greenhouse systems are widely used to produce ornamentals, based on the use of soilless growing media, which lack $\mathrm{Si}$ in their formulation. Indicating a requirement of $\mathrm{Si}$ as supplementation to produce higher quality bedding plants (Frantz et al., 2004). Highly organic soils or soils that have been densely 
leached, poor in nutrients, acidic, and desilicified, can have low quantities of Si available to plants, requiring Si supplementation (Epstein and Bloom, 2005). Silicon has commonly been used as fertilizers to a variety of species to enhance crop yields, such as rice and sugarcane (Saccharum officinarum) (Ma and Yamaji, 2006).

The most effective way to deliver Si to plants still in discussion, some options are spray application or as a fertilizer supplement. Several different Si products are already commercially available, however, growers are hesitant to use them. The unwillingness to use $\mathrm{Si}$ supplementation comes from a couple of factors; the impression that growers have that siliconbased materials would clog nozzles and drippers, that would application will increase growing expenses, and moreover the unknown of specific benefits for their crops (Frantz et al., 2010).

Silicon can be supplied by common pesticides and fertilizers, even when not listed as one of the ingredients. Water sources can also provide some quantities of Si to plants. Fertigation is an effective form of application; however, it can be expensive and requires close attention to correct mixing and pH management (Frantz et al., 2010). Foliar application of Si plays a similar role in plant as when applied to the roots. This technique is useful for plant species that present a passive or rejective uptake from roots (Ma and Takahashi, 2002). The most common products used as $\mathrm{Si}$ fertilizers in agriculture are potassium silicate $\left(\mathrm{K}_{2} \mathrm{SiO}_{3}\right)$ and sodium silicate $\left(\mathrm{Na}_{2} \mathrm{SiO}_{3}\right)$ (Leatherwood and Mattson, 2015). Natural base fertilizers of Si are slag, rice hulls, and biofuel crops, to provide a more sustainable production (Frantz et al., 2010).

\section{Titanium}

\section{Introduction to Titanium}

Titanium is the ninth most abundant element in the Earth's crust (Emsley, 2001). It is present in soil surface in a range of $0.02 \%$ to $2.4 \%$, averaging $0.33 \%$ (Lyu et al., 2017). Titanium 
is present in different mineral sources. Present as the compound $\mathrm{TiO}_{2}$ in rutile, anatase, and brookite. Ilmenite $\left(\mathrm{FeTiO}_{3}\right)$ and leucoxene $\left(\mathrm{FeO}_{3} \mathrm{nTiO}_{3}\right)$ have $65 \%$ of $\mathrm{TiO}_{2}$ in their composition. Titanium also occurs in other minerals, such as arizonite $\left(\mathrm{Fe}_{2} \mathrm{O}_{3} \cdot \mathrm{nTiO}_{2} \cdot \mathrm{mH}_{2} \mathrm{O}\right)$, perovskite $\left(\mathrm{CaTiO}_{3}\right)$, geikielite $\left(\mathrm{MgTiO}_{3}\right)$, titanite or sphene $\left(\mathrm{CaTiSiO}_{5}\right)$, and titaniferous magnetite $\left((\mathrm{Fe} \cdot \mathrm{Ti})_{2} \mathrm{O}_{3}\right)$ (Zhang et al., 2011). Ilmenite is the main mineral to provide titanium, supplying 90\% of the world total Ti (Lyu et al., 2017), throughout a sulphate and chloride process (Skocaj et al., 2011).

Plants have difficulties in extracting Ti from the soil. The Ti present is common on sands that contain ilmenite $\left(\mathrm{FeTiO}_{3}\right)$ or rutile $\left(\mathrm{TiO}_{2}\right)$ in their composition. The element is not soluble at the $\mathrm{pH}$ range of 4 to 8 , the same range that is suitable for plant growth (Carvajal and Alcaraz, 1998). It has been "found Ti IV ascorbate to be a water-soluble compound, which is $\mathrm{pH}$ stable and not toxic for the living systems. It is a chelate complex with red-brown color and is stable up to $\mathrm{pH}$ 8. It is produced by combining ascorbic acid with $\mathrm{TiCl}_{4}$ in the presence of gaseous $\mathrm{HC} 1$ (Pais et al., 1977)" (Carvajal and Alcaraz, 1998). Supplying Ti as a chelated form to plants can promote Ti absorption and used by plants to enhance growth (Jones, 2012).

\section{Plant Uptake and Metabolism}

Titanium contents in plant dry weight vary from 1 to $578 \mathrm{mg} \cdot \mathrm{kg}^{-1}$ averaging $33.4 \mathrm{mg} \cdot \mathrm{kg}^{-1}$ (Lyu et al., 2017). Ornamental plants contain about $1 \mu \mathrm{g} \cdot \mathrm{g}^{-1}$ of Ti (Emsley, 2001). Plant absorption of Ti is species specific. Plants have a more effective absorption by foliar supplementation. Titanium can also be applied as soil fertilization and hydroponically (Lyu et al., 2017). Titanium has low mobility inside of the plant tissue, accumulating close to the region where it was absorbed and this characteristic demonstrates the importance of adequate coverage during foliar applications (Alcaraz et al., 1991). 
In foliar fertilization the basic mechanism to leaf absorption of elements is by a nonselective and passive process, driven by the difference in the concentration between outside and inside of the leaf surface (Eichert and Fernandez, 2012). As a result of the chelated form of $\mathrm{Ti}$ (ascorbate or citrate), it is theorized that Ti enters the leaf apoplast in a similar pathway as Fe, through stomata, cuticular cracks, ectodesmata, lenticels, and aqueous pores. In nongraminaceous plants, the absorption of Ti-ascorbate can occur by the reduction Ti through ferric reduction oxidase, or directly by iron-regulated transporter. In graminaceous plants, Ti-ascorbate could be absorbed directly with the specific transporter YS1 (yellow stripe 1). The mechanism of transport between cells still unknown but is assumed to be similar to Fe translocated into the plant by phloem flow (Lyu et al., 2017).

The cellular distribution of bulk Ti compounds has been described by two experiments. The first experiment was performed by "Nautsch-Laufer (1974) was first to report the cellular distribution of Ti in plants. When corn (Zea mays) plants were grown in a nutrient solution containing $144 \mathrm{mg} \cdot \mathrm{L}^{-1} \mathrm{Ti}, 65 \%$ of cellular Ti was found in the cell wall, $27.7 \%$ in leaf cell vacuoles, and 5.1\% in root cell vacuoles (Nautsch-Laufer, 1974)" (Lyu et al., 2017). Kelemen, et al. (1993) reported Ti intracellular location in wheat plants when Ti was applied by leaves and roots. Titanium was found to be unidirectionally translocated from the shoots into roots with little or no accumulation in the cells of treated organs, which indicate a diffusible form. However, in some cells, Ti would bound firmly to nuclei (Kelemen et al., 1993). Plants do not demonstrate Ti deficiency symptoms. The beneficial effects of Ti are shown in supplementation at low concentrations, while higher contents can cause phytotoxicity in plants (Lyu et al., 2017). 


\section{Beneficial Effects on Plant Growth}

Titanium is a transition element owning a valency change capacity, which indicates a potential use on electrons transfer in plants. Alcaraz et al. (1991) theorized the recognition of Ti as an essential element to higher plants due to the improvement in plant development, through increases in yield, plant quality, and biomass production. Low quantities of Ti also enhance the uptake of essential elements, improving overall plant nutrition quality (Alcaraz et al., 1991). Pais (1983) states that Ti is an important element to keep in mind to improve food production and decrease hunger in the world.

Beneficial effects of titanium ions on plants can be related to at least four processes: 1) by enhancing the activity of oxidation-reduction reactions; 2) by increasing in nutrient uptake; 3) by amplification of pollen vigor; and 4) by strengthening plant resistance to fungal pathogens (Radkowski, 2013). The mechanism of action of Ti inside of plant tissue at the cellular and molecular levels is still unknown. Knowledge of physiological events indicates the participation of Ti in $\mathrm{N}$ fixation, influence in plant metabolism by an increase of essential nutrients absorption, improvement of Fe activity in plants, stimulation of several enzymatic activities, and photosynthesis process (Lyu et al., 2017).

Lyu et al. (2017) proposed that the beneficial roles of $\mathrm{Ti}$ in plant growth are provided by the interaction of the element with other nutrients, mostly Fe due to the frequency they occur together in the soil (ilmenite- $\mathrm{FeTiO}_{3}$ ). Iron and $\mathrm{Ti}$ have a synergistic and antagonistic relationship. In Fe deficiency, Ti induces the expression of genes that enhance Fe absorption increasing the uptake and use of Fe in plant metabolism. However, Ti in high quantities can compete with Fe for ligands and proteins, leading to a Ti phytotoxicity. Iron is an essential nutrient to plant growth and Ti portrays a complementary role (Lyu et al., 2017). 
Titanium presents characteristics of a biostimulator element (Kleiber and Markiewicz, 2013). Plant biostimulators, also termed as phytostimulators, are non-toxic substances that enhance and stimulate different plants mechanisms directly by regulating plant metabolism or in a multidirectional form (Posmyk and Szafrańska, 2016). Analyzing the effects of Ti in greenhouse tomato (Lycopersicon esculentum) growth, high levels of $\mathrm{Ti}\left(960 \mathrm{~g} \mathrm{Ti} \cdot \mathrm{ha}^{-1}\right)$ have stimulated the highest yield and fruit diameter produced and increased the absorption of macronutrients as $\mathrm{N}, \mathrm{P}, \mathrm{Ca}$, and $\mathrm{Mg}$. Improving the fruit quality, increasing vitamin $\mathrm{C}$ levels and total sugars in the fruits (Kleiber and Markiewicz, 2013).

Kleiber (2012) reported Ti increased plant yield for hydroponically grown lettuce (Lactuca sativa L. cv. Zeralda), with supplementation by $\mathrm{Ti}^{4+}$ ascorbate $\left(\right.$ Tytanit $\left.{ }^{\circledR}\right)$. The medium dose used in the experiment, $0.72 \mathrm{mg} \cdot \mathrm{dm}^{-3}$, presented the highest mean weight of a lettuce head and dry matter in the leaves, it also influenced the chlorophyll content on the leaves. The study focus was to determine the Ti effect on lettuce growth under Mn toxicity stress, where Ti did not influence the Mn content in leaves but did enhance yield in the plants, alleviating Mn-stress effects in plant growth (Kleiber, 2012).

Tlustoš et al. (2005) reported potatoes (Solanum tuberosum), winter wheat, and spring barley were positively affected by the Ti supplementation through a foliar application, but dependent on the nutrient status of the plant. The plants did not respond to Ti treatments under $\mathrm{N}$ deficiency. However, at $\mathrm{N}$ treated plants some significant differences were found, such as a slight tendency to enhance $\mathrm{Mg}$ content on plants (Tlustoš et al., 2005). Potato growth was also influenced by Ti through reducing the activity of urease and increasing peroxidase and nitrate reductase activity. On tuberization, Ti application had a positive correlation with superoxide 
dismutase and peroxidase enzyme. Stimulating enzymatic activity in treated plants (Bacilieri et al., 2017).

Pais (1983) did an extensive study in Ti applied as a chelate from 1974 to 1983, concluding that Ti has a beneficial effect in plant biochemistry and can increase yield and crop quality. Titanium promotes photosynthesis processes by increasing the carbohydrate biosynthesis, enhancing the synthesis of protein and pigments. Titanium also acts in activating several enzymes, such as catalase, peroxidase, nitrate reductase, and nitrogenase. In the experiments, more than $90 \%$ of all crops studied have an increase in yield on an average of $10 \%$ to $20 \%$, also presenting a quality improvement. The results were more expressive in treatments at low concentrations of $1 \mathrm{mg} / \mathrm{kg}$, applying 1 to $3 \mathrm{~g} \cdot \mathrm{ha}^{-1}$. The use of higher doses is recommended just in high-value crops (Pais, 1983).

Titanium ascorbate in hydroponic culture of oats (Avena sativa L. Zlatak) provided several beneficial effects for plant growth. In nitrate solutions at $2 \mathrm{mg} / \mathrm{kg}$ Ti treatment, Ti improved plant health status by increasing top and root dry weights and chlorophyll contents. However, the same nitrate solution at $18 \mathrm{mg} / \mathrm{kg}$ Ti levels and in all treatment levels of Ti at ammonium solutions presented inhibitory effects on plant development, having lower plant health status when compared to control plants. These beneficial effects of Ti can be associated with the Ti-induced increase in nitrate reductase activity in plant tissue, enhancing the synthesis of porphyrine ring structures in chlorophylls and hemoproteins as catalase and peroxidase (Hruby et al., 2002).

Titanium increased the absorption of $\mathrm{Fe}, \mathrm{Mg}$, and $\mathrm{Ti}$ independent of the $\mathrm{N}$ source in the solution. The overall beneficial effects that $\mathrm{Ti}$ can cause in plants can be related to the activation of the plant's defense mechanism, against the Ti processes of replacing essential elements in 
their biding sites. Titanium binds to important structures, such as nucleic acid, removing Fe and $\mathrm{Mg}$ from those placements, forcing the plant to activate detoxification mechanisms against Ti. Starting a couple of actions, such as increase uptake of Fe and $\mathrm{Mg}$, enhance the synthesis of chlorophyll, increase nitrate reductase activity, and the synthesis of Ti-chelating $\alpha$-hydroxy acids. These actions will generate the beneficial effects of the element (Hruby et al., 2002). This effect was associated with hormesis, a biphasic response from an organism to an environmental agent where at a low dose stimulates a favorable biological response and a high dose can cause an inhibitory or toxic effect (Mattson, 2008). The interest in the foliar application of Ti in oats is summarized by the increase in Fe and $\mathrm{Mg}$ contents in plants, decrease $\mathrm{K}$-caused chlorosis, and increase vitamin $\mathrm{C}$ (ascorbate) in leaves. Moreover, enhance in the effectiveness of $\mathrm{N}$ supplementation, reducing $\mathrm{N}$ content in leaves by stimulation of nitrate reductase activity (Hruby et al., 2002).

The study with oats was repeated a year later with plants growing in different types of soils and Ti supplied as a foliar application, trying to mimic agricultural production. In soil experimentation, the Ti effect was more significant at high $\mathrm{Mg}$ concentrations. In nutrient solution fertilization Ti increased Fe levels, however, it was decreased by foliar application in soil-grown plants. Increased $\mathrm{Zn}$ contents in low and medium $\mathrm{Mg}$ concentration in soil but decreased it when Mg was present in high concentration. Manganese was also decreased by Ti and the presence of $\mathrm{Mg}$. The effects of foliar application were weaker than hydroponicallyapplied Ti supplementation. The general takeaway from the experiment was that through either hydroponic or field cultivation, the mechanism of the effect of Ti seem to follow, and be explained by hormesis (Kuzel et al., 2003). However, hormesis is a process that can occur to any 
element and living organism, so it cannot be considered a specific mechanism to Ti functions in a plant (Lyu et al., 2017).

Supplementation of Ti by foliar applications of Tytanit ${ }^{\circledR}$ in Timothy-grass (Phleum pretense) seed plantation has a positive effect on the chlorophyll content of the leaves, influencing the leaf greenness index measured by Soil Plant Analysis Development (SPAD) chlorophyll meter readings. Radkowski (2013) reported that the highest treatment applied of $0.08 \%$ Ti led to the highest SPAD readings, averaging a $6 \%$ increase in comparison to the control plants. The anthesis stage was the most responsive to Ti application during plant development (Radkowski, 2013). Titanium applied as Tytanit ${ }^{\circledR} 0.4 \mathrm{dm}^{3} \mathrm{Ti} \cdot \mathrm{ha}^{-1}$, stimulated leaf growth, increasing assimilation leaf area and chlorophyll content (SPAD index) in leaves of very early-maturing potato cultivars Lord and Miłek under stress conditions of cold and very moist growing season (Wadas and Kalinowski, 2017).

The total chlorophyll of winter wheat and winter rape (Brassica napus) also increased by Ti application as Mg-Titanit, increasing the amount of assimilative pigments chlorophyll $a$ and $b$. Plants were more responsive to $0.2 \mathrm{~L} \cdot \mathrm{ha}^{-1}$ treatment. First and second spray applications were positively significant, while the third spraying decreased the total chlorophyll content (Kováčik et al., 2014).

Applying Ti to edible cowpea (Vigna unguiculate Walp, cv 'Ife Brown') had a significant improvement in the plant development and yield, also decreased the severity of Cercospora leaf spots (Cercospora rosicola Pass.) and brown blotch (Mycospharella cruenta Sacc.). Plants treated twice with $125 \mathrm{cc} \cdot \mathrm{ha}^{-1} \mathrm{TiO}_{2}$ had the largest leaf area, a higher number of pods per plant, longer pods, highest number of seeds per pod, and 100-seed weight at the grain yield. The severity of foliar and pod diseases was decreased by the application of $\mathrm{Ti}$ in all different doses 
and frequency applied. However, a higher and frequent concentration $\left(125 \mathrm{cc} \cdot \mathrm{ha}^{-1}\right.$ applied twice $)$ had a lower incidence of the diseases. The effects of Ti in cowpea may be linked to the ability of the element in increase photosynthesis rate due to the photocatalyst ability. Furthermore, Ti may be used as a control of foliar diseases in cowpea (Owolade and Ogunleti, 2008).

Titanium supplementation is a potential control to Xanthomonas bacterial blight and leaf spot on the greenhouse production of potted flowers. Norman and Chen (2011) studied the effects of Xanthomonas hortorum pv. pelargonii in potted zonal geranium 'Patriot Bright Violet' (Pelargonium $\times$ hortorum) and Xanthomonas axonopodis pv. Poinsettiicola in poinsettia 'Snowcap' (Euphorbia pulcherrima), with supplementation of $\mathrm{TiO}_{2}$ by two foliar applications at the concentration of 25 and $75 \mathrm{mM}$. Geranium was a significantly affected in the first trial but not in the second, having a decrease in leave lesions by $53 \%$ at $25 \mathrm{mM}$ Ti and $67 \%$ on the treatment of $75 \mathrm{mM}$ Ti when compared to control plants. Poinsettia was significantly affected in both trails and plants demonstrated a reduction of $85 \%$ at $25 \mathrm{mM}$ Ti and $93 \%$ at $75 \mathrm{mM} \mathrm{Ti}$.

Toxicity was not visualized in the plants and plant dry weight also was not significantly different between treatments and control. (Norman and Chen, 2011).

Objectifying the increase in fungicide efficacy and potentially decrease on application rates, Ti can be added to fungicide applications. Applying a mix of fungicide spray and $\mathrm{Ti}$ (Tytanit $^{\circledR}$ ) at a dose of $0.2 \mathrm{~L} \cdot \mathrm{ha}^{-1}$ to grapevines 'Italian Riesling' and 'Sauvignon' (Vitis spp.) it has decreased the leaf infection rate of downy mildew (Peronospora sparsa) by 33\%, powdery mildew (Oidium sp.) by $28 \%$ and grey mold (Botrytis sp.) by $21 \%$ (Lešnik et al., 2017).

Biomass of celery leaves (Apium graveolens L. var. dulce Mill. Pers.) was significantly increased by a high rate of $\mathrm{Ti}, 150 \mathrm{mg}$. Ti per pot. The effect of Ti in other essential elements levels differ according to the rate applied. Levels of Mn and Fe decreased by high levels of $\mathrm{Ti}$ 
supplementation and $\mathrm{Cu}$ have higher bioaccumulation at lower levels of Ti (Malinowska and Kalembasa, 2012).

Titanium application also increased the biomass of meadow sward, composed by meadow fescue $25 \%$, early perennial ryegrass $10 \%$, intermediate perennial ryegrass $10 \%$, late perennial ryegrass $10 \%$, smooth-stalked meadow-grass $10 \%$, red fescue $10 \%$, white clover $10 \%$, red clover $10 \%$, and timothy $5 \%$. The highest dose applied $0.08 \%$ of Ti by Tytanit ${ }^{\circledR}$, increased dry matter yield and nutrient content when compared to control plants. The protein and energy values also increased with better responses at the $0.04 \% \mathrm{Ti}$ concentration. The lower Ti rate was effective in drought conditions, improving plant quality by enhancing roughages through the increase of crude protein content, crude fat content, and protein enzymatic value (Radkowski and Radkowska, 2013). In potato tubers, Ti applied in different levels $\left(0.2 \mathrm{dm}^{3} \cdot \mathrm{ha}^{-1}\right.$ and $0.4 \mathrm{dm}^{3} \cdot \mathrm{ha}^{-1}$ of Tytanit ${ }^{\circledR}$ ) and stage of plant applications did not influence the plant dry matter, starch, monosaccharides, protein, L-ascorbic acid or nitrates levels (Kalinowski et al., 2018).

Timothy-grass was positively affected by Ti supplementation via foliar spray. The highest dose in the experiment, $6.8 \mathrm{~g} \mathrm{Ti} \cdot \mathrm{ha}^{-1}$, significantly enhanced seed yield, thousand-grain weight, and germination capacity. Medium and higher Ti rates, 3.4 and $6.8 \mathrm{~g} \cdot \mathrm{ha}^{-1}$, respectively, increased the yield of timothy by $17 \%$ to $20 \%$ based on seed yield, seed kernel weight, and germination capacity. Titanium fertilization accelerated plant aging trough shortening plant development stages, and increased chlorophyll contents (SPAD index) in treated plants when compared to control (Radkowski et al., 2015).

Titanium has increased the number of seeds produced by onion (Allium cepa) production, cultivars 'Sochaczewska', 'Supra', and 'Błońska'. Independently of the plants' stage, Ti enhanced the yield of onion seeds for all cultivars, and the highest yield and better seed health 
status was achieved at foliar application during full flowering. Titanium also improved seed quality, the weight of 1000 seeds, and germination rate for all cultivars (Janas, 2009).

Application of $\mathrm{TiO}_{2}$ in strawberries (Fragaria $\times$ ananassa Duch. cv. Daewang) increased hardness, yield, chlorophyll contents ( $a$ and $b$ ) when related to control plants, increasing fruit

quality, and yield. However, phenolic compounds in the fruits decreased by Ti treatments (Choi et al., 2015).

Fruit trees benefit from the effect of Ti application on product quality. When applied to peach (Prunus persica), Ti improved plant performance and fruit quality and size. Trees demonstrated a higher branch elongation and increase the set intensity of flower and fruit. Fruits had better resistance to compression and penetration, lower weight loss, and better color evolution in postharvest. Relating to essential nutrients, Ti increased $\mathrm{Fe}, \mathrm{Cu}$, and $\mathrm{Zn}$ concentrations on fruit peel, and $\mathrm{Ca}$ on the peel and flesh. The improvement in Ca levels can be associated with the enhancement in $\mathrm{Ca}$ absorption, translocation and assimilation process (Alcaraz- López et al., 2004).

\section{Beneficial Effects for Ornamental Species}

Research with Ti in ornamental crops is very limited but has demonstrated beneficial effects. Prusinski and Kaszkowiak (2005) applied Ti as Tytanit to yellow lupin (Lupinus luteus). Tytanit $^{\circledR}$ applicatons at $7.4 \%$ to $18 \%$ increased yellow lupin seed yield. Tytanit ${ }^{\circledR}$ did not show a significant effect on the structural components of the seed yield from the main stem; its application resulted in a significant, as compared with the control, increase in the number of pods and seeds as well as in the seed weight from branches. As for yellow lupin yielding, the optimal solution seems to be offered by a double application of $0.02 \%$ to $0.04 \%$ of Tytanit ${ }^{\circledR}$ straight after plant blossom fall and 7 to 10 days later. 
The application of Ti had the best effects on Sparaxis tricolor at low concentrations. At $0.04 \%$ of $\mathrm{Ti}$, the yield of corms increased by $20 \%$ and commercial yield by $7 \%$, and at $0.02 \%$ of Ti, the structure of corms yield was improved by higher circumference, especially on unfavorable conditions as drought and high temperatures. Higher concentrations of Ti at $0.08 \%$ Ti, had negative effects on commercial yield of corms. The concentration of other essential nutrients varies by treatment levels and years of cultivation (Marcinek and Hetman, 2008).

Titanium affected growth and quality characteristics of ornamental plants, as annual bedding plants, growth in soilless growing media. Plant height was increased for geranium (Pelargonium $\times$ hortorum 'Elite Cherry'), petunia (Petunia $\times$ hybrid 'Celebrity White'), and snapdragon (Antirrhinum majus 'Montego Purple'). The number of days to flower decreased for petunia and increased for impatiens (Impatiens walleriana 'Accent White'). Chlorophyll content (SPAD index) have a linear decrease for impatiens. Titanium seems to have species-specific beneficial results when related to annual bedding plant species, requiring more research on the field (Whitted-Haag et al., 2014).

\section{Titanium Supplementation}

Due to all the impacts Ti can have on plant growth, the element can be considered beneficial. The difficulty in absorption of Ti from the natural environment make supplementation of Ti essential to achieve plant improvement and the beneficial effects desired (Carvajal and Alcaraz, 1998). 


\title{
CHAPTER III: LANDSCAPE PERFORMANCE OF ANNUAL BEDDING PLANTS FOLLOWING FOLIAR APPLICATION OF SILICON AND TITANIUM
}

\begin{abstract}
The U.S. floriculture industry was estimated at $\$ 4.77$ billion in 2018 with annual bedding plants representing the main segment valued at $\$ 1.46$ billion dollars. Silicon $(\mathrm{Si})$ and titanium (Ti) are beneficial nutrients which can improve growth and quality of greenhouse horticultural crops when applied exogenously. Information is lacking as to whether $\mathrm{Si}$ and Ti enhancement during greenhouse production increases bedding plant performance in the outdoor landscape. Therefore, this study examined landscape performance of four annual bedding plant species treated with foliar applications of $\mathrm{Si}$ and Ti during greenhouse production over two growing seasons. Plant species were selected based on U.S. consumer popularity and included 'Black Velvet Rose F1' geranium (Pelargonium zonale), 'Mega Bloom Pink Halo F1' vinca (Catharanthus roseus), 'Double Hot Cherry' zinnia (Zinnia hybrid) and 'Accent White Hybrid' impatiens (Impatiens walleriana). Silicon treatments were supplied as foliar sodium silicate $\left(\mathrm{NaSiO}_{3}\right)$ treatments at rates of $0,50,150$ and $250 \mathrm{mg} \mathrm{Si} \cdot \mathrm{L}^{-1}$ in a randomized block design. In a similar separate experiment, Ti treatments were supplied as foliar Ti-ascorbate $\left(\right.$ Tytanit $^{\circledR}$ ) at rates of 0, 50, 100 and $150 \mathrm{mg} \mathrm{Ti} \cdot \mathrm{L}^{-1}$. Each study was conducted during the 2018 and 2019 growing seasons. The treatment applications were applied weekly for 4 weeks for impatiens, vinca, and zinnias, and 7 weeks for geraniums. Once plants reached marketable size, they were transplanted into the field in a randomized block design, mulched, and irrigated as needed. Growth and quality trait (plant height, number of leaves and flowers/inflorescences, basal stem and flower/ inflorescence diameter, SPAD chlorophyll content, and growth index) data were collected before and during treatment application under greenhouse culture and every 15 days in the field starting
\end{abstract}


30 days after transplanting up until frost. Silicon treatments had a significant effect on the landscape performance of zinnia for the number of inflorescences $(P=0.016)$ and growth index $(P=0.071)$ in 2019. The $50 \mathrm{mg} \mathrm{Si} \cdot \mathrm{L}^{-1}$ treatment produced the highest number of inflorescences $(P=0.019)$ and highest growth index $(P=0.056)$. Titanium treatments also had a significant effect over time for geranium for plant height $(P=0.013)$ in 2019 and chlorophyll content $(P=0.011)$ for impatiens in 2018. The $100 \mathrm{mg} \mathrm{Ti} \cdot \mathrm{L}^{-1}$ and $150 \mathrm{mg} \mathrm{Ti} \cdot \mathrm{L}^{-1}$ treatments had a significant effect on plant height $(P=0.016)$ for geraniums. The $50 \mathrm{mg} \mathrm{Ti} \cdot \mathrm{L}^{-1}$ and $100 \mathrm{mg} \mathrm{Ti} \cdot \mathrm{L}^{-1}$ treatments had a significant effect for chlorophyll content $(P=0.0122)$ for impatiens. Overall, $\mathrm{Si}$ and $\mathrm{Ti}$ supplementation affected the quality and performance of annual bedding plants in the landscape. However, this response was species, concentration applied, and year specific.

KEYWORDS: beneficial nutrients, landscape performance, quality traits, silicon, titanium, ornamentals 


\section{Introduction}

The floriculture market is a specialized branch of horticulture industry which includes the commercial production of floral crops such as annual bedding and garden plants, potted herbaceous perennials, potted flowering plants for indoor and patio use, foliage plants for indoor or patio use, cut flowers, cut cultivated greens, and propagative floriculture materials (NASS, 2019). Floral and ornamental international plant market is projected to reach $\$ 96.4$ billion in 2021 (Technavio, 2018). The floriculture market represents an important share of U.S. economy. The U.S. ranks fourth globally in per capita consumption of flowering plants and related goods, spending an estimated $\$ 95.70$ per person in 2016 (AIPH and Union Fleurs, 2019). This personal consumption expenditures on flowers, seed and potted plants have been increasing since 2008, achieving almost $\$ 35$ billion in the last quarter of 2019 (BEA, 2020). The total wholesale value of floriculture crops in 2018 was $\$ 4.6$ billion, an increase of 9\% from 2015 (operations with $\$ 100,000.00$ or more for 15 states program) (NASS, 2019). Annual bedding and garden plants also represents a large share of U.S. floriculture market, being responsible for $31.6 \%$ of the total wholesale value of floriculture crops, accounting for $\$ 1.46$ billion in 2018 , an increase of $13 \%$ from 2015 (NASS, 2019).

The annual bedding and garden plants section of floriculture refers to any herbaceous plants produced and sold for landscape uses, garden beds or patio containers. These plants can include ornamental and vegetable species (Kaiser and Ernst, 2019). The most commonly commercialized annual bedding plant species in the U.S. based in the National Agricultural Statistics Survey Floriculture Crops 2018 Summary are begonia (Begonia spp.), geranium (Pelargonium spp.), impatiens (Impatiens spp.), marigold (Tagetes spp.), pansy (Viola spp.), and petunia (Petunia $x$ hybrid) (NASS, 2019). Growers in northern latitudes $\left(\geq 40^{\circ} \mathrm{N}\right)$ start their 
greenhouse production of annual bedding plants in midwinter to spring to have plants in marketable size (characterized as having at least one open flower and filling out the container) and blooming at the peak market demand (Olberg and Lopez, 2016).

A greenhouse is a structure design to grow plants year-round, controlling the environmental factors of light, temperature, and irrigation, with the focus to promote ideal conditions for plant growth (Link and Ross, 1978). Several important practices take place in a greenhouse environment to facilitate growing operations, of the most important of which is the use of soilless growing media. Soilless growing media is commonly composed of lightweight organic and mineral components, providing the plant with support, air, nutrient and water supply (Hamrick, 2003). However, when compared to soil, soilless growing media have a low nutrient holding capacity, so for adequate plant quality and development fertilization and nutritional management is required (Reed, 1996).

Nutritional deficiency in plants can delay crop development, decrease plant quality and reduce cost efficiency (Hamrick, 2003). Providing adequate nutrition is especially important for ornamental species, where visual quality it is extremely important (Veatch-Blohm et al., 2012). Research into the optimizing plant nutrition for annual bedding plant growth is an on-going process. In 1939, Arnon and Stout proposed the term of essential elements, referring to elements that met three criteria: 1) the plant cannot complete their life cycle in the element absence; 2) the element must be directly involved in the plant metabolism; and 3) their function cannot be replaced by other elements. These elements are grouped into two categories as macronutrients needed and present in larger amounts on the plants, and the micronutrients required in relatively smaller amounts (Marschner, 1995). 
There are several elements found in plant metabolism and tissues which can affect plant growth and development even though they do not meet the criteria for essentiality. These elements are deemed beneficial nutrients and they can stimulate growth and affect physiological functions in certain plants, in different taxa, and under specific growing conditions. Some examples of beneficial mineral elements are aluminum (Al), selenium $(\mathrm{Se})$, sodium $(\mathrm{Na})$, cobalt (Cu), silicon (Si) (Pilon-Smits et al., 2009).

Silicon is the second most abundant element in the Earth's crust, existing as silicate minerals, a key component to soil composition (Emsley, 2001). In the soil solution, Si is present as monosilicic acid $\left[\mathrm{Si}(\mathrm{OH})_{4}\right]$ in concentrations that vary from 14 to $20 \mathrm{mg} \mathrm{Si} \cdot \mathrm{L}^{-1}$, with lower concentrations present at high $\mathrm{pH}$ (>7) (Marschner, 1995). Previous research has shown several benefits from Si supplementation especially under stress conditions. Silicon has effectively alleviated biotic and abiotic effects, by decreasing the susceptibility of the plant to insect and pathogen attacks, inducing plant defense reactions to diseases, mitigating abiotic stresses such as freezing and salinity, mechanisms that reduce excessive loss of water in transpiration at drought circumstances, reducing heavy metal toxicity in plants, and also increasing plant growth and development (Ma, 1991; Liang et al., 2015; Synder, et al., 2006; Pilon-Smits et al., 2009).

Titanium is the ninth most abundant element in the Earth's crust (Emsley, 2001). Across plant species, Ti tissue content can vary from 1 to $578 \mathrm{mg} \cdot \mathrm{kg}^{-1}$, with a mean of $33.4 \mathrm{mg} \cdot \mathrm{kg}^{-1}$. Titanium absorption by the plant occurs in different ways. Titanium can be applied to plants as a dry soil application, as a dissolved element in hydroponic culture, or as a foliar application, which is the most effective form of delivery for most plants (Lyu et al., 2017). Soil application of Ti is not effective due to the element being characterized by low mobility in the soil, causing a limited uptake by root systems (Bacilieri et al., 2017). Some of the improvements in plant quality 
after Ti fertilization are visualized in seed germination, protein and chlorophyll synthesis, activity of antioxidant enzymes, yield biomass, uptake of nutrients (overall nutritional status of the plant), photosynthesis, carbohydrate production, growth, control of plant diseases fruit and vegetable quality and strengthening stress tolerance (Carvajal and Alcaraz, 1998; Lyu et al., 2017). Reports in Ti are vague and rare (Marschner, 1995). The mechanisms behind the potential beneficial effect of Ti remain unclear and there is need for more research to specifically address its effect on different plant species (Lyu et al., 2017).

Previous research examining the potential effects from Si and Ti application reported differing results depending on plant species, plant stage and tissue concentration of nutrients (Mills and Jones, 1996). Because of the promising results of research, Si and Ti may have the potential to impact the growth and quality traits of annual bedding plants grown in soilless media when applied during production (Whitted-Haag et al., 2014), and may provide improvement on the landscape performance of these plants, benefiting the greenhouse producer and consumers. Considering these factors, the purpose of this experiment is to analyze the effects of Si and Ti on the landscape performance of four species of annual bedding plants in Central Illinois, with the objective of determining if foliarly-applied Si and Ti have an effect on species commonly grown as annual bedding plants in greenhouse settings and their effect on plant development during the growing season in a simulated landscape environment. The objectives of this research were to determine the beneficial effects of $\mathrm{Si}$ and $\mathrm{Ti}$ applications to annual bedding plants during greenhouse production on landscape plant performance. 


\section{Material and Methods}

\section{Annual Bedding Plant Selection}

The selection of annual bedding plants species used in this experiment was based on three main criteria: 1) popularity of U.S. consumers in the bedding plant market; 2) All-American Selection winners, a program that has the objective to promote new garden varieties with superior garden performance judged in impartial trials through all North America, with the purpose to test new cultivars and inform gardeners since 1932 (All-American Selection [AAS], 2020); and 3) continuity of research experimentation of Whitted-Haag et al. (2014) which examined the effects of Si and Ti supplementation in growth and quality traits of annual bedding plants during greenhouse production. The plant species and cultivars selected were impatiens 'Accent White Hybrid' (Impatiens walleriana) one of the most responsive to the $\mathrm{Si}$ and $\mathrm{Ti}$ supplementation in previous research. Geranium 'Black Velvet Rose F1' (Pelargonium zonale) is an AAS winner of 2002, Vinca 'Mega Bloom Pink Halo F1' (Catharanthus roseus) is an AAS winner from 2017, Zinnia ‘Double Hot Cherry’ (Zinnia hybrid) AAS winner from 2017.

\section{Greenhouse Culture}

A greenhouse crop experiment and a field performance evaluation were conducted over the 2018 and 2019 growing seasons in Central IL. The greenhouse production was initiated by the second week of February until middle of May for both years. The four annual plant species and cultivars selected were geranium (Pelargonium x hortorum 'Black Velvet Rose F1'), impatiens (Impatiens walleriana 'Accent White'), vinca (Catharanthus roseus 'Mega Bloom Pink Halo F1'), and Zinnia (Zinnia hybrid 'Double Hot Cherry'). Seeds (Harris Seeds, Rochester, MN, besides impatiens, which is from Park Seed, Greenwood, SC) were sown into a soilless germination mix (Fafard superfine germination mix, Agawam, MA) using germination 
trays (53.96 cm x $27.46 \mathrm{~cm} \times 3.28 \mathrm{~cm}$; Growers Solution), covered with vermiculite (PVP Industries, Inc., North Bloomfield, $\mathrm{OH}$ ) ('Accent White' impatiens not covered), and bottom heat of $23^{\circ} \mathrm{C}$ until complete germination. Plants were grown in a glass-covered greenhouse (lat. $40^{\circ} 30^{\prime} \mathrm{N}$ long. $88^{\circ} 59^{\prime} \mathrm{W}$ ) with night/day temperatures of $14^{\circ} \mathrm{C} / 22^{\circ} \mathrm{C}$ and average relative humidity of $80 \%$. After germination, supplemental light was applied using 600-watt HPS lights (PL Lighting, Beamsville, OH) at the same photoperiod hours of the day. Plant production scheduling followed seed package recommendations (Harris Seeds, Rochester, MN, for geranium, zinnia, and vinca. Park Seed, Greenwood, SC, for impatiens) and Ball RedBook- Crop Production (Hamrick, 2003).

Seedlings were transplanted after achieving three to four true leaves. Zinnias, impatiens, and vinca were transplanted into 4-inch square $\left(25.8 \mathrm{~cm}^{2}\right)$ greenhouse pots (Growers Solution, Cookeville, TN), containing a soilless commercial media (Growers mix, Midwest Groundcovers, St. Charles, IL). Geranium seedlings were transplanted into greenhouse pots of $0.98 \mathrm{~L}$ (Growers Solution, Cookeville, TN), containing the same soilless commercial media Growers Mix. Plants were fertilized following commercial greenhouse common production practices, using the recommendations from Ball Redbook- Crop Production (2003) to each species, until a week before the treatments began using a $20 \mathrm{~N}-10 \mathrm{P}-20 \mathrm{~K}$ ( $20 \%$ of $\mathrm{N}$ as $8 \%$ ammonium and $12 \%$ nitrate; $10 \%$ of $\mathrm{P}_{2} \mathrm{O}_{5} ; 20 \%$ of $\mathrm{K}_{2} \mathrm{O}$ ) complete fertilizer with micronutrients. Analysis for the fertilizer is present in Table 1 (Peter's Professional, The Scotts Co., Marysville, OH). After approximately 3 weeks and adequate root development, plants were arranged on benches in a randomized complete block design by species and treatment group and foliar nutrient to initiate the treatments. 
Impatiens 'Accent White' and Zinnia 'Double Hot Cherry' were affect by aphids during 2019 greenhouse growing culture. The infestations started before Si and Ti supplementation, affecting all plants. The aphids were treated using Natural Guard Insecticidal Soap (Ferti-Lome) following the product guidelines. The product controlled the aphids on zinnias following two applications in a 7-day period. However, insecticide application burned the leaves of the impatiens, decreasing plant quality in more than 50\%, leading to a discard of impatiens for the 2019 experiments.

\section{Experiment 1: Silicon Supplementation}

In this experiment, $\mathrm{Si}$ was applied as sodium meta-silicate pentahydrate $\left(\mathrm{Na}_{2} \mathrm{SiO}_{3} 5 \mathrm{H}_{2} \mathrm{O}\right.$, Fisher Scientific, Waltham, MA) dissolved in deionized water at three different concentrations each with six replicates (six plants per replicate) per treatment, plus control with zero

concentration. Silicon concentrations were $0,50,150$ and $250 \mathrm{mg} \mathrm{Si} \mathrm{L}^{-1}$. A nonionic surfactant (DRI ${ }^{\circledR}, \mathrm{KALO}$, Overland Park, KS) at $0.125 \%$ were added to the stock solutions to ensure adequate spray coverage. No precipitate was visible in stock solutions. Treatments were applied using a 32 oz. (946 ml) heavy-duty spray bottle (Menards, Eau Claire, WI). Plants received uniform applications of $3.3 \mathrm{ml}$ of solution per spray until runoff occurs. In total, there were four weekly foliar applications, except for geranium, which received seven weekly applications. The concentrations of the nutrient sources and timing for treatment applications were determined from the best results of previous research (Whitted-Hagg et al., 2014).

\section{Experiment 2: Titanium Supplementation}

In this experiment, the Ti source used was Ti-ascorbate $\left(\right.$ Tytanit $^{\circledR}$, Intermag, Olkusz, Poland) dissolved in deionized water and was applied at three different concentrations each with six replicates (six plants per replicate) per treatment. Titanium concentrations were 0, 50, 100 
and $150 \mathrm{mg} \mathrm{Ti} \mathrm{L}^{-1}$. A nonionic surfactant (DRI ${ }^{\circledR}, \mathrm{KALO}$, Overland Park, KS) at $0.125 \%$ were added to the stock solutions to ensure adequate spray coverage. No precipitate was visible in stock solutions. Treatments were applied using a $32 \mathrm{oz}$. (946 ml) heavy-duty spray bottle (Menards, Eau Claire, WI). Plants received $3.3 \mathrm{ml}$ of solution per spray until runoff occurred. In total, four weekly foliar applications were completed, except for geranium, which received seven weekly applications. The concentrations of the nutrient sources and treatment applications were determined from the best results of previous research (Whitted-Hagg et al., 2014).

\section{Data Collection on Greenhouse}

Data collected weekly before treatment application to each plant included plant height (cm), basal stem diameter (mm), number of mature leaves, chlorophyll content, number of branches ('Accent White' impatiens only), number of flowers/inflorescence and flower/ inflorescence diameter (cm) ('Accent White' impatiens, 'Double Hot Cherry' zinnia, and 'Mega Bloom Pink Halo F1' vinca only). The plant height was measured by the plant stem base to the apical bud. Chlorophyll content was estimated using a SPAD meter (Konica Minolta Sensing, Inc., Osaka, Japan) in three random fully expanded leaves per plant. Flower/inflorescence diameter was determined by the diameter of three random flowers per plant at the stage of anthesis. Vinca 'Mega Bloom Halo F1' and impatiens 'Accent white' have single flowers, while geranium 'Black Velvet Rose F1' and zinnia 'Double Hot Cherry' are composed by several flowers referred as inflorescences, geranium is an umbel and zinnia is a capitulum. For zinnia the flower diameter was measured by the extremities of the ray florets (petals).

\section{Landscape Culture}

After treatment application in the greenhouse and achieving marketable size (field-grown stage - plants at bloom and filled out the container covering all exposed media) (Olberg and 
Lopez, 2016), plants were transplanted to an outdoor field plot at the Illinois State University Horticulture Center (lat. $40^{\circ} 53^{\prime} \mathrm{N}$ long. $89^{\circ} 00^{\prime} \mathrm{W}$. Elevation $265 \mathrm{~m}$ ). Dates of transplanting, data collections, and plant removal from outdoors in 2018 and 2019 growing season are present in Table 2. The plot is located into a soil 145C2 zone, which is classified as a Saybrook Silt Loam, $5-10 \%$ slope, eroded type. The soil was amendment with a $5 \mathrm{~cm}$ layer of organic matter incorporated into the soil. Soil nutritional analysis is present in Table 3 for 2018 and 2019. Organic matter was added in the form of yard waste compost from Illinois State University Farm, analysis of the compost is present in Table 4 and 5, for both years 2018 and 2019 respectively. The spacing utilized to each specie followed the seed package recommendation of the plant mature size. Geranium and zinnia were spaced at $42 \mathrm{~cm}$, and vinca at $30 \mathrm{~cm}$, grown in full sun and all three species arranged in a complete randomized block design inside of each experiment. Impatiens for 2018 growing season were grown under shade cloth of $50 \%$, at spacing of $30 \mathrm{~cm}$, arranged in a complete randomized block design to each experiment. Impatiens require part shade to achieve best performance, reducing temperatures and light intensity (Hamrick, 2003). Irrigation was provided as needed by overhead sprinklers, on square spacing of $4.62 \mathrm{~m}$ to achieve head to head coverage of adjustable nozzles Hunter15' pro-spray. The plants were mulched after transplanting with a 5 to $7 \mathrm{~cm}$ layer of shredded hardwood mulch following common homeowner practices recommended by University of Illinois Extension (Hentschel, 2018). All weed control was achieved manually, with a prior application of preemergent after transplanting, using Preen (Lebanon Seaboard Corporation, Lebanon, PA). No insect or disease control was performed in both years. Deadheading was performed in zonal geraniums every 15 days after data collection, according to Ball Redbook- Crop Production (2003) recommendation practice for consumers to ensure continuous blooming. 


\section{Data Collection on Landscape}

Data collection in the landscape started 30 days after transplanting (DAT) to provide adequate plant establishment and development (Latimer, 1991). Data were collected every 15 days until the first frost of the season (Pemberton and Roberson, 2001). Quality traits measured were plant height, chlorophyll content, number of flowers/inflorescences, and growth index. Plant height was determined by the plant stem base to the apical bud. Chlorophyll content was estimated using a SPAD meter (Konica Minolta Sensing, Inc., Osaka, Japan), measuring the chlorophyll content of three random fully expanded leaves per plant. Growth index was utilized as a quantitative indicator of plant growth to each plant, calculated by the equation:

$$
\mathrm{GI}=\mathrm{H}+((\mathrm{WEW}+\mathrm{WNS}) / 2) / 2
$$

where $\mathrm{H}$ is plant height $(\mathrm{cm}), \mathrm{WEW}$ is the canopy width in the east-west direction $(\mathrm{cm})$ and WNS is the canopy width in the north-south (cm) (Irmak et al., 2004; Niu et al., 2007). Before the first frost of the season, plants were removed from the field, by cutting the plants by the base of the stem removing all above ground growth. Plants were grouped into the replicates (6 plants to each replicate), and measured fresh mass (FM, g), them dried in commercial ovens at $60^{\circ} \mathrm{C}$ until achieving a uniform weight. Once plant tissues were dried, biomass was recorded.

\section{Data Analysis}

Data was analyzed using GLM procedures of Statistical Analysis Software (Version 9.1, SAS Institute, Cary, NC). For the greenhouse data, a multivariate analysis of variance was used to determine main patterns of treatment effects in overall quality traits of plants, then an analysis of variance and Duncan mean separation was performed. For landscape data, repeated measurement multivariate analysis of covariance was performed, with the first growth index in the landscape being the covariate. Following up with analysis of variance and LS means Tukey- 
Kramer separation. Fresh and dry mass (DM) were analyzed by analysis of variance and Duncan mean separation. Regression linear and quadratic was performed for all data.

\section{Results and Discussion}

\section{Experiment 1: Silicon Supplementation}

\section{A. Greenhouse Data Discussion}

The source of Si and concentration rate applied significantly affected morphology traits on ornamental species (Dębicz et al., 2017; Kamenidou et al., 2008; Kamenidou et al., 2010; Kamenidou et al., 2009; Mattson and Leatherwood, 2015; Whitted-Haag et al., 2014).

Morphologic quality traits analyzed at the marketable size for the species in the study were plant height, number of leaves, basal stem diameter, chlorophyll content, number of flowers/inflorescences, and flower/inflorescence diameter. Silicon supplementation affected some of these quality traits on geranium 'Black Velvet Rose' $(P=0.005)$ and zinnia 'Double Hot Cherry' $(P=0.037$ ) for 2019 greenhouse production (Table 6). Plant response at greenhouse production varied according to annual bedding plant species, quality trait measured, treatment levels, and year of production.

\section{Plant Height}

Silicon supplementation had a significant effect in plant height for geranium 'Black Velvet Rose' $(P=0.036)$ in 2019 . Both highest treatment levels tested, $150 \mathrm{mg} \mathrm{Si} \cdot \mathrm{L}^{-1}(32.5 \mathrm{~cm})$ and $250 \mathrm{mg} \mathrm{Si} \cdot \mathrm{L}^{-1}(32.38 \mathrm{~cm})$, provided a greater plant height when compared to the control plant group $(29.96 \mathrm{~cm})$. The highest treatment levels of Si increased plant height by greater than $2.4 \mathrm{~cm}$. Plant height for geranium increased linearly in response to Si treatments $(P=0.038)$ (Table 7). Similar results were found by Whitted-Haag et al. (2014) for snapdragon 'Montego purple' where the increase in Si supplmentation from $50 \mathrm{mg} \mathrm{Si} \cdot \mathrm{L}^{-1}$ to $100 \mathrm{mg} \mathrm{Si} \cdot \mathrm{L}^{-1}$, supplied as 
$\mathrm{NaSiO}_{3}$, produced a linear increase on plant height. Plant height was also increased by foliar supplementation of $\mathrm{NaSiO}_{3}$ in five weekly foliar sprays of $50 \mathrm{mg} \mathrm{Si} \cdot \mathrm{L}^{-1}$ for Gerbera hybrid L. 'Acapella', producing taller plants when compared to the control group (Kamenidou et al., 2010). An increase in plant height was also found on ornamental sunflowers 'Ring of Fire' when $\mathrm{KSiO}_{3}$ was applied as a powder at $140 \mathrm{~g} \cdot \mathrm{m}^{-3}$ (Kamenidou et al., 2008). In contrast, a higher dose of $\mathrm{Si}, 200 \mathrm{~g} \cdot \mathrm{m}^{-3}$, applied as $\mathrm{KSiO}_{3}$ in substrate drench, decreased plant height for the ornamental sunflowers and zinnia (Kamenidou et al., 2008; Kamenidou et al., 2009). Significant linear decreases in plant height were also reported by Whitted-Haag, et al. (2014) for geranium 'Elite Cherry', impatiens 'Accent White', and petunia 'Celebrity white' in response to increasing Si treatment levels. Mattson and Leatherwood (2010), analyzing several ornamental species treated with $100 \mathrm{mg} \cdot \mathrm{L}^{-1} \mathrm{Si}$ by potassium silicate drenches for 10 weeks, reported the most common growth response among the species studied was a change in plant height. Three species increased

plant height, as lobelia, New Guinea impatiens and portulaca (Mattson and Leatherwood, 2015). Linear increase in plant height on paper daisy 'Gold' (Xerochrysum bracteatum (Vent.) Tzvelv) and gaura 'Corinas Choice' (Gaura lindheimeri Engelm. Et A.Gray), was found with a linear increase on rates of Si supplementation by Actisil (Wróblewska and Dębicz, 2011). Our results and reported literature indicated that ornamental species response to Si application on plant height is dependent of treatment level, source of $\mathrm{Si}$, and plant species.

\section{Stem Diameter}

The basal stem diameter of zinnia 'Double Hot Cherry' $(P=0.091)$ was significantly impacted by Si supplementation. The treatment level of $250 \mathrm{mg} \cdot \mathrm{L}^{-1} \mathrm{Si}$ promoted a higher basal stem diameter of $0.538 \mathrm{~cm}$ when compared to the control group of $0.506 \mathrm{~cm}$. Basal stem diameter for zinnia increased linearly with increasing Si supplementation levels $(P=0.033)$ 
(Table 8). Kamenidou et al. (2009) found similar trend of basal stem dimeter increase for zinnia 'Oklahoma Formula Mix' (Zinnia elegans) treated with $\mathrm{KSiO}_{3}\left(200 \mathrm{mg} \cdot \mathrm{L}^{-1} \mathrm{Si}\right)$ in substrate drenches and rice husk ash $\left(100 \mathrm{~g} \cdot \mathrm{m}^{3} \mathrm{Si}\right)$ incorporated to the media. In the same experiment, foliar supplementation of $\mathrm{NaSiO}_{3}$ was not significant (Kamenidou et al., 2009). However, $\mathrm{NaSiO}_{3}$ was significantly effective in increasing stem diameter for ornamental sunflower 'Ring of Fire' (Helianthus annuus L.) along with rice husk ash and $\mathrm{KSiO}_{3}$ (Kamenidou et al., 2008). Previous research with annual ornamental plants and foliar supplementation of $\mathrm{NaSiO}_{3}$ found a linear decrease in basal stem diameter. Impatiens 'Accent white' (Impatiens walleriana) and snapdragon 'Montego purple' (Antirrhinum majus) demonstrated a smaller basal stem diameter when compared to control plants (Whitted-Haag et al., 2014). Among 21 ornamentals, the basal stem diameter of 'Wojo's Jem' vinca was the only plant significantly affected by Si treatments, producing an increase of $0.49 \mathrm{~mm}$ in the treated plants with $100 \mathrm{mg} \cdot \mathrm{L}^{-1} \mathrm{Si}$ by potassium silicate drenches over 10 weeks (Mattson and Leatherwood, 2015). The results of this research and reported literature indicates that the effect of $\mathrm{Si}$ on plant basal stem diameter is specific to the concentration of Si utilized, the application source of Si, and plant species.

\section{Chlorophyll Content}

Chlorophyll content, measured by SPAD index, was significantly affected by $\mathrm{Si}$ supplementation. Strong correlations were found between SPAD measurements and chlorophyll content in ornamental species leaves (Wik et al., 2006). Geranium 'Black Velvet Rose' $(P=0.077)$ presented a lower chlorophyll content when Si was supplemented, treatment levels of $150 \mathrm{mg} \mathrm{Si} \cdot \mathrm{L}^{-1}$ averaged $48.57 \mathrm{mg} \cdot \mathrm{m}^{-2}$ of chlorophyll content and $50 \mathrm{mg} \mathrm{Si} \cdot \mathrm{L}^{-1}$ with $48.5 \mathrm{mg} \cdot \mathrm{m}^{-2}$, statistically differed from control levels $51.67 \mathrm{mg} \cdot \mathrm{m}^{-2}$ (Table 7). However, for zinnia 'Double Hot Cherry' $(P=0.062)$ the opposite result was recorded. The lowest treatment $50 \mathrm{mg} \mathrm{Si} \cdot \mathrm{L}^{-1}$ 
provided a significant higher chlorophyll content of $29.27 \mathrm{mg} \cdot \mathrm{m}^{-2}$ when compared to control plants $27.76 \mathrm{mg} \cdot \mathrm{m}^{-2}$ (Table 8). Orthogonal contrasts were not significant for both species.

Increase in chlorophyll content was observed for creeping zinnia 'Sunbini' (Sanvitalia speciosa) and vervain 'Patio Blue' (Verbena), higher chlorophyll content was found in higher Si concentrations (180 $\left.\mathrm{mg} \cdot \mathrm{dm}^{-3} \mathrm{Si}\right)$, however, Si had a negative effect on the chlorophyll content for purslane 'Duna Red' (Portulaca umbraticola) (Dębicz and Wróblewska, 2011). A chlorophyll content decrease in response to Si supplementation was also observed for geranium 'Elite Cherry' and pansy 'Delta Premium Marina' (Whitted-Haag et al., 2014). The same pattern of species-specific results were shown for other ornamental species. African daisy 'Grande Pink Blush' (Osteospermum ecklonis (DC.) Norl.) increased in chlorophyll content with increasing Si supplementation. In gaura 'Corinas Choice' (Gaura lindheimeri Engelm. Et A.Gray), an increase in chlorophyll was seen at a $0.1 \%$ Si concentration and for Boston daisy 'Blazer Rose' (Argyrathemum frutescens (L.) Sch. Bip.) at $0.1 \%$ and $0.2 \%$ concentration. However, for paper daisy 'Gold' (Xerochrysum bracteatum (Vent.) Tzvelv) Si supplementation had a negative effect on chlorophyll content (Wróblewska and Dębicz, 2011). Along with previous research, our research indicates that results from $\mathrm{Si}$ supplementation on chlorophyll content is dependent on plant species, application concentration, and fertilizer source.

\section{Number of Flowers and Inflorescences}

Silicon supplementation had a limited effect on the number of flowers and inflorescences among the plant species tested. In zinnia 'Double Hot Cherry', the number of inflorescences $(P=0.075)$ significantly differed among the Si treatments. Zinnia had 5.5 inflorescences per plant at marketable size for the $250 \mathrm{mg} \mathrm{Si} \cdot \mathrm{L}^{-1}$ treatment level and 3.6 inflorescences per plant at the $150 \mathrm{mg} \mathrm{Si} \cdot \mathrm{L}^{-1}$ treatment level. The control group had 3.8 inflorescences per plant. The highest 
Si treatment represented an increase of $30 \%$ in the number of inflorescences for zinnia.

Orthogonal contrasts were not significant (Table 8).

Silicon supplementation by foliar application of $180 \mathrm{mg} \cdot \mathrm{dm}^{-3}$ significantly increased the number of inflorescences for Gazania 'Kiss Yellow' (Gazania rigens) by 26\%, Salvia 'Fairy Queen' (Salvia farinacea) by 96\%, and Verbena 'Obsession Lilac' (Verbena) by 76\% (Dębicz, Pawlikowska, Wróblewska, \& Bąbelewski, 2017). African daisy ‘Grande Pink Blush’ (Osteospermum ecklonis (DC.) Norl.) and paper daisy 'Gold' (Xerochrysum bracteatum (Vent.) Tzvelv) increased the number of inflorescences according to the increase in Si concentration applied. Cultivars of gaura 'Corinas Choice' (Gaura lindheimeri Engelm. Et A.Gray) and boston daisy 'Blazer Rose' (Argyrathemum frutescens (L.) Sch. Bip.) the highest flower production was achieved by $0.2 \%$ Si concentration. (Wróblewska \& Dębicz, 2011). Diverse effects on flowering was reported by Kamenidou et al. (2008) in ornamental sunflower supplied by Si. Depending on the form and concentration of Si applied, the effects on flower number could be beneficial or detrimental (Kamenidou, Cavins, \& Marek, 2008). Relating to previous literature and our results, Si supplementation seems to be effective in increase the number of inflorescences in ornamental species, but the effect is dependent in plant species, application form, and Si source.

\section{B. Landscape Data Discussion}

\section{Chlorophyll Content}

During 2018 field culture Si treatments significantly impacted the chlorophyll content for impatiens 'Accent White' $(P=0.056)$ and zinnia 'Double Hot Cherry' $(P=0.012)$ (Table 9). Although, the foliar supplementation prior transplanting during greenhouse production did not produce significant results. The chlorophyll SPAD of impatiens 'Accent White' was significant effected by Si treatment levels overtime during field production when compared to the first data 
collection. However, it was not significant to a specific data collection made, just for an orthogonal contrast at 76 DAT, by the end of the season. Chlorophyll content for impatiens decreased linearly with increasing Si treatments $(P=0.06)$ (Table 10). Silicon supplementation significantly affected chlorophyll SPAD content in zinnia 'Double Hot Cherry' at the end of the season, 12 weeks after transplanting (98 DAT) $(P=0.017)$. The mean chlorophyll SPAD content of the zinnia control plants was $39.76 \mathrm{mg} \cdot \mathrm{m}^{-2}$, which was statistically different than the mean $150 \mathrm{mg} \mathrm{Si} \cdot \mathrm{L}^{-1}$ treatment levels of $35.387 \mathrm{mg} \cdot \mathrm{m}^{-2}$. However, it did not differ from the lowest 50 $\mathrm{mg} \mathrm{Si} \cdot \mathrm{L}^{-1}$ and highest $250 \mathrm{mg} \mathrm{Si} \cdot \mathrm{L}^{-1}$ treatment of $38.75 \mathrm{mg} \cdot \mathrm{m}^{-2}$ and $37.08 \mathrm{mg} \cdot \mathrm{m}^{-2}$, respectively. The orthogonal contrast for zinnia ‘Double Hot Cherry' on chlorophyll decreased, then increased quadratically in response to increasing Si treatments $(P=0.006)$ (Table 11).

A field study conducted on onion 'Allora' (Allium cepa L.), demonstrated beneficial effects on chlorophyll contents by Si supplementation by Agribooster ${ }^{\mathrm{TM}}$. All three concentrations of silica viz applied, $7.5,10,12.5 \mathrm{ml} \cdot \mathrm{L}^{-1}$, increased chlorophyll $a$ content when compared to plants that received just regular amount of fertilizer and control group. The authors concluded that soluble silica supplementation enhanced productivity by improving the photosynthesis rate, indicating a potential use of it to increase yield and product quality (Rangwala et al., 2019). As described by Wróblewska and Dębicz (2011), a greenhouse experiment with ornamental cultivars produced different results on the effect of $\mathrm{Si}$ supplementation on chlorophyll content and differences were plant species specific. An increase in chlorophyll content was reported for African daisy 'Grande Pink Blush’ (Osteospermum ecklonis (DC.) Norl.) in response to all levels of Si applied. To gaura 'Corinas Choice' (Gaura lindheimeri Engelm. Et A.Gray) the increase in chlorophyll content was at $0.1 \% \mathrm{Si}$ concentration and for Boston daisy 'Blazer Rose' (Argyrathemum frutescens (L.) Sch. Bip.) at $0.1 \%$ and $0.2 \%$ 
concentration. However, for paper daisy 'Gold' (Xerochrysum bracteatum (Vent.) Tzvelv) Si supplementation had a negative effect on chlorophyll content (Wróblewska and Dębicz, 2011), demonstrating the specificity of plant species to Si supplementation. Previous research and our research indicate that results from Si supplementation on chlorophyll content is dependent on plant species, concentration supplied, and fertilizer source.

\section{Number of Flowers and Inflorescences}

In 2019, the number of flowers and inflorescences was statistically influenced by $\mathrm{Si}$ treatment in the landscape performance for geranium 'Black Velvet Rose' $(P=0.018)$, zinnia 'Double Hot Cherry' $(P=0.016)$, and vinca 'Mega Bloom Halo' $(P=0.023)$ (Table 12).

Silicon supplementation for geranium affected plant performance at 6 and 8 weeks after transplanting to the field. For both data collection dates the control group had a higher number of inflorescences than the Si treatment levels, indicating a negative effect, in the bloom peak of the season. At 6 weeks- 50 DAT $(P=0.018)$ in the landscape, the control group produced more inflorescences than the highest treatment of $250 \mathrm{mg} \mathrm{Si} \cdot \mathrm{L}^{-1}$. The same pattern was found at 8 weeks (64 DAT) $(P=0.018)$. For both data collection dates in geranium the number of inflorescences decreased linearly in response to increasing Si treatments ( $P=0.003$ for 50 DAT; $P=0.016$ for 64 DAT) (Table 13). The number of flowers for vinca were affected by the end of the season on 12 and 14 weeks after transplanting, 92 and 108 DAT. Vinca had a similar response as geranium, with control group having a higher number of flowers than Si treatment groups. On 12 weeks (92 DAT) $(P=0.002)$ in the landscape control group differed and was higher than all treatment levels of Si supplementation. On 14 weeks (108 DAT) $(P=0.027)$, control group presented 49.13 flowers per plant, statistically differing from the highest treatment $250 \mathrm{mg} \mathrm{Si} \cdot \mathrm{L}^{-1}$ with 33.24 flowers per plant. The number of flowers for vinca decreased linearly 
as Si treatment levels increased (Table 14). Analyzing the results from geranium and vinca, it may be hypothesized that a negative effect on the number of flowers is produced by high levels of Si for these two species in the landscape overtime. Kamenidou et al. (2008) observed flower deformation in ornamental sunflower when $\mathrm{Si}$ was supplemented in high doses, as weekly application of $\mathrm{KSiO}_{3}$ by substrate drenches in the concentration of $200 \mathrm{mg} \mathrm{Si} \cdot \mathrm{L}^{-1}$ (Kamenidou et al., 2008). Silicon substrate application on three cultivars of gladiolus 'White Friendship', 'Rose Friendship', and 'Red Beauty' (Gladiolus x grandiflorus) did not affected any morphological traits, including plant height, flowers per spike, or flower diameter, suggesting that Si application does not affect gladiolus production (Carvalho-Zanão et al., 2017).

The number of $\mathrm{f}$ inflorescences for zinnia was significant increased by $\mathrm{Si}$ supplementation in landscape development of the plants in this study. The effects were visualized later in the season by the last two data observations at 12 and 14 weeks after transplanting, 92 and $109 \mathrm{DAT}$ (Table 15). Inflorescences number for the $50 \mathrm{mg} \mathrm{Si} \cdot \mathrm{L}^{-1}$ treatment was statistically different than control plants. By 12 weeks in the landscape (92 DAT) $(P=0.019)$ at the peak of blooming for zinnia, Si supplementation of $50 \mathrm{mg} \mathrm{Si} \cdot \mathrm{L}^{-1}$ increased $36 \%$ the number of inflorescences in comparison to the control group. Zinnia increased then decreased quadratically $(P=0.091)$ for number of inflorescences in response to increasing Si treatment levels at 92 DAT. On week 14 (109 DAT) $(P=0.028)$, approximating to the end of the season on 09/29/2019, the supplementation of $50 \mathrm{mg} \mathrm{Si} \cdot \mathrm{L}^{-1}$ still producing a superior number of inflorescences, 19.49 inflorescences per plant compared to 11.37 inflorescences per plant in the control group. To this same set of plants, at marketable size the highest treatment of $250 \mathrm{mg}$ $\mathrm{Si} \cdot \mathrm{L}^{-1}$ was the most responsive to the number of inflorescences per plant. However, in the field 
culture, the lowest treatment $50 \mathrm{mg} \mathrm{Si} \cdot \mathrm{L}^{-1}$ was the most effective on inflorescences number at the peak and end of the season.

Beneficial effects of Si on flower quality and quantity was determined for several species of the family Asteraceae, such as for ornamental sunflower (Kamenidou et al., 2008), zinnia (Kamenidou et al., 2009), gerbera (Kamenidou et al., 2010), and African daisy and paper daisy (Wróblewska and Dębicz, 2011). As our findings and literature on Si effects on flower number in ornamental plants is dependent on the species, rate of Si applied, and the source of Si. The effects also can vary according to the environment plants are exposed to; either greenhouse production or landscape/field performance.

\section{Growth Index}

Zinnia also displayed a significant effect on growth index (GI) $(P=0.0710)$ from $\mathrm{Si}$ supplementation in 2019 growing season (Table 16). The Si treatment level effects were significant by the end of the season (14 weeks in the landscape) $(P=0.056)$ (Table 17). Growth index was statistically different among the Si treatment levels. The lowest treatment $50 \mathrm{mg} \mathrm{Si} \cdot \mathrm{L}^{-1}$ increased growth index by $3.8 \mathrm{~cm}^{3}$, presenting a GI of $46.45 \mathrm{~cm}^{3}$ over $42.59 \mathrm{~cm}^{3}$ from control group. The supplementation by $50 \mathrm{mg} \mathrm{Si} \cdot \mathrm{L}^{-1}$ also significantly increased the number of inflorescences for zinnia, which can be related to a better overall plant growth and for consumers a more desirable plant. Silicon supplementation affected plant growth of creeping zinnia 'Sunbini' and portulaca 'Duna Red' by stimulating lateral shoot elongation, which directly reflected into an increase in plant diameter. For portulaca 'Duna Red', a positive influence of Si was recorded at $0.3 \% \mathrm{Si}$ applied as Actisil, while low Si concentration solutions had a negative effect on main shoot length (Dębicz and Wróblewska, 2011). 


\section{Fresh Mass}

Fresh mass of plants was affected by Si supplementation in vinca 'Mega Bloom Halo' and zinnia 'Double Hot Cherry' during the 2019 growing season (Table 18). For vinca 'Mega Bloom Halo' the FM $(P=0.0004)$ of control group accounted for $410.84 \mathrm{~g}$ per plant, being a higher mass than all Si levels of supplementation. The $50 \mathrm{mg} \mathrm{Si} \cdot \mathrm{L}^{-1}$ concentration produced a $343.77 \mathrm{~g}$ per plant of $\mathrm{FM}$, differing from the concentrations of $150 \mathrm{mg} \mathrm{Si} \cdot \mathrm{L}^{-1}$ and $250 \mathrm{mg} \mathrm{Si} \cdot \mathrm{L}^{-1}$ which produced $281.52 \mathrm{~g}$ and $266.16 \mathrm{~g}$ per plant, respectively. Vinca decreased linearly in FM as the concentration of Si applied increased $(P=0.002)$. In zinnia 'Double Hot Cherry’ FM $(P=0.035)$ significantly differed from the lowest concentration applied $50 \mathrm{mg} \mathrm{Si} \cdot \mathrm{L}^{-1}$ with 379.47 g per plant to the highest concentration $250 \mathrm{mg} \mathrm{Si} \cdot \mathrm{L}^{-1}$ and control group, demonstrating a FM of 285.39 g per plant and 261.7 g per plant, respectively. The lowest concentration of Si applied increased the FM for zinnia in $117.77 \mathrm{~g}$ per plant in comparison to the control group. Zinnia fresh weight increased, then decreased quadratically as Si treatment levels increased $(P=0.090)$. Mattson and Leatherwood (2015) analyzed 21 ornamental species supplied with 10 weekly potassium silicate drenches at $100 \mathrm{mg} \mathrm{Si} \cdot \mathrm{L}^{-1}$ found significant increases in $\mathrm{FM}$ for two species. For bracteantha 'Golden Beauty' (Bracteantha bracteata (Vent.) Anderb. \& Heagi), Si supplementation increased the FM by $41.6 \mathrm{~g}$ in comparison to the control treatment, and for lobelia 'Hot Waterblue Improved' (Lobelia erinus L.) an increase of $30 \mathrm{~g}$ over control plants was reported (Mattson and Leatherwood, 2015).

\section{Dry Mass}

Vinca ‘Mega Bloom Halo’ and zinnia ‘Double Hot Cherry’ DM was influenced by Si application in 2019 growing season (Table 19). In vinca, the DM $(P=0.007)$ of control group was statistically different than the two highest concentrations of $\mathrm{Si}$ applied, $150 \mathrm{mg} \mathrm{Si} \cdot \mathrm{L}^{-1}$ and 
$250 \mathrm{mg} \mathrm{Si} \cdot \mathrm{L}^{-1}$. Dry mass for vinca decreased linearly as Si treatment levels increased $(P=0.008)$. Sivanesan et al., 2014, found similar results for FM and DM of ferns 'Gorditas' (Nephrolepis exaltata), decreased with increasing concentrations of $\mathrm{Si}$ in the nutrient solution at 50 or $100 \mathrm{mg}$ $\cdot \mathrm{L}^{-1} \mathrm{Si}$ level supplied through a drip-irrigation system.

Zinnia DM $(P=0.039)$ in Si treatment of $50 \mathrm{mg} \mathrm{Si} \cdot \mathrm{L}^{-1}$ presented a DM of $120.37 \mathrm{~g}$ per plant, being significantly higher than the highest concentration of $250 \mathrm{mg} \mathrm{Si} \cdot \mathrm{L}^{-1}$, with $83.66 \mathrm{~g}$ per plant and the control group of $83.21 \mathrm{~g}$ per plant. This was an increase in DM of $37.16 \mathrm{~g}$ from Si supplementation of $50 \mathrm{mg} \mathrm{Si} \cdot \mathrm{L}^{-1}$ in comparison with control. Dry mass increased, then decreased quadratically in response to increasing Si foliar treatment levels $(P=0.071)$. Increases in DM was also reported for bracteantha 'Golden Beauty' (Bracteantha bracteata (Vent.) Anderb. \& Heagi), lobelia 'Hot Waterblue Improved' (Lobelia erinus L.), and Verbena 'Tropical Breeze Deep Purple' (Verbena hybrida Groenl. \& Rumpler) in response to Si supplementation, with the highest dry weight increase for bracteantha 'Golden Beauty' by $5 \mathrm{~g}$ in comparison to control plants (Mattson and Leatherwood, 2015).

\section{Experiment 2: Titanium Supplementation}

\section{A. Greenhouse Data Discussion}

Morphologic quality traits analyzed at the markable size for the species in the study were plant height, number of leaves, basal stem diameter, chlorophyll content, number and diameter of flowers and inflorescences. Titanium supplementation affected these quality traits for the 2018 growing season for geranium 'Black Velvet Rose' $(P=0.078)$ and vinca 'Mega Bloom Halo' $(P=0.022)$, presented in Table 20. Geranium did not have a specific quality trait affected, just the overall growth. However, the number of inflorescences increased linearly in response to increasing Ti treatment levels for geranium $(P=0.021)$ (Table 21). Plant response at greenhouse 
production varied according to annual bedding plant species, quality trait measured, treatment levels, and year of production.

\section{Chlorophyll Content}

Chlorophyll content measured by the SPAD index was significantly affected by Ti application. At marketable size the chlorophyll content of vinca 'Mega Bloom Halo' $(P=0.095)$ significantly differ. The lowest concentration of $\mathrm{Ti}$ applied $50 \mathrm{mg} \mathrm{Ti} \cdot \mathrm{L}^{-1}$ presented a chlorophyll content of $48.71 \mathrm{mg} \cdot \mathrm{m}^{-2}$, which was higher than the two other Ti concentrations applied, $100 \mathrm{mg}$ $\mathrm{Ti} \cdot \mathrm{L}^{-1}$ with $47.02 \mathrm{mg} \cdot \mathrm{m}^{-2}$ and $150 \mathrm{mg} \mathrm{Ti} \cdot \mathrm{L}^{-1}$ providing $46.92 \mathrm{mg} \cdot \mathrm{m}^{-2}$ chlorophyll content (Table 22). Titanium provided varied responses when supplied to different species of annual bedding plants. Titanium supplementation did not affect snapdragon 'Montego Purple', however, impatiens 'Accent White' and petunia 'Celebrity White' exhibited a decrease in SPAD chlorophyll content and geranium 'Elite Cherry' showed an increase in SPAD chlorophyll content (Whitted-Haag et al., 2014). Titanium increased plant yield for hydroponically grown lettuce (Lactuca sativa L. cv. Zeralda) growing under Mn-stress. The supplementation of 0.72 $\mathrm{mg} \mathrm{Ti} \cdot \mathrm{dm}^{-3}$ presented the highest mean weight of a lettuce head and dry matter in the leaves. Titanium also positively influenced the lettuce chlorophyll content (Kleiber, 2012). Titanium ascorbate in hydroponic culture of oats (Avena sativa L. cv. Zlatak) provided several beneficial effects for plant growth when supplied as nitrate solutions at $2 \mathrm{mg} / \mathrm{kg}$ of Ti. Improving plant health status by increasing top and root dry weights and chlorophyll contents. These beneficial effects are associated with the Ti-induced increase in nitrate reductase activity in plant tissue, enhancing the synthesis of porphyrine ring structures in chlorophylls and hemoproteins as catalase and peroxidase (Hruby et al., 2002). Supplementation of Ti by foliar applications of Tytanit $^{\circledR}$ in Timothy grass (Phleum pratense L.) seed plantation has a positive effect on the 
chlorophyll content of the leaves, influencing the leaf greenness index measured by SPAD readings. The highest treatment applied, of $0.08 \% \mathrm{Ti}$, led to the highest SPAD readings, averaging a $6 \%$ increase in comparison to the control plants. The anthesis stage was the most responsive during plant development (Radkowski, 2013). Previous research, along with our study, supports that Ti supplementation can affect the chlorophyll content of annual bedding plant species.

\section{Flower and Inflorescences Diameter}

Titanium supplementation had a negative effect for flower diameter in vinca 'Mega Bloom Halo' $(P=0.002)$. The control provided a higher flower diameter of $5.63 \mathrm{~cm}$, significantly superior from all Ti concentrations supplied, as for $50 \mathrm{mg} \mathrm{Ti} \cdot \mathrm{L}^{-1}, 100 \mathrm{mg} \mathrm{Ti} \cdot \mathrm{L}^{-1}, 150 \mathrm{mg} \mathrm{Ti} \cdot \mathrm{L}^{-1}$, providing flower diameters of $5.35 \mathrm{~cm}, 5.31 \mathrm{~cm}$, and $5.25 \mathrm{~cm}$, respectively (Table 22). Flower diameter decreased linearly as Ti treatment concentrations increased for vinca $(P=0.0002)$. Whitted-Haag, et al. (2014) did not report any significant responses by Ti supplementation on flower diameter for annual bedding plants. On pansy 'Delta Premium Marina' the flower diameter was significant in the model but not in regression analysis (Whitted-Haag et al., 2014). Our results and previous literature demonstrated Ti supplementation may have a negative effect on flower diameter, requiring more studies.

\section{B. Landscape Data Collection}

\section{Plant Height}

Titanium supplementation affected the plant height in landscape performance of geranium 'Black Velvet Rose' $(P=0.013)$ for 2019 growing season (Table 23). However, just the first data collection (07/06/2019) at 32 DAT presented significant differences in Ti supplementation and plant height $(P=0.016)$. Titanium supplementation of $100 \mathrm{mg} \mathrm{Ti} \cdot \mathrm{L}^{-1}$ and 150 
$\mathrm{mg} \mathrm{Ti} \cdot \mathrm{L}^{-1}$ of Ti provided plant heights of $35.49 \mathrm{~cm}$ and $34.93 \mathrm{~cm}$, significantly differing from the control group of $31.81 \mathrm{~cm}$. Titanium supplementation effected plant height on geranium 'Black Velvet Rose' over time in plant development when related to the first observation, however, did not have effect in a specific point in the growing season. However, for orthogonal contrasts, geranium plants presented a linear increase in plant height in response to increasing Ti levels applied in the first weeks of the season, at 32 DAT $(P=0.002), 50$ DAT $(P=0.005)$, and 64 DAT $(P=0.015)($ Table 24).

Whitted-Haag et al., (2014) reported a range of effects by Ti supplementation on plant height for annual bedding plants in a greenhouse growing system. Impatiens 'Accent White' was not responsive to Ti application, petunia 'Celebrity White' responded negatively, while snapdragon 'Montego Purple' demonstrated a positive relationship. Geranium 'Elite Cherry' increased in height from $7.6 \mathrm{~cm}$ for the control group to $8.6 \mathrm{~cm}$ in the Ti supplementation of 50 and $75 \mathrm{mg} \mathrm{Ti} \cdot \mathrm{L}^{-1}$ (Whitted-Haag et al., 2014). Titanium increased biomass of apple 'Elma' (Malus domestica L.) linked to the increase in the uptake of zinc ( $\mathrm{Zn})$ and phosphorus (P) (Wojcik and Wojcik, 2001). Supplementation of Ti in peach (Prunus persica L.) improved plant performance and fruit quality and size, trees demonstrated a higher branch elongation and increase the set intensity of flower and fruit. Relating to essential nutrients, Ti increased $\mathrm{Fe}, \mathrm{Cu}$, and $\mathrm{Zn}$ concentrations on fruit peel, and $\mathrm{Ca}$ on the peel and flesh (Alcaraz- López et al., 2004). Zinc and phosphorus are stimulators of cell division and regulate plant growth (Ingels, 2010).

Our study did not measure essential element concentrations in plant tissue, so we cannot conclude that responses in plant height are due increase in essential nutrients uptake by $\mathrm{Ti}$ application. However, previous literature and our study indicates a positive effect of Ti 
supplementation in plant height of annual bedding plants in greenhouse system or landscape performance.

\section{Chlorophyll content}

Chlorophyll content for impatiens 'Accent White' $(P=0.011)$ in 2018 growing season on landscape was statistically significant affected by Ti supplementation over time during plant growth in the season (Table 25). Titanium supplementation have a significant effect at 6 weeks after transplanting 45 DAT $(P=0.045)$, providing a better start for the plants in the field. The

chlorophyll content $(P=0.012)$ differed between Ti concentrations, $43.73 \mathrm{mg} \cdot \mathrm{m}^{-2}$ and 43.82 $\mathrm{mg} \cdot \mathrm{m}^{-2}$ chlorophyll content was visualized at Ti application of 150 and $50 \mathrm{mg} \mathrm{Ti} \cdot \mathrm{L}^{-1}$, respectively, both are statistically different than the control group, which presented a chlorophyll content of $37.46 \mathrm{mg} \cdot \mathrm{m}^{-2}$. Chlorophyll SPAD content increased linearly in response to increasing Ti supplementation lelves at $30 \mathrm{DAT}(P=0.094)$ and at $45 \mathrm{DAT}(P=0.037)$ for impatiens (Table 26).

Greenhouse production of annual bedding plants Ti provided varied responses, for snapdragon “Montego Purple' was not significant, decreased chlorophyll contents for impatiens 'Accent White' and petunia 'Celebrity White', and increase to geranium 'Elite Cherry' (WhittedHaag et al., 2014). In field production application of Mg-Titanit ${ }^{\circledR} 0.2 \mathrm{~L} \cdot \mathrm{ha}^{-1} \mathrm{Ti}_{\text {increased the }}$ amount of assimilative pigments chlorophyll $a$ and $b$ for winter wheat and winter rape. First and second spray application were positively significant, while the third spraying tends to decrease the total chlorophyll content (Kováčik et al., 2014). Our research and previous research suggest that Ti supplementation can affect chlorophyll content of plants. 


\section{Number of Flowers and Inflorescences}

Number of inflorescences for geranium 'Black Velvet Rose' $(P=0.066)$ in the landscape at 2019 growing season was affected by Ti application (Table 27). Titanium supplementation was significant at 8 and 10 weeks after transplanting (Time $3-08 / 07 / 2019 P=0.046$ and Time 4 $-08 / 23 / 2019 P=0.03)$. On the peak of the season at 8 weeks after transplanting (64 DAT) $(P=0.043)$ the control group produced 31.3 inflorescences, differing statistically from $100 \mathrm{mg}$ $\mathrm{Ti} \cdot \mathrm{L}^{-1}$ which provided 25.5 inflorescences per plant. At 10 weeks, $80 \mathrm{DAT}(P=0.031)$ the control group differed from the $150 \mathrm{mg} \mathrm{Ti} \cdot \mathrm{L}^{-1}$, demonstrating 19.5 to 13.6 inflorescences, respectively (Table 28). At 64 DAT ( $P=0.038)$, the number of inflorescences decreased, then increased quadratically in response to increasing Ti supplementation. At 80 DAT $(P=0.018)$ and 96 DAT $(P=0.095)$ number of inflorescences for geranium decreased linearly as Ti concentrations levels applied increased (Table 28). The results suggest that Ti supplementation have a negative effect in the number of inflorescences for geranium. Applied to peach Ti improved plant performance and fruit quality and size, trees demonstrated a higher branch elongation and increase the set intensity of flower and fruit (Alcaraz- López et al., 2004). There are currently no reports on the effect of Ti supplementation in the number of flowers and inflorescences of annual bedding plants, indicating a need for more research in the area.

\section{Fresh Mass}

Fresh mass was affected by Ti supplementation for geranium 'Black Velvet Rose' and vinca 'Mega Bloom Halo' in 2019 growing season (Table 29). For geranium $(P=0.019)$ the control group presented a FM of 478.2 g per plant, statistically differing from Ti application of $100 \mathrm{mg} \mathrm{Ti} \cdot \mathrm{L}^{-1}$ with a $324.77 \mathrm{~g}$ per plant, but not differing from 50 and $150 \mathrm{mg} \mathrm{Ti} \cdot \mathrm{L}^{-1}$. Geranium FM decreased, then increased quadratically in response to increasing Ti treatment levels 
$(P=0.039)$. The control group was also superior for vinca $(P=0.031)$, significantly differing from all Ti concentrations applied. In 2019, vinca FM decreased, then increased quadratically in response to increasing Ti treatments $(P=0.022)$ (Table 29). Haghighi and Daneshmand (2018) analyzed the effect of Ti supplementation in 'Fiora' tomato, the results regarding plant growth and flowering varied. Shoot diameter, root DM, shoot DM and shoot FM did not change by Ti supplementation. However, flower number and root FM increased with the application of 2 $\mathrm{mg} \cdot \mathrm{L}^{-1} \mathrm{Ti}$ (Haghighi and Daneshmand, 2018). Our results and literature indicate that Ti effects on FM can vary by species and part of the plant analyzed.

\section{Dry Mass}

The DM for geranium 'Black Velvet Rose' was also affected by Ti application. For the DM on geranium $(P=0.014)$ the control group provided $81.12 \mathrm{~g}$ per plant, superior than the Ti supplementation of $100 \mathrm{mg} \mathrm{Ti} \cdot \mathrm{L}^{-1}$ with $53.18 \mathrm{~g}$, but not differing from the other $\mathrm{Ti}$ supplementation of 50 and $150 \mathrm{mg} \mathrm{Ti} \cdot \mathrm{L}^{-1}$. Dry mass for geranium decreased, then increased quadratically in response to increasing Ti treatments $(P=0.017)$. Titanium supplemented by $\mathrm{Ti}^{4+}$ ascorbate $\left(\right.$ Tytanit $^{\circledR}$ ) at rate $0.72 \mathrm{mg} \cdot \mathrm{dm}^{-3}$ increased plant yield for hydroponically grown lettuce (Lactuca sativa L. cv. Zeralda), presenting the highest mass of a lettuce head and DM in the leaves, it also influenced the chlorophyll content on the leaves (Kleiber, 2012). Norman and Chen (2011), studying the effects of Xanthomonas hortorum pv. pelargonii in potted zonal geranium 'Patriot Bright Violet' and Xanthomonas axonopodis pv. Poinsettiicola in poinsettia 'Snowcap', visualized a beneficial effect in the decrease of disease infection, however, plant DM was not significantly different between treatments and control (Norman and Chen, 2011). Biomass was increased by Ti when applied to meadow sward. The highest dose applied $0.08 \%$ of Ti by Tytanit ${ }^{\circledR}$, increased DM yield and nutrient content when compared to control plants 
(Radkowski and Radkowska, 2013). In potato tubers, Ti applied in different levels $\left(0.2 \mathrm{dm}^{3} \cdot \mathrm{ha}^{-1}\right.$ and $0.4 \mathrm{dm}^{3} \cdot \mathrm{ha}^{-1}$ of Tytanit ${ }^{\circledR}$ ) and stage of plant growth did not influence the plant DM, starch, monosaccharides, protein, L-ascorbic acid or nitrates levels (Kalinowski et al., 2018). According to the literature and our results the effect of $\mathrm{Ti}$ in plant $\mathrm{DM}$ is species-specific. 


\section{CHAPTER IV: CONCLUSION AND RECOMMENDATIONS}

The goals of these experiments were to determine if Si and Ti foliar supplementation on selected annual bedding plant species during greenhouse production affected the growth and quality characteristics of selected annual bedding plants in the landscape. Based on the results from the experiments, it can be reasoned that both $\mathrm{Si}$ and $\mathrm{Ti}$ affected the growth and quality traits of the plants in the greenhouse and in the landscape. However, these responses were species, nutrient concentration, and year of production specific. Therefore, at the present time it is difficult to recommend a single treatment concentration for annual bedding plant quality and growth enhancement.

Whitted-Hagg et al. (2014) reported the beneficial effects of Si and Ti in greenhouse production of annual bedding plants, with results being specific to plant species and nutrient concentration. Our current experiment reinforces their results. Both of these beneficial nutrients improved plant performance of annual bedding species, specific to plant specie, nutrient concentration and year. Some other factors may have played a role in greenhouse conditions from year to year causing the differences between years, such as temperature control and humidity differences. Indicating the need of more research, maybe utilizing growth chmabers, to provide accurate guidelines for greenhouse growers.

Silicon and Ti affected different quality traits on different species it the landscape, also varying according to the nutrient concentration supplied and the year of experimentation. Some of the quality traits affected followed the reported prior effects in greenhouse production, while others were only expressed during landscape performance evaluation. Accordingly, the beneficial effects of Si and Ti may not be visualized during greenhouse production. However, effects on plant development may be seen in the outdoor growing environment. 
The experiment was conducted during two growing seasons to decrease environmental influences. However, biotic and abiotic factors may have an impact. Such as, soils composition, nutrient availability, water supplementation, temperature, wind, light intensity, plant allocation in the landscape and spacing, and landscape practices followed by consumers. Despite these variations, this study has demonstrated potential benefits of growers applying Si and Ti as foliar fertilization supplementation as a greenhouse production practice and the ability to provide plants of better growth characteristics and quality traits for consumers. However, $\mathrm{Si}$ and $\mathrm{Ti}$ supplementation requires further research to identify specific species, concentration and growing condition variability.

Further research is required to expend the knowledge about $\mathrm{Si}$ and $\mathrm{Ti}$ effect in the annual bedding plant production, from the grower's point of view, their effects on landscape performance, and ultimately on consumer preference. 


\section{Table 1}

Product analysis for Peter's Professional 20N-10P-20K water soluble fertilizer

\begin{tabular}{lc}
\hline Nutrient & Total Percent $(\%)$ \\
\hline Total nitrogen $(\mathrm{N})$ & 20.0 \\
$\quad 8 \%$ ammonium & \\
$\quad 12 \%$ nitrate & \\
Potash $\left(\mathrm{K}_{2} \mathrm{O}\right)$ & 20.0 \\
Phosphate $\left(\mathrm{P}_{2} \mathrm{O}_{5}\right)$ & 10.0 \\
Magnesium $(\mathrm{Mg})$ & 0.15 \\
Boron $(\mathrm{B})$ & 0.0125 \\
Copper $(\mathrm{Cu})$ & 0.0125 \\
Iron $(\mathrm{Fe})$ & 0.0500 \\
Manganese $(\mathrm{Mn})$ & 0.0250 \\
Molybdenum $(\mathrm{Mo})$ & 0.0050 \\
Zinc $(\mathrm{Zn})$ & 0.0250
\end{tabular}

Nutrient carries include: ammonium nitrate, potassium nitrate, potassium phosphate, magnesium sulfate, boric acid, copper EDTA, iron EDTA, manganese EDTA, ammonium molybdate, and zinc EDTA. 


\section{Table 2}

'Black Velvet Rose F1' geranium (Pelargonium zonale), 'Mega Bloom Pink Halo F1' vinca (Catharanthus roseus), 'Double Hot Cherry' zinnia (Zinnia hybrid) and 'Accent White Hybrid' impatiens (Impatiens walleriana) landscape data collection (by days after transplanting-DAT) schedule for 2018 and 2019 growing season for Si and Ti experiment at the Horticulture Center, Illinois State University, Normal, IL

\begin{tabular}{|c|c|c|c|c|c|c|c|c|c|}
\hline $\begin{array}{l}\text { Plant } \\
\text { Species }\end{array}$ & Year & $\begin{array}{c}\text { Transplant } \\
\text { date }\end{array}$ & $\begin{array}{c}1^{\text {st }} \text { Data } \\
\text { Collection }^{\mathrm{a}}\end{array}$ & $\begin{array}{l}2^{\text {nd }} \text { Data } \\
\text { Collection }\end{array}$ & $\begin{array}{c}3^{\text {rd }} \text { Data } \\
\text { Collection }\end{array}$ & $\begin{array}{c}4^{\text {th }} \text { Data } \\
\text { Collection }\end{array}$ & $\begin{array}{c}5^{\text {th }} \text { Data } \\
\text { Collection }\end{array}$ & $\begin{array}{c}6^{\text {th }} \text { Data } \\
\text { Collection }\end{array}$ & $\begin{array}{l}\text { Landscape } \\
\text { Removal }^{\mathrm{a}}\end{array}$ \\
\hline Impatiens & 2018 & $06 / 16$ & 30 & 45 & 58 & 76 & 92 & - & 116 \\
\hline Geranium & 2018 & 06/01 & 33 & 47 & 60 & 79 & 96 & 103 & 130 \\
\hline Vinca & 2018 & $06 / 13$ & 30 & 41 & 59 & 77 & 92 & 106 & 120 \\
\hline Vinca & 2019 & 06/09 & 30 & 45 & 60 & 76 & 92 & 108 & 123 \\
\hline Zinnia & 2019 & $06 / 12$ & 31 & 48 & 61 & 77 & 92 & 109 & 120 \\
\hline
\end{tabular}

${ }^{a}$ Days After Transplanting (DAT) 


\section{Table 3}

Soil testing results for 2018 and 2019 growing season at the Horticulture Center at Illinois State University, Normal, IL

\begin{tabular}{lccc}
\hline Soil Parameters & Unit & 2018 & 2019 \\
\hline $\mathrm{pH}$ & & 7.6 & 7.7 \\
Phosphorus (P) & $\mathrm{kg} / \mathrm{ha}$ & 726 & 706 \\
Potassium (K) & $\mathrm{kg} / \mathrm{ha}$ & 824 & 928 \\
(LOI) Organic Matter & $\%$ & 9.9 & 11.3 \\
\hline
\end{tabular}




\section{Table 4}

Yard Waste Compost Analysis for 2018 (08/20/2018)

\begin{tabular}{|c|c|c|c|c|}
\hline Nutrients & Unit & Analysis (as rec'd) & Analysis (dry weight) & Total content (lbs per ton) (as rec'd) \\
\hline \multicolumn{5}{|l|}{ Nitrogen } \\
\hline Total Nitrogen & $\%$ & 1.04 & 2.28 & 20.8 \\
\hline Organic Nitrogen & $\%$ & 0.85 & 1.86 & 17.0 \\
\hline Ammonium Nitrogen & $\%$ & 0.002 & 0.004 & --- \\
\hline Nitrate Nitrogen & $\%$ & 0.19 & 0.42 & 3.8 \\
\hline \multicolumn{5}{|c|}{ Major and Secondary Nutrients } \\
\hline Phosphorus & $\%$ & 0.18 & 0.39 & 3.6 \\
\hline Phosphorus as $\mathrm{P} 2 \mathrm{O} 5$ & $\%$ & 0.41 & 0.9 & 8.2 \\
\hline Potassium & $\%$ & 0.46 & 1.01 & 9.2 \\
\hline Potassium as $\mathrm{K} 2 \mathrm{O}$ & $\%$ & 0.55 & 1.21 & 11.0 \\
\hline Sulfur & $\%$ & 0.11 & 0.24 & 2.2 \\
\hline Calcium & $\%$ & 1.87 & 4.1 & 37.4 \\
\hline Magnesium & $\%$ & 0.36 & 0.79 & 7.2 \\
\hline Sodium & $\%$ & 0.040 & 0.088 & 0.8 \\
\hline \multicolumn{5}{|l|}{ Micronutrients } \\
\hline Zinc & $\mathrm{mg} / \mathrm{kg}$ & 98 & 215 & 0.2 \\
\hline Iron & $\mathrm{mg} / \mathrm{kg}$ & 4420 & 9693 & 8.8 \\
\hline Manganese & $\mathrm{mg} / \mathrm{kg}$ & 238 & 552 & 0.5 \\
\hline
\end{tabular}




\section{Table 4. Continued}

\begin{tabular}{|c|c|c|c|c|}
\hline Nutrients & Unit & Analysis (as rec'd) & Analysis (dry weight) & Total content (lbs per ton) (as rec'd) \\
\hline Copper & $\mathrm{mg} / \mathrm{kg}$ & $<20$ & --- & ---- \\
\hline Boron & $\mathrm{mg} / \mathrm{kg}$ & $<100$ & --- & ---- \\
\hline \multicolumn{5}{|l|}{ Other Proprieties } \\
\hline Organic Matter & $\%$ & 21.10 & 46.27 & 422.0 \\
\hline $\mathrm{pH}$ & & 7.6 & & \\
\hline $\mathrm{C}: \mathrm{N}$ ratio & & $11: 1$ & & \\
\hline Total Carbon & $\%$ & 11.15 & 24.45 & \\
\hline Conductivity 1:5 (Soluble Salts) & $\mathrm{mS} / \mathrm{cm}$ & 5.58 & & \\
\hline
\end{tabular}




\section{Table 5}

Yard Waste Compost Analysis for 2019 (07/05/2019).

\begin{tabular}{|c|c|c|c|c|}
\hline Nutrients & Unit & Analysis (as rec'd) & Analysis (dry weight) & Total content (lbs per ton) (as rec'd) \\
\hline \multicolumn{5}{|l|}{ Nitrogen } \\
\hline Total Nitrogen & $\%$ & 0.88 & 1.34 & 17.6 \\
\hline Organic Nitrogen & $\%$ & 0.84 & 1.28 & 16.9 \\
\hline Ammonium Nitrogen & $\%$ & 0.006 & 0.009 & 0.1 \\
\hline Nitrate Nitrogen & $\%$ & 0.03 & 0.05 & 0.6 \\
\hline \multicolumn{5}{|c|}{ Major and Secondary Nutrients } \\
\hline Phosphorus & $\%$ & 0.3 & 0.46 & 6.0 \\
\hline Phosphorus as P2O5 & $\%$ & 0.69 & 1.05 & 13.8 \\
\hline Potassium & $\%$ & 0.34 & 0.52 & 6.8 \\
\hline Potassium as $\mathrm{K} 2 \mathrm{O}$ & $\%$ & 0.41 & 0.62 & 8.2 \\
\hline Sulfur & $\%$ & 0.15 & 0.23 & 3.0 \\
\hline Calcium & $\%$ & 2.81 & 4.26 & 56.2 \\
\hline Magnesium & $\%$ & 0.48 & 0.73 & 9.6 \\
\hline Sodium & $\%$ & 0.030 & 0.046 & 0.6 \\
\hline \multicolumn{5}{|l|}{ Micronutrients } \\
\hline Zinc & $\mathrm{mg} / \mathrm{kg}$ & 219 & 332 & 0.4 \\
\hline Iron & $\mathrm{mg} / \mathrm{kg}$ & 6660 & 10106 & 13.3 \\
\hline Manganese & $\mathrm{mg} / \mathrm{kg}$ & 391 & 593 & 0.8 \\
\hline
\end{tabular}

(Table Continues) 


\section{Table 5. Continued}

\begin{tabular}{|c|c|c|c|c|}
\hline Nutrients & Unit & Analysis (as rec'd) & Analysis (dry weight) & Total content (lbs per ton) (as rec'd) \\
\hline Copper & $\mathrm{mg} / \mathrm{kg}$ & 37.4 & 57 & --- \\
\hline Boron & $\mathrm{mg} / \mathrm{kg}$ & 103 & 156 & 0.2 \\
\hline \multicolumn{5}{|l|}{ Other Proprieties } \\
\hline Organic Matter & $\%$ & 29.40 & 44.61 & 558.0 \\
\hline $\mathrm{pH}$ & & 7.7 & & \\
\hline $\mathrm{C}: \mathrm{N}$ ratio & & $13: 1$ & & \\
\hline Total Carbon & $\%$ & 11.35 & 17.22 & \\
\hline Conductivity 1:5 (Soluble Salts) & $\mathrm{mS} / \mathrm{cm}$ & 1 & & \\
\hline
\end{tabular}




\section{Table 6}

Results for multivariate analysis of variance for silicon supplementation effect on overall quality traits for 'Black Velvet Rose F1' geranium (elargonium zonale), 'Mega Bloom Pink Halo F1'vinca (Catharanthus roseus), 'Double Hot Cherry' zinnia (Zinnia hybrid) and 'Accent White Hybrid' impatiens (Impatiens walleriana) growing under greenhouse conditions at Illinois State University, Normal, IL for silicon treatments varying from 0, 50, 150, and $250 \mathrm{mg} \mathrm{Si \cdot L^{-1 }}$

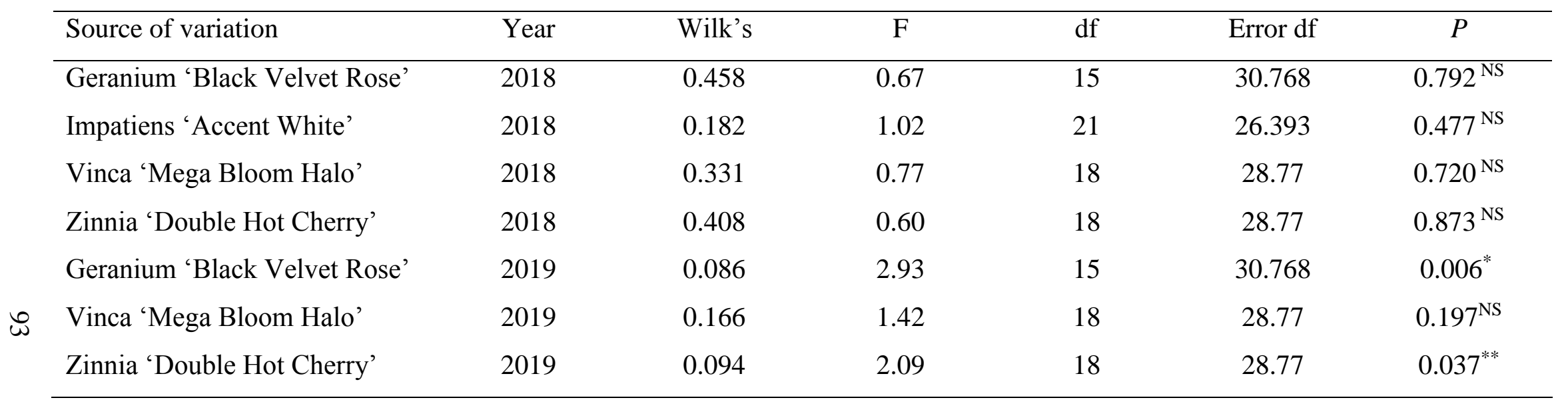

NS, ${ }^{*},{ }^{* *},{ }^{* * *}$ Nonsignificant or significant at $P \leq 0.01, P \leq 0.05, P \leq 0.10$, respectively. 


\section{Table 7}

Mean values ${ }^{a}$ of 'Black Velvet Rose' geranium (Pelargonium zonale) growth parameters after plants reached marketable size under greenhouse conditions at Illinois State University for 2019 growing season, Normal, IL with silicon treatments (Si Concentration)

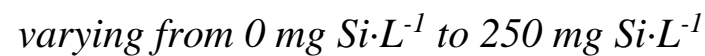

\begin{tabular}{|c|c|c|c|c|c|}
\hline $\begin{array}{l}\text { Si Concentration } \\
\left(\mathrm{mg} \cdot \mathrm{L}^{-1}\right)\end{array}$ & $\begin{array}{c}\text { Number of } \\
\text { Leaves }\end{array}$ & $\begin{array}{l}\text { Basal Stem Diameter } \\
\qquad(\mathrm{cm})\end{array}$ & $\begin{array}{c}\text { Plant Height }{ }^{\mathrm{b}} \\
(\mathrm{cm})\end{array}$ & $\begin{array}{l}\text { SPAD Chlorophyll }{ }^{\mathrm{c}} \\
\left(\mathrm{mg} \cdot \mathrm{m}^{-2}\right)\end{array}$ & $\begin{array}{c}\text { Number of } \\
\text { Inflorescences }\end{array}$ \\
\hline 0 & $42.36 \pm 2.24 \mathrm{a}$ & $1.29 \pm 0.03 \mathrm{a}$ & $29.96 \pm 1.36 \mathrm{~b}$ & $51.68 \pm 1.89 \mathrm{a}$ & $4.40 \pm 0.77 \mathrm{a}$ \\
\hline 150 & $41.83 \pm 3.87 \mathrm{a}$ & $1.26 \pm 0.03 \mathrm{a}$ & $32.50 \pm 2.33 \mathrm{a}$ & $48.57 \pm 3.61 \mathrm{~b}$ & $4.25 \pm 1.09 \mathrm{a}$ \\
\hline 250 & $42.78 \pm 4.22 \mathrm{a}$ & $1.29 \pm 0.04 \mathrm{a}$ & $32.39 \pm 0.96 \mathrm{a}$ & $49.09 \pm 1.89 \mathrm{ab}$ & $3.64 \pm 0.76 \mathrm{a}$ \\
\hline$L$ & $0.482^{\mathrm{NS}}$ & $0.909^{\mathrm{NS}}$ & $0.004^{*}$ & $0.201^{\mathrm{NS}}$ & $0.261^{\mathrm{NS}}$ \\
\hline$Q$ & $0.565^{\mathrm{NS}}$ & $0.344^{\mathrm{NS}}$ & $0.009^{*}$ & $0.109^{\mathrm{NS}}$ & $0.524^{\mathrm{NS}}$ \\
\hline
\end{tabular}

${ }^{a}$ Mean of 6 replications, 6 plants each \pm standard deviation, similar letters within a column indicate no significant difference by Duncan mean separation;

${ }^{\mathrm{b}}$ Plant height was measured from base of the crown to tip of the apical bud in centimeters $(\mathrm{cm})$.

${ }^{\mathrm{c}}$ Mean chlorophyll content of mature leaves measured using a hand-held SPAD meter (mean of 3 random fully expanded leaves per plant).

${ }^{\mathrm{d}}$ Significance for linear (L) and quadratic (Q) orthogonal contrasts for Si level

NS, *,**,*** Nonsignificant or significant at $P \leq 0.01, P \leq 0.05, P \leq 0.10$, respectively. 


\section{Table 8}

Mean values ${ }^{a}$ of 'Double Hot Cherry' zinnia (Zinnia hybrid) growth parameters after plants reached marketable size under greenhouse conditions at Illinois State University for 2019 growing season, Normal, IL with silicon treatments (Si Concentration) varying from $0 \mathrm{mg} \mathrm{Si} \cdot \mathrm{L}^{-1}$ to $250 \mathrm{mg} \mathrm{Si} \cdot \mathrm{L}^{-1}$

\begin{tabular}{|c|c|c|c|c|c|c|}
\hline $\begin{array}{l}\text { Si Concentration } \\
\left(\mathrm{mg} \cdot \mathrm{L}^{-1}\right)\end{array}$ & $\begin{array}{l}\text { Number of } \\
\text { Leaves }\end{array}$ & $\begin{array}{l}\text { Basal Stem } \\
\text { Diameter } \\
(\mathrm{cm})\end{array}$ & $\begin{array}{c}\text { Plant Height }^{\mathrm{b}} \\
(\mathrm{cm})\end{array}$ & $\begin{array}{c}\text { SPAD } \\
\text { Chlorophyll }^{\mathrm{c}} \\
\left(\mathrm{mg} \cdot \mathrm{m}^{-2}\right)\end{array}$ & $\begin{array}{c}\text { Number of } \\
\text { Inflorescences }\end{array}$ & $\begin{array}{c}\text { Inflorescence } \\
\text { Diameter } \\
\text { (cm) }\end{array}$ \\
\hline 0 & $94.31 \pm 5.12 \mathrm{a}$ & $0.50 \pm 0.02 \mathrm{~b}$ & $26.82 \pm 1.84 \mathrm{a}$ & $27.76 \pm 0.64 \mathrm{~b}$ & $3.86 \pm 0.68 \mathrm{ab}$ & $4.74 \pm 0.11 \mathrm{a}$ \\
\hline 50 & $97.47 \pm 13.41 \mathrm{a}$ & $0.51 \pm 0.03 \mathrm{ab}$ & $26.21 \pm 1.92 \mathrm{a}$ & $29.27 \pm 0.84 \mathrm{a}$ & $5.00 \pm 2.03 \mathrm{ab}$ & $4.76 \pm 0.27 \mathrm{a}$ \\
\hline 150 & $91.89 \pm 10.34 \mathrm{a}$ & $0.52 \pm 0.02 \mathrm{ab}$ & $26.37 \pm 2.32 \mathrm{a}$ & $28.14 \pm 0.67 \mathrm{ab}$ & $3.64 \pm 1.16 b$ & $4.77 \pm 0.23 \mathrm{a}$ \\
\hline 250 & $89.22 \pm 4.62 \mathrm{a}$ & $0.54 \pm 0.02 \mathrm{a}$ & $24.96 \pm 1.92 \mathrm{a}$ & $28.29 \pm 1.02 \mathrm{ab}$ & $5.50 \pm 0.88 \mathrm{a}$ & $4.69 \pm 0.08 \mathrm{a}$ \\
\hline \multicolumn{7}{|l|}{ Contrast $^{\mathrm{d}}$} \\
\hline$L$ & $0.169^{\mathrm{NS}}$ & $0.033^{* *}$ & $0.139^{\mathrm{NS}}$ & $0.930^{\mathrm{NS}}$ & $0.203^{\mathrm{NS}}$ & $0.658^{\mathrm{NS}}$ \\
\hline$Q$ & $0.363^{\mathrm{NS}}$ & $0.107^{\mathrm{NS}}$ & $0.306^{\mathrm{NS}}$ & $0.539^{\mathrm{NS}}$ & $0.275^{\mathrm{NS}}$ & $0.772^{\mathrm{NS}}$ \\
\hline
\end{tabular}

${ }^{a}$ Mean of 6 replications, 6 plants each \pm standard deviation, similar letters within a column indicate no significant difference by Duncan mean separation;

${ }^{\mathrm{b}}$ Plant height was measured from base of the crown to tip of the apical bud in centimeters $(\mathrm{cm})$.

${ }^{\mathrm{c}}$ Mean chlorophyll content of mature leaves measured using a hand-held SPAD meter (mean of 3 random fully expanded leaves per plant).

${ }^{\mathrm{d}}$ Significance for linear (L) and quadratic (Q) orthogonal contrasts for Si level.

NS, *,**,*** Nonsignificant or significant at $P \leq 0.01, P \leq 0.05, P \leq 0.10$, respectively. 


\section{Table 9}

Results for repeated measurements multivariate analysis of covariance for SPAD chlorophyll content over time through plant development on landscape conditions for 'Black Velvet Rose F1' geranium (Pelargonium zonale), 'Mega Bloom Pink Halo F1' vinca (atharanthus roseus), 'Double Hot Cherry' zinnia (Zinnia hybrid) and 'Accent White Hybrid' impatiens (Impatiens walleriana) at the Horticulture Center at Illinois State University, Normal, IL in response to silicon treatments varying from 0, 50, 150 , and $250 \mathrm{mg} \mathrm{Si} \cdot \mathrm{L}^{-1}$.

\begin{tabular}{|c|c|c|c|c|c|c|}
\hline Source of variation & Year & Wilk's & $\mathrm{F}$ & df & Error df & $P$ \\
\hline Geranium 'Black Velvet Rose' & 2018 & 0.343 & 0.88 & 15 & 28.01 & $0.588^{\mathrm{NS}}$ \\
\hline Impatiens 'Accent White' & 2018 & 0.201 & 2.04 & 12 & 29.39 & $0.056^{* * *}$ \\
\hline Vinca 'Mega Bloom Halo' & 2018 & 0.263 & 1.16 & 15 & 28.01 & $0.353^{\mathrm{NS}}$ \\
\hline Zinnia 'Double Hot Cherry’ & 2018 & 0.135 & 2.77 & 12 & 29.39 & $0.012^{* *}$ \\
\hline Geranium 'Black Velvet Rose' & 2019 & 0.221 & 1.31 & 15 & 28.01 & $0.258^{\mathrm{NS}}$ \\
\hline Vinca 'Mega Bloom Halo' & 2019 & 0.533 & 0.48 & 15 & 28.01 & $0.932^{\mathrm{NS}}$ \\
\hline Zinnia 'Double Hot Cherry’ & 2019 & 0.52 & 0.50 & 15 & 28.01 & $0.920^{\mathrm{NS}}$ \\
\hline
\end{tabular}

NS, ${ }^{*}, * * * * * *$ Nonsignificant or significant at $P \leq 0.01, P \leq 0.05, P \leq 0.10$, respectively. 


\section{Table 10}

Mean values ${ }^{a}$ of chlorophyll content (SPAD) for 'Accent White' impatiens (Impatiens walleriana) on landscape culture at the Horticulture Center at Illinois State University for 2018 growing season, Normal, IL by silicon treatments (Si Concentration) varying from $0 \mathrm{mg} \mathrm{Si} \cdot \mathrm{L}^{-1}$ to $250 \mathrm{mg} \mathrm{Si} \cdot \mathrm{L}^{-1}$

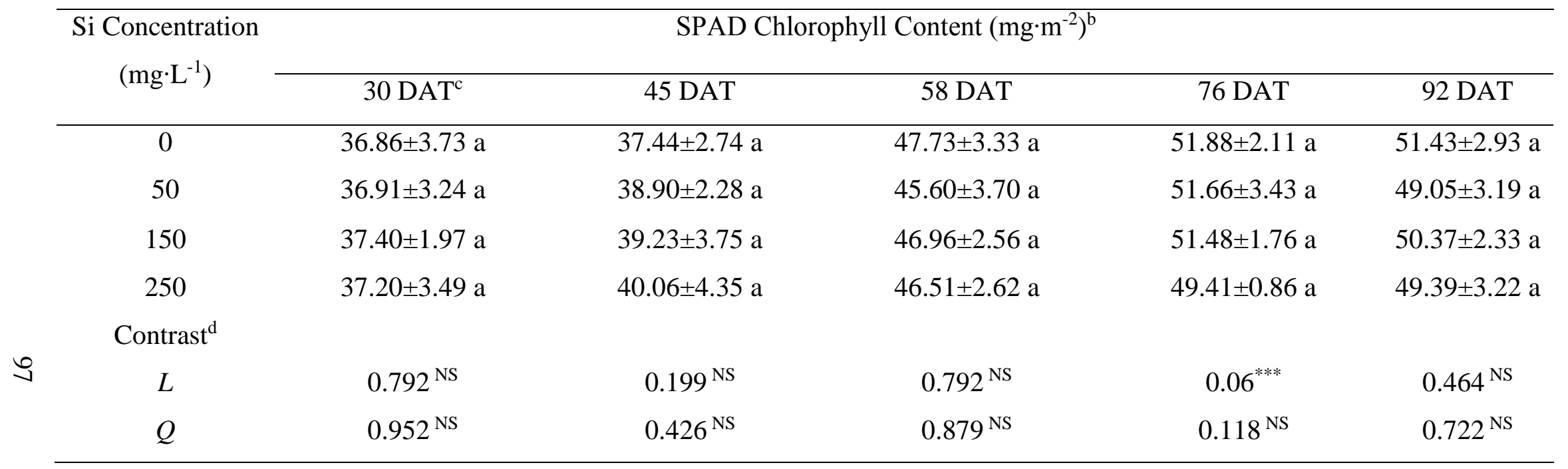

\footnotetext{
${ }^{a}$ Mean of 6 replications, 6 plants each \pm standard deviation. LS means Tukey-Kramer separation, similar letters within a column indicate no significant difference.

${ }^{\mathrm{b}}$ Mean chlorophyll content of mature leaves measured using a hand-held SPAD meter (mean of 3 random fully expanded leaves per plant).

${ }^{\mathrm{c}}$ Days After Transplanting (DAT).

${ }^{\mathrm{d}}$ Significance for linear (L) and quadratic (Q) orthogonal contrasts for Si level.

NS, ${ }^{*}, * * * * *$ Nonsignificant or significant at $P \leq 0.01, P \leq 0.05, P \leq 0.10$, respectively.
} 


\section{Table 11}

Mean values ${ }^{a}$ of chlorophyll content (SPAD) for 'Double Hot Cherry' zinnia (Zinnia hybrid) on landscape culture at the Horticulture Center at Illinois State University for 2018 growing season, Normal, IL by silicon treatments (Si Concentration)

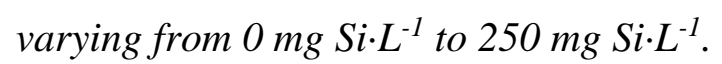

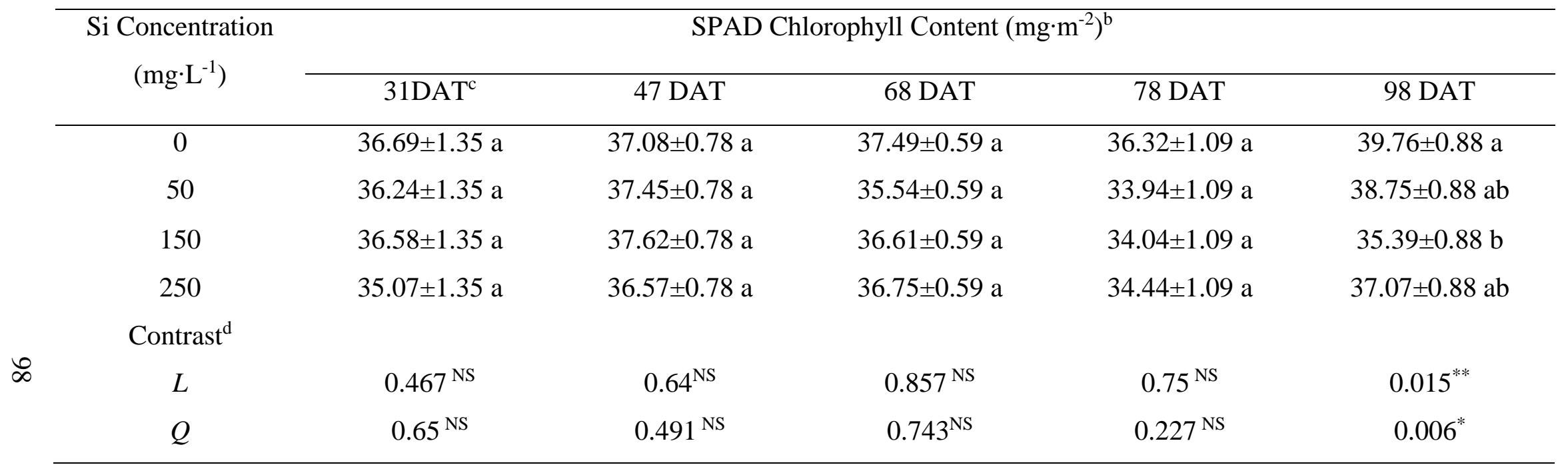

\footnotetext{
${ }^{a}$ Mean of 6 replications, 6 plants each \pm standard deviation. LS means Tukey-Kramer separation, similar letters within a column indicate no significant difference.

${ }^{\mathrm{b}}$ Mean chlorophyll content of mature leaves measured using a hand-held SPAD meter (mean of 3 random fully expanded leaves per plant).

${ }^{\mathrm{c}}$ Days After Transplanting (DAT).

${ }^{\mathrm{d}}$ Significance for linear (L) and quadratic (Q) orthogonal contrasts for Si level.

NS, *, **,*** Nonsignificant or significant at $P \leq 0.01, P \leq 0.05, P \leq 0.10$, respectively.
} 


\section{Table 12}

Results for repeated measurements multivariate analysis of covariance for the number of flowers and inflorescences over time through plant development on landscape conditions for 'Black Velvet Rose F1' geranium (Pelargonium zonale), 'Mega Bloom Pink Halo F1' vinca (atharanthus roseus), 'Double Hot Cherry' zinnia (Zinnia hybrid) and 'Accent White Hybrid' impatiens (Impatiens walleriana) at the Horticulture Center at Illinois State University, Normal, IL in response to silicon treatments varying from 0, 50, 150, and $250 \mathrm{mg} \mathrm{Si \cdot L^{-1 }}$

\begin{tabular}{|c|c|c|c|c|c|c|}
\hline Source of variation & Year & Wilk's & $\mathrm{F}$ & $\mathrm{df}$ & Error df & $P$ \\
\hline Geranium 'Black Velvet Rose' & 2018 & 0.408 & 0.72 & 15 & 28.01 & $0.747^{\mathrm{NS}}$ \\
\hline Impatiens 'Accent White' & 2018 & 0.357 & 1.16 & 12 & 29.39 & $0.352^{\mathrm{NS}}$ \\
\hline Vinca 'Mega Bloom Halo' & 2018 & 0.361 & 0.83 & 15 & 28.01 & $0.637^{\mathrm{NS}}$ \\
\hline Zinnia 'Double Hot Cherry' & 2018 & 0.442 & 0.88 & 12 & 29.39 & $0.571^{\mathrm{NS}}$ \\
\hline Geranium 'Black Velvet Rose' & 2019 & 0.097 & 2.48 & 15 & 28.01 & $0.018^{* *}$ \\
\hline Vinca 'Mega Bloom Halo' & 2019 & 0.103 & 2.38 & 15 & 28.01 & $0.023^{* *}$ \\
\hline Zinnia 'Double Hot Cherry' & 2019 & 0.093 & 2.55 & 15 & 28.01 & $0.016^{* *}$ \\
\hline
\end{tabular}

NS, ${ }^{* * *},{ }^{* * *}$ Nonsignificant or significant at $P \leq 0.01, P \leq 0.05, P \leq 0.10$, respectively. 


\section{Table 13}

Mean values ${ }^{a}$ of number of inflorescences for 'Black Velvet Rose F1' geranium (Pelargonium zonale) on landscape culture at the Horticulture Center at Illinois State University for 2019 growing season, Normal, IL by silicon treatments (Si Concentration)

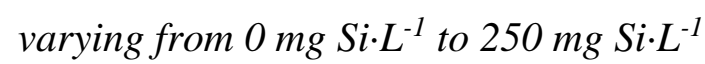

\begin{tabular}{|c|c|c|c|c|c|c|}
\hline \multirow{2}{*}{$\begin{array}{c}\text { Si Concentration } \\
\left(\mathrm{mg} \cdot \mathrm{L}^{-1}\right)\end{array}$} & \multicolumn{6}{|c|}{ Number of Inflorescences } \\
\hline & $32 \mathrm{DAT}^{\mathrm{b}}$ & $50 \mathrm{DAT}$ & 64 DAT & $80 \mathrm{DAT}$ & $96 \mathrm{DAT}$ & $111 \mathrm{DAT}$ \\
\hline 0 & $2.86 \pm 0.37 \mathrm{a}$ & $20.63 \pm 1.16 \mathrm{a}$ & $30.58 \pm 1.47 \mathrm{a}$ & $18.83 \pm 0.92 \mathrm{a}$ & $15.79 \pm 1.47 \mathrm{a}$ & $1.93 \pm 0.51 \mathrm{a}$ \\
\hline 50 & $4.19 \pm 0.37 \mathrm{a}$ & $18.16 \pm 1.16 \mathrm{ab}$ & $26.60 \pm 1.46 \mathrm{ab}$ & $17.50 \pm 0.92 \mathrm{a}$ & $16.07 \pm 1.47 \mathrm{a}$ & $0.39 \pm 0.51 \mathrm{a}$ \\
\hline 150 & $3.59 \pm 0.37 \mathrm{a}$ & $17.55 \pm 1.16 \mathrm{ab}$ & $26.39 \pm 1.47 \mathrm{ab}$ & $19.55 \pm 0.92 \mathrm{a}$ & $16.29 \pm 1.47 \mathrm{a}$ & $0.75 \pm 0.52 \mathrm{a}$ \\
\hline 250 & $3.04 \pm 0.38 \mathrm{a}$ & $14.36 \pm 1.19 \mathrm{~b}$ & $22.62 \pm 1.51 \mathrm{~b}$ & $17.86 \pm 0.95 \mathrm{a}$ & $16.53 \pm 1.51 \mathrm{a}$ & $0.87 \pm 0.53 \mathrm{a}$ \\
\hline \multicolumn{7}{|l|}{ Contrast $^{\mathrm{c}}$} \\
\hline$L$ & $0.603^{\mathrm{NS}}$ & $0.003^{*}$ & $0.016^{* *}$ & $0.648^{\mathrm{NS}}$ & $0.851^{\mathrm{NS}}$ & $0.195^{\mathrm{NS}}$ \\
\hline$Q$ & $0.156^{\mathrm{NS}}$ & $0.012^{* *}$ & $0.06^{* * *}$ & $0.677^{\mathrm{NS}}$ & $0.968^{\mathrm{NS}}$ & $0.293^{\mathrm{NS}}$ \\
\hline
\end{tabular}

${ }^{a}$ Mean of 6 replications, 6 plants each \pm standard deviation. LS means Tukey-Kramer separation, similar letters within a column indicate no significant difference.

${ }^{\mathrm{b}}$ Days After Transplanting (DAT).

${ }^{c}$ Significance for linear (L) and quadratic (Q) orthogonal contrasts for Si level.

NS, ${ }^{*}, * * * * *$ Nonsignificant or significant at $P \leq 0.01, P \leq 0.05, P \leq 0.10$, respectively. 


\section{Table 14}

Mean values a number of flowers for 'Mega Bloom Pink Halo F1' vinca (Catharanthus roseus) on landscape culture at the Horticulture Center at Illinois State University for 2019 growing season, Normal, IL by silicon treatments (Si Concentration)

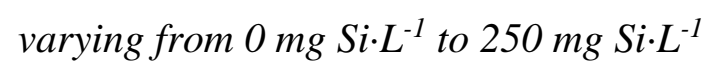

\begin{tabular}{|c|c|c|c|c|c|c|}
\hline \multirow{2}{*}{$\begin{array}{l}\text { Si Concentration } \\
\left(\mathrm{mg} \cdot \mathrm{L}^{-1}\right)\end{array}$} & \multicolumn{6}{|c|}{ Number of Flowers } \\
\hline & $30 \mathrm{DAT}^{\mathrm{b}}$ & $45 \mathrm{DAT}$ & $60 \mathrm{DAT}$ & $76 \mathrm{DAT}$ & $92 \mathrm{DAT}$ & $108 \mathrm{DAT}$ \\
\hline 0 & $12.58 \pm 0.80 \mathrm{a}$ & $35.73 \pm 3.57 \mathrm{a}$ & $31.14 \pm 2.74 \mathrm{a}$ & $39.93 \pm 3.35 \mathrm{a}$ & $45.58 \pm 2.27 \mathrm{a}$ & $49.13 \pm 3.63 \mathrm{a}$ \\
\hline 50 & $12.09 \pm 0.70 \mathrm{a}$ & $30.84 \pm 3.12 \mathrm{a}$ & $29.05 \pm 2.39 \mathrm{a}$ & $33.87 \pm 2.93 \mathrm{a}$ & $35.62 \pm 1.98 \mathrm{~b}$ & $46.59 \pm 3.18 \mathrm{ab}$ \\
\hline 150 & $12.26 \pm 0.78 \mathrm{a}$ & $27.19 \pm 3.46 \mathrm{a}$ & $27.94 \pm 2.65 \mathrm{a}$ & $30.38 \pm 3.25 \mathrm{a}$ & $29.91 \pm 2.21 b$ & $35.16 \pm 3.52 \mathrm{ab}$ \\
\hline 250 & $11.87 \pm 0.71 \mathrm{a}$ & $27.43 \pm 3.17 \mathrm{a}$ & $26.70 \pm 2.65 \mathrm{a}$ & $29.34 \pm 2.98 \mathrm{a}$ & $30.15 \pm 2.02 \mathrm{~b}$ & $33.24 \pm 3.23 \mathrm{~b}$ \\
\hline \multicolumn{7}{|l|}{ Contrast $\mathrm{c}^{\mathrm{c}}$} \\
\hline$L$ & $0.050^{* *}$ & $0.02^{* *}$ & $0.044^{* *}$ & $0.028^{* *}$ & $0.008^{*}$ & $0.024^{* *}$ \\
\hline$Q$ & $0.084^{* * * *}$ & $0.024^{* *}$ & $0.093^{* * * *}$ & $0.053^{* * *}$ & $0.008^{*}$ & $0.081^{* * *}$ \\
\hline
\end{tabular}

${ }^{a}$ Mean of 6 replications, 6 plants each \pm standard deviation. LS means Tukey-Kramer separation, similar letters within a column indicate no significant difference.

${ }^{\mathrm{b}}$ Days After Transplanting (DAT).

${ }^{\mathrm{c}}$ Significance for linear (L) and quadratic (Q) orthogonal contrasts for Si level.

NS, ${ }^{*},{ }^{* *},{ }^{* * *}$ Nonsignificant or significant at $P \leq 0.01, P \leq 0.05, P \leq 0.10$, respectively. 


\section{Table 15}

Mean values ${ }^{a}$ of number of inflorescences for 'Double Hot Cherry' zinnia (Zinnia hybrid) on landscape culture at the Horticulture Center at Illinois State University for 2019 growing season, Normal, IL by silicon treatments (Si Concentration) varying from 0 mg

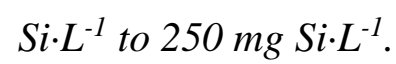

\begin{tabular}{|c|c|c|c|c|c|c|}
\hline \multirow{2}{*}{$\begin{array}{l}\text { Si Concentration } \\
\left(\mathrm{mg} \cdot \mathrm{L}^{-1}\right)\end{array}$} & \multicolumn{6}{|c|}{ Number of Inflorescences } \\
\hline & $31 \mathrm{DAT}^{\mathrm{b}}$ & $48 \mathrm{DAT}$ & $61 \mathrm{DAT}$ & $77 \mathrm{DAT}$ & $92 \mathrm{DAT}$ & $109 \mathrm{DAT}$ \\
\hline 0 & $3.32 \pm 0.36 \mathrm{a}$ & $6.00 \pm 1.15 \mathrm{a}$ & $11.42 \pm 1.89 \mathrm{a}$ & $18.12 \pm 2.18 \mathrm{a}$ & $25.96 \pm 2.88 \mathrm{~b}$ & $11.37 \pm 1.68 \mathrm{~b}$ \\
\hline 50 & $4.21 \pm 0.37 \mathrm{a}$ & $6.57 \pm 1.18 \mathrm{a}$ & $11.67 \pm 1.94 \mathrm{a}$ & $19.39 \pm 2.28 \mathrm{a}$ & $41.01 \pm 2.94 \mathrm{a}$ & $19.49 \pm 1.72 \mathrm{a}$ \\
\hline 150 & $4.54 \pm 0.37 \mathrm{a}$ & $7.17 \pm 1.16 \mathrm{a}$ & $8.78 \pm 1.91 \mathrm{a}$ & $16.23 \pm 2.19 \mathrm{a}$ & $35.89 \pm 2.91 \mathrm{ab}$ & $16.89 \pm 1.69 \mathrm{ab}$ \\
\hline 250 & $4.21 \pm 0.38 \mathrm{a}$ & $6.99 \pm 1.21 \mathrm{a}$ & $14.94 \pm 1.99 \mathrm{a}$ & $19.52 \pm 2.29 \mathrm{a}$ & $35.21 \pm 3.04 \mathrm{ab}$ & $14.24 \pm 1.77 \mathrm{ab}$ \\
\hline \multicolumn{7}{|l|}{ Contrast $^{\mathrm{c}}$} \\
\hline$L$ & $0.26^{\mathrm{NS}}$ & $0.770^{\mathrm{NS}}$ & $0.459^{\mathrm{NS}}$ & $0.516^{\mathrm{NS}}$ & $0.776^{\mathrm{NS}}$ & $0.875^{\mathrm{NS}}$ \\
\hline$Q$ & $0.111^{\mathrm{NS}}$ & $0.688^{\mathrm{NS}}$ & $0.257^{\mathrm{NS}}$ & $0.792^{\mathrm{NS}}$ & $0.091^{* * * *}$ & $0.11^{\mathrm{NS}}$ \\
\hline
\end{tabular}

${ }^{a}$ Mean of 6 replications, 6 plants each \pm standard deviation. LS means Tukey-Kramer separation, similar letters within a column indicate no significant difference.

${ }^{\mathrm{b}}$ Days After Transplanting (DAT).

${ }^{c}$ Significance for linear (L) and quadratic (Q) orthogonal contrasts for Si level.

NS, ${ }^{*}, * * * * *$ Nonsignificant or significant at $P \leq 0.01, P \leq 0.05, P \leq 0.10$, respectively. 


\section{Table 16}

Results for repeated measurements multivariate analysis of covariance for growth index over time through plant development on landscape conditions for 'Black Velvet Rose F1' geranium (Pelargonium zonale), 'Mega Bloom Pink Halo F1' vinca (atharanthus roseus), 'Double Hot Cherry' zinnia (Zinnia hybrid) and 'Accent White Hybrid' impatiens (Impatiens walleriana) at the Horticulture Center at Illinois State University, Normal, IL in response to silicon treatments varying from 0, 50, 150, and 250 mg $S i \cdot L^{-1}$

\begin{tabular}{|c|c|c|c|c|c|c|}
\hline Source of variation & Year & Wilk’s & $\mathrm{F}$ & df & Error df & $P$ \\
\hline Geranium 'Black Velvet Rose' & 2018 & 0.408 & 0.99 & 12 & 23.39 & $0.483^{\mathrm{NS}}$ \\
\hline Impatiens 'Accent White' & 2018 & 0.511 & 1.04 & 9 & 29.35 & $0.436^{\mathrm{NS}}$ \\
\hline Vinca 'Mega Bloom Halo' & 2018 & 0.419 & 0.95 & 12 & 29.39 & $0.512^{\mathrm{NS}}$ \\
\hline Zinnia 'Double Hot Cherry’ & 2018 & 0.414 & 1.42 & 9 & 29.35 & $0.223^{\mathrm{NS}}$ \\
\hline Geranium 'Black Velvet Rose' & 2019 & 0.328 & 1.28 & 12 & 23.39 & $0.280^{\mathrm{NS}}$ \\
\hline Vinca 'Mega Bloom Halo' & 2019 & 0.402 & 1.01 & 12 & 23.39 & $0.467^{\mathrm{NS}}$ \\
\hline Zinnia ‘Double Hot Cherry’ & 2019 & 0.214 & 1.94 & 12 & 23.39 & $0.071^{* * *}$ \\
\hline
\end{tabular}

NS, ${ }^{*}, * *, * * *$ Nonsignificant or significant at $P \leq 0.01, P \leq 0.05, P \leq 0.10$, respectively. 


\section{Table 17}

Mean values ${ }^{a}$ of growth index for 'Double Hot Cherry' zinnia (Zinnia hybrid) on landscape culture at the Horticulture Center at Illinois State University for 2019 growing season, Normal, IL by silicon treatments (Si Concentration) varying from $0 \mathrm{mg}$ Si. $L^{-1}$ to $250 \mathrm{mg} \mathrm{Si} \cdot \mathrm{L}^{-1}$

\begin{tabular}{|c|c|c|c|c|c|}
\hline $\begin{array}{c}\text { Si Concentration } \\
\left(\mathrm{mg} \cdot \mathrm{L}^{-1}\right)\end{array}$ & \multicolumn{5}{|c|}{ Growth Index $\left(\mathrm{cm}^{3}\right)$} \\
\hline 0 & $27.49 \pm 0.53 \mathrm{a}$ & $32.05 \pm 0.98 \mathrm{a}$ & $36.75 \pm 0.97 \mathrm{a}$ & $40.51 \pm 0.93 \mathrm{a}$ & $42.59 \pm 0.87 \mathrm{~b}$ \\
\hline 50 & $27.84 \pm 0.54 \mathrm{a}$ & $33.36 \pm 1.01 \mathrm{a}$ & $37.79 \pm 0.99 \mathrm{a}$ & $43.25 \pm 0.95 \mathrm{a}$ & $46.45 \pm 0.89 \mathrm{a}$ \\
\hline 150 & $27.60 \pm 0.53 \mathrm{a}$ & $30.93 \pm 0.99 \mathrm{a}$ & $37.31 \pm 0.98 \mathrm{a}$ & $42.35 \pm 0.93 \mathrm{a}$ & $44.66 \pm 0.88 \mathrm{ab}$ \\
\hline \multicolumn{6}{|l|}{ Contrast $^{\mathrm{c}}$} \\
\hline$L$ & $0.565^{\mathrm{NS}}$ & $0.883^{\mathrm{NS}}$ & $0.834^{\mathrm{NS}}$ & $0.735^{\mathrm{NS}}$ & $0.668^{\mathrm{NS}}$ \\
\hline$Q$ & $0.598^{\mathrm{NS}}$ & $0.824^{\mathrm{NS}}$ & $0.668^{\mathrm{NS}}$ & $0.192^{\mathrm{NS}}$ & $0.116^{\mathrm{NS}}$ \\
\hline
\end{tabular}

${ }^{a}$ Mean of 6 replications, 6 plants each \pm standard deviation. LS means Tukey-Kramer separation, similar letters within a column indicate no significant difference.

${ }^{\mathrm{b}}$ Days After Transplanting (DAT).

${ }^{\mathrm{c}}$ Significance for linear (L) and quadratic (Q) orthogonal contrasts for Si level.

NS, ${ }^{*},{ }^{* *},{ }^{* * *}$ Nonsignificant or significant at $P \leq 0.01, P \leq 0.05, P \leq 0.10$, respectively. 


\section{Table 18}

Mean values a fresh mass on landscape culture for 'Mega Bloom Pink Halo F1' vinca (Catharanthus roseus) and 'Double Hot Cherry' zinnia (Zinnia hybrid) at the Horticulture Center at Illinois State University for 2019 growing season, Normal, IL by silicon

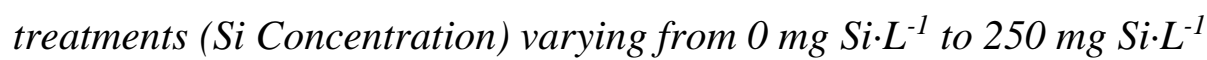

\begin{tabular}{|c|c|c|}
\hline \multirow{2}{*}{$\begin{array}{l}\text { Si Concentration } \\
\left(\mathrm{mg} \cdot \mathrm{L}^{-1}\right)\end{array}$} & \multicolumn{2}{|c|}{ Fresh Mass (g) } \\
\hline & 'Mega Bloom Pink Halo F1' Vinca & 'Double Hot Cherry' Zinnia \\
\hline 0 & $410.84 \pm 71.32 \mathrm{a}$ & $261.69 \pm 50.05 \mathrm{~b}$ \\
\hline 50 & $343.77 \pm 64.82 b$ & $379.46 \pm 88.64 \mathrm{a}$ \\
\hline 150 & $281.52 \pm 69.19 \mathrm{c}$ & $337.82 \pm 67.03 \mathrm{ab}$ \\
\hline 250 & $266.15 \pm 88.70 \mathrm{c}$ & $285.39 \pm 84.89 \mathrm{~b}$ \\
\hline \multicolumn{3}{|l|}{ Contrast $\mathrm{t}^{\mathrm{b}}$} \\
\hline$L$ & $0.002^{*}$ & $0.854^{\mathrm{NS}}$ \\
\hline$Q$ & $0.004^{*}$ & $0.09^{* * *}$ \\
\hline
\end{tabular}

${ }^{a}$ Mean of 6 replications, 6 plants each \pm standard deviation. Duncan mean separation, similar letters within a column indicate no significant difference.

${ }^{\mathrm{b}}$ Significance for linear (L) and quadratic (Q) orthogonal contrasts for Si level.

NS, ${ }^{*},{ }^{* *},{ }^{* * *}$ Nonsignificant or significant at $P \leq 0.01, P \leq 0.05, P \leq 0.10$, respectively. 


\section{Table 19}

Mean values ${ }^{a}$ of dry mass on landscape culture for 'Mega Bloom Pink Halo F1' vinca (Catharanthus roseus) and 'Double Hot Cherry' zinnia (Zinnia hybrid) at the Horticulture Center at Illinois State University for 2019 growing season, Normal, IL by silicon

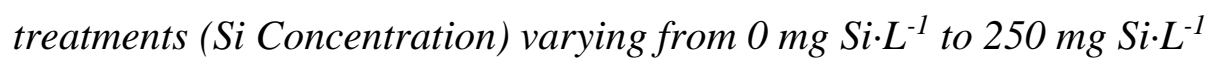

\begin{tabular}{|c|c|c|}
\hline \multirow{2}{*}{$\begin{array}{l}\text { Si Concentration } \\
\left(\mathrm{mg} \cdot \mathrm{L}^{-1}\right)\end{array}$} & \multicolumn{2}{|c|}{ Dry Mass (g) } \\
\hline & 'Mega Bloom Pink Halo F1' Vinca & 'Double Hot Cherry' Zinnia \\
\hline 0 & $73.44 \pm 15.65 \mathrm{a}$ & $83.20 \pm 15.90 \mathrm{~b}$ \\
\hline 50 & $51.64 \pm 27.12 \mathrm{~b}$ & $120.37 \pm 16.46 \mathrm{a}$ \\
\hline 150 & $49.28 \pm 10.21 \mathrm{~b}$ & $100.94 \pm 25.43 \mathrm{ab}$ \\
\hline 250 & $39.46 \pm 15.32 b$ & $83.66 \pm 27.47 \mathrm{~b}$ \\
\hline \multicolumn{3}{|l|}{ Contrast $^{\mathrm{b}}$} \\
\hline$L$ & $0.008^{*}$ & $0.441^{\mathrm{NS}}$ \\
\hline$Q$ & $0.021^{* *}$ & $0.071^{* * *}$ \\
\hline
\end{tabular}

${ }^{a}$ Mean of 6 replications, 6 plants each \pm standard deviation. Duncan mean separation, similar letters within a column indicate no significant difference.

${ }^{\mathrm{b}}$ Significance for linear (L) and quadratic (Q) orthogonal contrasts for Si level.

NS, ${ }^{*},{ }^{* *},{ }^{* * *}$ Nonsignificant or significant at $P \leq 0.01, P \leq 0.05, P \leq 0.10$, respectively. 


\section{Table 20}

Results for multivariate analysis of variance for titanium supplementation effect on overall quality traits for 'Black Velvet Rose F1' geranium (Pelargonium zonale), 'Mega Bloom Pink Halo F1'vinca (Catharanthus roseus), 'Double Hot Cherry' zinnia (Zinnia

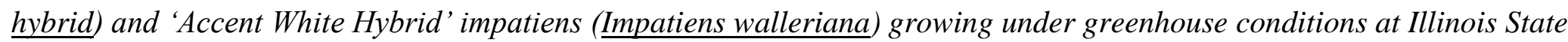
University, Normal, IL for titanium treatments varying from 0, 50, 100, and $150 \mathrm{mg} \mathrm{Ti \cdot L^{-1 }}$

\begin{tabular}{lcccccc}
\hline Source of variation & Year & Wilk's & F & df & Error df & $P$ \\
\hline Geranium 'Black Velvet Rose' & 2018 & 0.173 & 1.82 & 15 & 30.77 & $0.078^{* * *}$ \\
Impatiens 'Accent White' & 2018 & 0.123 & 1.35 & 21 & 26.39 & $0.232^{\mathrm{NS}}$ \\
Vinca 'Mega Bloom Halo' & 2018 & 0.079 & 2.31 & 18 & 28.77 & $0.022^{* *}$ \\
Zinnia 'Double Hot Cherry' & 2018 & 0.176 & 1.36 & 18 & 28.77 & $0.227^{\mathrm{NS}}$ \\
Geranium 'Black Velvet Rose' & 2019 & 0.341 & 0.98 & 15 & 30.77 & $0.500^{\mathrm{NS}}$ \\
Vinca 'Mega Bloom Halo' & 2019 & 0.237 & 1.06 & 18 & 28.77 & $0.434^{\mathrm{NS}}$ \\
Zinnia 'Double Hot Cherry' & 2019 & 0.183 & 1.32 & 18 & $28.77^{0.206^{\mathrm{NS}}}$ \\
\hline
\end{tabular}

NS, ${ }^{* * *, * * *}$ Nonsignificant or significant at $P \leq 0.01, P \leq 0.05, P \leq 0.10$, respectively. 


\section{Table 21}

Mean values ${ }^{a}$ of 'Black Velvet Rose F1' geranium (Pelargonium zonale) growth parameters after plants reached marketable size under greenhouse conditions at Illinois State University for 2018 growing season, Normal, IL with titanium treatments (Ti Concentration) varying from $0 \mathrm{mg} \mathrm{Ti} \cdot \mathrm{L}^{-1}$ to $150 \mathrm{mg} \mathrm{Ti} \cdot \mathrm{L}^{-1}$

\begin{tabular}{|c|c|c|c|c|c|}
\hline $\begin{array}{l}\text { Ti Concentration } \\
\left(\mathrm{mg} \cdot \mathrm{L}^{-1}\right)\end{array}$ & $\begin{array}{l}\text { Number of } \\
\text { Leaves }\end{array}$ & $\begin{array}{l}\text { Basal Stem Diameter } \\
\qquad(\mathrm{cm})\end{array}$ & $\begin{array}{c}\text { Plant Height } \\
\text { (cm) }\end{array}$ & $\begin{array}{l}\text { SPAD Chlorophyll } \\
\left(\mathrm{mg} \cdot \mathrm{m}^{-2}\right)\end{array}$ & $\begin{array}{c}\text { Number of } \\
\text { Inflorescences }\end{array}$ \\
\hline 0 & $27.86 \pm 3.22 \mathrm{a}$ & $1.33 \pm 0.03 \mathrm{a}$ & $40.58 \pm 2.69 \mathrm{a}$ & $45.02 \pm 2.44 \mathrm{a}$ & $12.13 \pm 0.98 \mathrm{a}$ \\
\hline 50 & $25.33 \pm 3.35 \mathrm{a}$ & $1.30 \pm 0.03 \mathrm{a}$ & $39.23 \pm 2.69 \mathrm{a}$ & $45.89 \pm 1.71 \mathrm{a}$ & $13.36 \pm 1.13 \mathrm{a}$ \\
\hline 100 & $27.41 \pm 1.35 \mathrm{a}$ & $1.34 \pm 0.03 \mathrm{a}$ & $40.3 \pm 1.82 \mathrm{a}$ & $46.69 \pm 2.38 \mathrm{a}$ & $13.33 \pm 0.55 \mathrm{a}$ \\
\hline 150 & $25.69 \pm 2.97 \mathrm{a}$ & $1.33 \pm 0.01 \mathrm{a}$ & $41.18 \pm 2.20 \mathrm{a}$ & $46.51 \pm 1.92 \mathrm{a}$ & $13.69 \pm 1.27 \mathrm{a}$ \\
\hline \multicolumn{6}{|l|}{ Contrast $^{\mathrm{d}}$} \\
\hline$L$ & $0.412^{\mathrm{NS}}$ & $0.555^{\mathrm{NS}}$ & $0.514^{\mathrm{NS}}$ & $0.174^{\mathrm{NS}}$ & $0.021^{* *}$ \\
\hline$Q$ & $0.687^{\mathrm{NS}}$ & $0.766^{\mathrm{NS}}$ & $0.423^{\mathrm{NS}}$ & $0.337^{\mathrm{NS}}$ & $0.043^{* *}$ \\
\hline
\end{tabular}

${ }^{a}$ Mean of 6 replications, 6 plants each \pm standard deviation, similar letters within a column indicate no significant difference by Duncan mean separation;

${ }^{\mathrm{b}}$ Plant height was measured from base of the crown to tip of the apical bud in centimeters $(\mathrm{cm})$.

${ }^{c}$ Mean chlorophyll content of mature leaves measured using a hand-held SPAD meter (mean of 3 random fully expanded leaves per plant).

${ }^{\mathrm{d}}$ Significance for linear (L) and quadratic (Q) orthogonal contrasts for Si level.

NS, *,**,*** Nonsignificant or significant at $P \leq 0.01, P \leq 0.05, P \leq 0.10$, respectively. 


\section{Table 22}

Mean values ${ }^{a}$ of 'Mega Bloom Pink Halo F1'vinca (Catharanthus roseus) growth parameters after plants reached marketable size under greenhouse conditions at Illinois State University for 2018 growing season, Normal, IL with titanium treatments (Ti

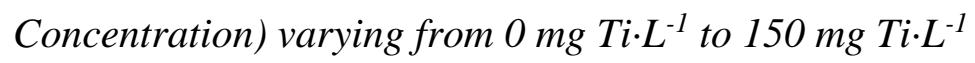

\begin{tabular}{|c|c|c|c|c|c|c|}
\hline $\begin{array}{c}\mathrm{Ti} \\
\text { Concentration } \\
\left(\mathrm{mg} \cdot \mathrm{L}^{-1}\right)\end{array}$ & $\begin{array}{c}\text { Number of } \\
\text { Leaves }\end{array}$ & $\begin{array}{c}\text { Basal Stem } \\
\text { Diameter } \\
(\mathrm{cm})\end{array}$ & $\begin{array}{c}\text { Plant Height } \mathrm{t}^{\mathrm{b}} \\
(\mathrm{cm})\end{array}$ & $\begin{array}{c}\text { SPAD } \\
\text { Chlorophyll }^{\mathrm{c}} \\
\left(\mathrm{mg} \cdot \mathrm{m}^{-2}\right)\end{array}$ & $\begin{array}{c}\text { Number of } \\
\text { Flowers }\end{array}$ & $\begin{array}{c}\text { Flower } \\
\text { Diameter } \\
(\mathrm{cm})\end{array}$ \\
\hline 0 & $84.26 \pm 16.17 \mathrm{a}$ & $0.67 \pm 0.06 \mathrm{a}$ & $28.44 \pm 2.00 \mathrm{a}$ & $47.33 \pm 0.85 \mathrm{ab}$ & $18.29 \pm 5.05 \mathrm{a}$ & $5.63 \pm 0.15 \mathrm{a}$ \\
\hline 50 & $88.77 \pm 9.22 \mathrm{a}$ & $0.70 \pm 0.05 \mathrm{a}$ & $28.58 \pm 1.29 \mathrm{a}$ & $48.71 \pm 1.13 \mathrm{a}$ & $15.92 \pm 3.58 \mathrm{a}$ & $5.35 \pm 0.14 b$ \\
\hline 100 & $86.55 \pm 7.52 \mathrm{a}$ & $0.70 \pm 0.04 \mathrm{a}$ & $27.19 \pm 2.26 \mathrm{a}$ & $47.01 \pm 0.61 \mathrm{~b}$ & $18.30 \pm 3.05 \mathrm{a}$ & $5.31 \pm 0.11 b$ \\
\hline 150 & $92.33 \pm 8.46 \mathrm{a}$ & $0.71 \pm 0.07 \mathrm{a}$ & $28.36 \pm 1.61 \mathrm{a}$ & $46.92 \pm 1.82 \mathrm{~b}$ & $19.50 \pm 4.83 \mathrm{a}$ & $5.25 \pm 0.13 b$ \\
\hline \multicolumn{7}{|l|}{ Contrast $^{\mathrm{d}}$} \\
\hline$L$ & $0.265^{\mathrm{NS}}$ & $0.377^{\mathrm{NS}}$ & $0.626^{\mathrm{NS}}$ & $0.233^{\mathrm{NS}}$ & $0.44^{\mathrm{NS}}$ & $0.0002^{*}$ \\
\hline$Q$ & $0.54^{\mathrm{NS}}$ & $0.629^{\mathrm{NS}}$ & $0.708^{\mathrm{NS}}$ & $0.196^{\mathrm{NS}}$ & $0.437^{\mathrm{NS}}$ & $0.0002^{*}$ \\
\hline
\end{tabular}

${ }^{\mathrm{a}}$ Mean of 6 replications, 6 plants each \pm standard deviation, similar letters within a column indicate no significant difference by Duncan mean separation;

${ }^{\mathrm{b}}$ Plant height was measured from base of the crown to tip of the apical bud in centimeters $(\mathrm{cm})$.

${ }^{c}$ Mean chlorophyll content of mature leaves measured using a hand-held SPAD meter (mean of 3 random fully expanded leaves per plant).

${ }^{\mathrm{d}}$ Significance for linear (L) and quadratic (Q) orthogonal contrasts for Si level.

NS, ${ }^{*}, * * * * *$ Nonsignificant or significant at $P \leq 0.01, P \leq 0.05, P \leq 0.10$, respectively. 


\section{Table 23}

Results for repeated measurements multivariate analysis of covariance for plant height over time through plant development on landscape conditions for 'Black Velvet Rose F1' geranium (Pelargonium zonale), 'Mega Bloom Pink Halo F1'vinca (Catharanthus roseus), 'Double Hot Cherry' zinnia (Zinnia hybrid) and 'Accent White Hybrid' impatiens (Impatiens walleriana) at the Horticulture Center at Illinois State University, Normal, IL in response to titanium treatments varying from 0, 50, 100, and 150 $m g T i \cdot L^{-1}$

\begin{tabular}{|c|c|c|c|c|c|c|}
\hline Source of variation & Year & Wilk's & $\mathrm{F}$ & df & Error df & $P$ \\
\hline Geranium 'Black Velvet Rose' & 2018 & 0.19 & 1.54 & 15 & 28.01 & $0.157^{\mathrm{NS}}$ \\
\hline Impatiens 'Accent White' & 2018 & 0.423 & 0.94 & 12 & 29.39 & $0.522^{\mathrm{NS}}$ \\
\hline Vinca 'Mega Bloom Halo' & 2018 & 0.202 & 1.47 & 15 & 28.01 & $0.185^{\mathrm{NS}}$ \\
\hline Zinnia 'Double Hot Cherry' & 2018 & 0.339 & 1.24 & 12 & 29.39 & $0.305^{\mathrm{NS}}$ \\
\hline Geranium 'Black Velvet Rose' & 2019 & 0.088 & 2.63 & 15 & 28.01 & $0.013^{* *}$ \\
\hline Vinca 'Mega Bloom Halo' & 2019 & 0.608 & 0.37 & 15 & 28.01 & $0.977^{\mathrm{NS}}$ \\
\hline Zinnia 'Double Hot Cherry' & 2019 & 0.424 & 0.68 & 15 & 28.01 & $0.781^{\mathrm{NS}}$ \\
\hline
\end{tabular}

NS, *,***** Nonsignificant or significant at $P \leq 0.01, P \leq 0.05, P \leq 0.10$, respectively. 


\section{Table 24}

Mean values ${ }^{a}$ of plant height for 'Black Velvet Rose F1' geranium (Pelargonium zonale) on landscape culture at the Horticulture Center at Illinois State University for 2019 growing season, Normal, IL by titanium treatments (Ti Concentration) of 0, 50, 100 and $150 \mathrm{mg} \mathrm{Ti} \cdot \mathrm{L}^{-1}$.

\begin{tabular}{|c|c|c|c|c|c|c|}
\hline \multirow{2}{*}{$\begin{array}{c}\text { Ti Concentration } \\
\left(\mathrm{mg} \cdot \mathrm{L}^{-1}\right)\end{array}$} & \multicolumn{6}{|c|}{ Plant Height $(\mathrm{cm})$} \\
\hline & $32 \mathrm{DAT}^{\mathrm{b}}$ & $50 \mathrm{DAT}$ & $64 \mathrm{DAT}$ & $80 \mathrm{DAT}$ & $96 \mathrm{DAT}$ & $111 \mathrm{DAT}$ \\
\hline 0 & $32.74 \pm 0.43 \mathrm{~b}$ & $33.25 \pm 0.64 \mathrm{a}$ & $35.08 \pm 0.58 \mathrm{a}$ & $37.00 \pm 0.56 \mathrm{a}$ & $35.88 \pm 0.61 \mathrm{a}$ & $38.06 \pm 0.72 \mathrm{a}$ \\
\hline 50 & $33.83 \pm 0.41 \mathrm{ab}$ & $33.83 \pm 0.62 \mathrm{a}$ & $34.67 \pm 0.56 \mathrm{a}$ & $35.52 \pm 0.53 \mathrm{a}$ & $36.55 \pm 0.59 \mathrm{a}$ & $38.13 \pm 0.69 \mathrm{a}$ \\
\hline 100 & $35.49 \pm 0.43 \mathrm{a}$ & $35.56 \pm 0.63 \mathrm{a}$ & $36.29 \pm 0.57 \mathrm{a}$ & $36.64 \pm 0.55 \mathrm{a}$ & $36.11 \pm 0.60 \mathrm{a}$ & $37.01 \pm 0.71 \mathrm{a}$ \\
\hline$L$ & $0.0018^{*}$ & $0.0048^{*}$ & $0.0150^{* *}$ & $0.2041^{\mathrm{NS}}$ & $0.1465^{\mathrm{NS}}$ & $0.3902^{\mathrm{NS}}$ \\
\hline$Q$ & $0.0081^{*}$ & $0.0208^{* *}$ & $0.0441^{* *}$ & $0.2403^{\mathrm{NS}}$ & $0.3446^{\mathrm{NS}}$ & $0.4602^{\mathrm{NS}}$ \\
\hline
\end{tabular}

${ }^{a}$ Mean of 6 replications, 6 plants each \pm standard deviation. LS means Tukey-Kramer separation, similar letters within a column indicate no significant difference.

${ }^{\mathrm{b}}$ Days After Transplanting (DAT).

${ }^{c}$ Significance for linear (L) and quadratic (Q) orthogonal contrasts for Si level.

NS, ${ }^{*}, * * * * *$ Nonsignificant or significant at $P \leq 0.01, P \leq 0.05, P \leq 0.10$, respectively. 


\section{Table 25}

Results for repeated measurements multivariate analysis of covariance for SPAD chlorophyll content over time through plant development on landscape conditions for 'Black Velvet Rose F1' geranium (Pelargonium zonale), 'Mega Bloom Pink Halo F1'

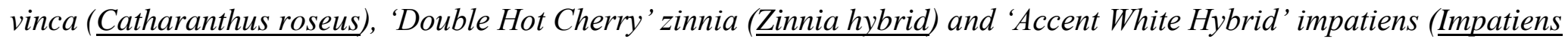
walleriana) at the Horticulture Center at Illinois State University, Normal, IL in response to titanium treatments varying from 0 , 50, 100 , and $150 \mathrm{mg} \mathrm{Ti} \cdot \mathrm{L}^{-1}$

\begin{tabular}{|c|c|c|c|c|c|c|}
\hline Source of variation & Year & Wilk's & $\mathrm{F}$ & df & Error df & $P$ \\
\hline Geranium 'Black Velvet Rose' & 2018 & 0.292 & 1.05 & 15 & 28.01 & $0.441^{\mathrm{NS}}$ \\
\hline Impatiens 'Accent White' & 2018 & 0.133 & 2.80 & 12 & 29.39 & $0.011^{* *}$ \\
\hline Vinca 'Mega Bloom Halo' & 2018 & 0.212 & 1.41 & 15 & 28.01 & $0.211^{\mathrm{NS}}$ \\
\hline Zinnia 'Double Hot Cherry’ & 2018 & 0.377 & 1.09 & 12 & 29.39 & $0.402^{\mathrm{NS}}$ \\
\hline Geranium 'Black Velvet Rose' & 2019 & 0.292 & 1.05 & 15 & 28.01 & $0.439^{\mathrm{NS}}$ \\
\hline Vinca 'Mega Bloom Halo' & 2019 & 0.248 & 1.23 & 15 & 28.01 & $0.309^{\mathrm{NS}}$ \\
\hline Zinnia 'Double Hot Cherry’ & 2019 & 0.374 & 0.80 & 15 & 28.01 & $0.668^{\mathrm{NS}}$ \\
\hline
\end{tabular}

NS, ${ }^{*},{ }^{* *}, * * *$ Nonsignificant or significant at $P \leq 0.01, P \leq 0.05, P \leq 0.10$, respectively. 


\section{Table 26}

Mean values ${ }^{a}$ of SPAD chlorophyll content for 'Accent White Hybrid' impatiens (Impatiens walleriana) on landscape culture at the Horticulture Center at Illinois State University for 2018 growing season, Normal, IL by titanium treatments (Ti Concentration) of $0,50,100$ and $150 \mathrm{mg} \mathrm{Ti} \cdot \mathrm{L}^{-1}$

\begin{tabular}{|c|c|c|c|c|c|}
\hline \multirow{2}{*}{$\begin{array}{l}\text { Ti Concentration } \\
\left(\mathrm{mg} \cdot \mathrm{L}^{-1}\right)\end{array}$} & \multicolumn{5}{|c|}{ SPAD Chlorophyll content ${ }^{\mathrm{b}}\left(\mathrm{mg} \cdot \mathrm{m}^{-2}\right)$} \\
\hline & $30 \mathrm{DAT}^{\mathrm{c}}$ & $45 \mathrm{DAT}$ & $58 \mathrm{DAT}$ & $76 \mathrm{DAT}$ & $92 \mathrm{DAT}$ \\
\hline 0 & $37.32 \pm 0.94 \mathrm{a}$ & $37.46 \pm 1.30 \mathrm{~b}$ & $47.74 \pm 1.31 \mathrm{a}$ & $51.87 \pm 1.24 \mathrm{a}$ & $51.42 \pm 1.03 \mathrm{a}$ \\
\hline 100 & $40.94 \pm 0.98 \mathrm{a}$ & $39.46 \pm 1.36 \mathrm{ab}$ & $49.45 \pm 1.37 \mathrm{a}$ & $52.92 \pm 1.29 \mathrm{a}$ & $52.01 \pm 1.07 \mathrm{a}$ \\
\hline 150 & $39.71 \pm 0.93 \mathrm{a}$ & $43.73 \pm 1.29 \mathrm{a}$ & $49.78 \pm 1.30 \mathrm{a}$ & $51.95 \pm 1.23 \mathrm{a}$ & $50.65 \pm 1.02 \mathrm{a}$ \\
\hline$L$ & $0.094^{* * *}$ & $0.037^{* *}$ & $0.395^{\mathrm{NS}}$ & $0.956^{\mathrm{NS}}$ & $0.672^{\mathrm{NS}}$ \\
\hline$Q$ & $0.145^{\mathrm{NS}}$ & $0.093^{* * *}$ & $0.379^{\mathrm{NS}}$ & $0.548^{\mathrm{NS}}$ & $0.685^{\mathrm{NS}}$ \\
\hline
\end{tabular}

${ }^{a}$ Mean of 6 replications, 6 plants each \pm standard deviation. LS means Tukey-Kramer separation, similar letters within a column indicate no significant difference.

${ }^{\mathrm{b}}$ Mean chlorophyll content of mature leaves measured using a hand-held SPAD meter (mean of 3 random fully expanded leaves per plant).

${ }^{c}$ Days After Transplanting (DAT).

${ }^{\mathrm{d}}$ Significance for linear (L) and quadratic (Q) orthogonal contrasts for Si level.

$\mathrm{NS}, *, * * * * * *$ Nonsignificant or significant at $P \leq 0.01, P \leq 0.05, P \leq 0.10$, respectively. 


\section{Table 27}

Results for repeated measurements multivariate analysis of number of flowers and inflorescences over time through plant development on landscape conditions for 'Black Velvet Rose F1' geranium (Pelargonium zonale), 'Mega Bloom Pink Halo F1'

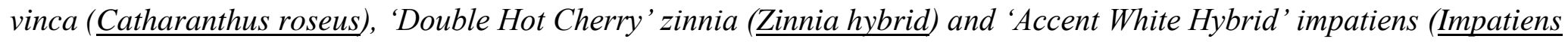
walleriana) at the Horticulture Center at Illinois State University, Normal, IL in response to titanium treatments varying from 0 , 50, 100 , and $150 \mathrm{mg} \mathrm{Ti} \cdot \mathrm{L}^{-1}$

\begin{tabular}{|c|c|c|c|c|c|c|}
\hline Source of variation & Year & Wilk's & $\mathrm{F}$ & df & Error df & $P$ \\
\hline Geranium 'Black Velvet Rose' & 2018 & 0.18 & 1.61 & 15 & 28.01 & $0.135^{\mathrm{NS}}$ \\
\hline Impatiens 'Accent White' & 2018 & 0.449 & 0.86 & 12 & 39.39 & $0.589^{\mathrm{NS}}$ \\
\hline Vinca 'Mega Bloom Halo' & 2018 & 0.273 & 1.12 & 15 & 28.01 & $0.383^{\mathrm{NS}}$ \\
\hline Zinnia 'Double Hot Cherry' & 2018 & 0.279 & 1.52 & 12 & 29.39 & $0.174^{\mathrm{NS}}$ \\
\hline Geranium 'Black Velvet Rose' & 2019 & 0.142 & 1.92 & 15 & 28.01 & $0.066^{* * *}$ \\
\hline Vinca 'Mega Bloom Halo' & 2019 & 0.169 & 1.69 & 15 & 28.01 & $0.112^{\mathrm{NS}}$ \\
\hline Zinnia 'Double Hot Cherry' & 2019 & 0.323 & 0.94 & 15 & 28.01 & $0.531^{\mathrm{NS}}$ \\
\hline
\end{tabular}

NS, ${ }^{*}, * * * * *$ Nonsignificant or significant at $P \leq 0.01, P \leq 0.05, P \leq 0.10$, respectively. 


\section{Table 28}

Mean values ${ }^{a}$ of number of inflorescences for 'Black Velvet Rose F1' geranium (Pelargonium zonale) on landscape culture at the Horticulture Center at Illinois State University for 2019 growing season, Normal, IL by titanium treatments (Ti Concentration) of $0,50,100$ and $150 \mathrm{mg} \mathrm{Ti} \cdot \mathrm{L}^{-1}$

\begin{tabular}{|c|c|c|c|c|c|c|}
\hline \multirow{2}{*}{$\begin{array}{c}\text { Ti Concentration } \\
\left(\mathrm{mg} \cdot \mathrm{L}^{-1}\right)\end{array}$} & \multicolumn{6}{|c|}{ Number of Inflorescences } \\
\hline & $32 \mathrm{DAT}^{\mathrm{b}}$ & $50 \mathrm{DAT}$ & 64 DAT & $80 \mathrm{DAT}$ & $96 \mathrm{DAT}$ & $111 \mathrm{DAT}$ \\
\hline 0 & $2.77 \pm 0.39 \mathrm{a}$ & $20.34 \pm 1.05 \mathrm{a}$ & $31.29 \pm 1.41 \mathrm{a}$ & $19.47 \pm 1.19 \mathrm{a}$ & $15.69 \pm 1.06 \mathrm{a}$ & $1.83 \pm 1.20 \mathrm{a}$ \\
\hline 50 & $3.06 \pm 0.38 \mathrm{a}$ & $19.72 \pm 1.00 \mathrm{a}$ & $26.88 \pm 1.35 \mathrm{ab}$ & $15.58 \pm 1.14 \mathrm{ab}$ & $12.99 \pm 1.01 \mathrm{a}$ & $0.94 \pm 1.15 \mathrm{a}$ \\
\hline 100 & $2.37 \pm 0.39 \mathrm{a}$ & $18.36 \pm 1.03 \mathrm{a}$ & $25.51 \pm 1.39 \mathrm{~b}$ & $15.35 \pm 1.17 \mathrm{ab}$ & $13.15 \pm 1.05 \mathrm{a}$ & $2.66 \pm 1.18 \mathrm{a}$ \\
\hline 150 & $2.79 \pm 0.42 \mathrm{a}$ & $19.82 \pm 1.11 \mathrm{a}$ & $26.11 \pm 1.49 \mathrm{ab}$ & $13.56 \pm 1.26 \mathrm{~b}$ & $12.99 \pm 1.13 \mathrm{a}$ & $4.22 \pm 1.27 \mathrm{a}$ \\
\hline$L$ & $0.38^{\mathrm{NS}}$ & $0.256^{\mathrm{NS}}$ & $0.059^{* * *}$ & $0.018^{* *}$ & $0.095^{* * *}$ & $0.192^{\mathrm{NS}}$ \\
\hline$Q$ & $0.686^{\mathrm{NS}}$ & $0.401^{\mathrm{NS}}$ & $0.038^{* *}$ & $0.039^{* *}$ & $0.16^{\mathrm{NS}}$ & $0.299^{\mathrm{NS}}$ \\
\hline
\end{tabular}

a Mean of 6 replications, 6 plants each \pm standard deviation. LS means Tukey-Kramer separation, similar letters within a column indicate no significant difference.

${ }^{\mathrm{b}}$ Days After Transplanting (DAT).

${ }^{c}$ Significance for linear (L) and quadratic (Q) orthogonal contrasts for Si level.

NS, ${ }^{*}, * * * * *$ Nonsignificant or significant at $P \leq 0.01, P \leq 0.05, P \leq 0.10$, respectively. 


\section{Table 29}

Mean values ${ }^{a}$ of fresh mass on landscape culture for 'Black Velvet Rose F1' geranium (Pelargonium zonale) and 'Mega Bloom Pink Halo F1' vinca (Catharanthus roseus) at the Horticulture Center at Illinois State University for 2019 growing season,

Normal, IL by titanium treatments (Ti Concentration) of 0, 50, 100 and $150 \mathrm{mg} \mathrm{Ti} \cdot \mathrm{L}^{-1}$

\begin{tabular}{ccc}
\hline \multirow{2}{*}{$\begin{array}{c}\text { Ti Concentration } \\
\left(\mathrm{mg} \cdot \mathrm{L}^{-1}\right)\end{array}$} & \multicolumn{2}{c}{ Fresh Mass (g) } \\
\cline { 2 - 3 } 50 & 'Black Velvet Rose F1' Geranium & 'Mega Bloom Pink Halo F1' Vinca \\
\hline 100 & $478.19 \pm 100.08 \mathrm{a}$ & $321.94 \pm 71.47 \mathrm{~b}$ \\
150 & $437.44 \pm 88.48 \mathrm{a}$ & $301.29 \pm 51.07 \mathrm{~b}$ \\
$\bar{\sigma}$ & $324.77 \pm 65.75 \mathrm{~b}$ & $335.34 \pm 77.22 \mathrm{~b}$ \\
Contrast $^{\mathrm{b}}$ & $427.40 \pm 40.87 \mathrm{a}$ & $0.076^{* * *}$ \\
$L$ & $0.118^{\mathrm{NS}}$ & $0.022^{* *}$
\end{tabular}

${ }^{a}$ Mean of 6 replications, 6 plants each \pm standard deviation. Duncan mean separation, similar letters within a column indicate no significant difference.

${ }^{\mathrm{b}}$ Significance for linear (L) and quadratic (Q) orthogonal contrasts for Si level.

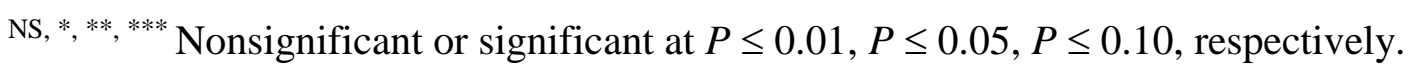




\section{Table 30}

Mean values ${ }^{a}$ of 'Black Velvet Rose F1' geranium (Pelargonium zonale) dry mass on landscape culture at the Horticulture Center at Illinois State University for 2019 growing season, Normal, IL by titanium treatments (Ti Concentration) of 0, 50,100 and 150 mg $T i \cdot L^{-1}$

\begin{tabular}{|c|c|}
\hline Ti Concentration $\left(\mathrm{mg} \cdot \mathrm{L}^{-1}\right)$ & Dry Mass (g) \\
\hline 0 & $81.17 \pm 17.39 \mathrm{a}$ \\
\hline 50 & $72.61 \pm 13.97 \mathrm{a}$ \\
\hline 100 & $53.17 \pm 9.64 b$ \\
\hline 150 & $71.88 \pm 4.66 \mathrm{a}$ \\
\hline \multicolumn{2}{|l|}{ Contrast $^{\mathrm{b}}$} \\
\hline$L$ & $0.096^{* * *}$ \\
\hline$Q$ & $0.017^{* *}$ \\
\hline
\end{tabular}

${ }^{a}$ Mean of 6 replications, 6 plants each \pm standard deviation. Duncan mean separation, similar letters within a column indicate no significant difference.

${ }^{\mathrm{b}}$ Significance for linear (L) and quadratic (Q) orthogonal contrasts for Si level.

NS, ${ }^{*},{ }^{* *},{ }^{* *}$ Nonsignificant or significant at $P \leq 0.01, P \leq 0.05, P \leq 0.10$, respectively. 


\section{REFERENCES}

Aggie Horticulture - Bedding Plants Crop Guide: Small Acreage Horticultural Crops. (n.d.). Retrieved July 03, 2020, from https://aggie-horticulture.tamu.edu/smallacreage/cropsguides/greenhouse-nursery/bedding-plants/

Alcaraz, C., Martinez-Sanchez, F., \& Gimenez, J. (1991). Ascorbato de titanio, fertilizante foliar. Agricultura: Revista Agropecuaria y Ganadera, 636-638.

Alcaraz-López, C., Botía, M., Alcaraz, C. F., \& Riquelme, F. (2004). Effect of foliar sprays containing calcium, magnesium and titanium on peach (Prunus persica L) fruit quality. Journal of the Science of Food and Agriculture, 84(9), 949-954. https://doi.org/10.1002/jsfa.1703

All-America Selections: AAS History: AAS Annual Reports: All-America Selections. (n.d.). Retrieved July 03, 2020, from https://all-americaselections.org/about/ Agriculture Marketing Resource Center - AgMRC - Floriculture. (2018, December). https://www.agmrc.org/commodities-products/specialty-crops/floriculture/

Babalar, M., Edrisi, B., \& Naderi, R. (2016). Evaluation of the mechanical strength of gerbera flower stem in response to silicon and salicylic acid application. Journal of Ornamental Plants, 163-171.

Bacilieri, F. S., Vasconcelos, A. C., Lana, R. M., Mageste, J. G., \& Torres, J. L. (2017). Titanium (Ti) in plant nutrition - A review. Australian Journal of Crop Science, 11(04), 382-386. https://doi.org/10.21475/ajcs.17.11.04.pne202

Barker, A. V., \& Pilbeam, D. J. (2015). Handbook of plant nutrition. CRC Press. 
Barrett, G., Alexander, P., Robinson, J., \& Bragg, N. (2016). Achieving environmentally sustainable growing media for soilless plant cultivation systems - A review. Scientia Horticulturae, 212, 220-234. https://doi.org/10.1016/j.scienta.2016.09.030

Beytes, C. (2003). Ball redbook. Greenhouses and equipment. Ball Publishing.

Black, R. J. (2006, September). Bedding Plants: Selection, Establishment and Maintenance [Blog]. http://blogs.ifas.ufl.edu/collierco/files/2018/03/BeddingPlantsMG31900.pdf Bureau of Economic Analysis (BEA) - Table 2.4.5U. Personal Consumption Expenditures by Type of Product. (2020, July 30). https://apps.bea.gov/iTable/iTable.cfm?reqid=19

Carvajal, M., \& Alcaraz, C. F. (1998). Why titanium is a beneficial element for plants. Journal of Plant Nutrition, 21(4), 655-664. https://doi.org/10.1080/01904169809365433

Carvalho-Zanão, M. P., Villa, F., \& Júnior, L. A. (2017). Gladiolus production and nutritional status as a function of silicon application to the substrate. Pesquisa Agropecuária Tropical, 47(2), 178-185. https://doi.org/10.1590/1983-40632016v4744683

Choi, H. G., Moon, B. Y., Bekhzod, K., Park, K. S., Kwon, J. K., Lee, J. H., . . Kang, N. J. (2015). Effects of foliar fertilization containing titanium dioxide on growth, yield and quality of strawberries during cultivation. Horticulture, Environment, and Biotechnology, 56(5), 575-581. https://doi.org/10.1007/s13580-015-0023-3

Dębicz, R., \& Wróblewska, K. (2012). The effect of silicon foliar application on the development of seasonal ornamental plants. Part I: Sanvitalia speciosa 'sunbini', verbena 'patio blue' and portulaca umbraticola 'duna red'. Acta Agrobotanica, 64(4), 99-106. https://doi.org/10.5586/aa.2011.051 
Dębicz, R., Pawlikowska, A., Wróblewska, K., \& Bąbelewski, P. (2017). The influence of silicon and multinutrient fertilizer on the quality and chemical composition of gazania rigens 'kiss yellow', salvia farinacea 'fairy queen' and verbena 'obsession lilac' plants. Journal of Horticultural Research, 25(1), 35-45. https://doi.org/10.1515/johr-2017-0004

Eichert, T., \& Fernandez, V. (2012). Uptake and release of elements by leaves and other aerial plant parts. In P. Marschner (Author), Marschner's mineral nutrition of higher plants (pp. 71-84). Academic Press.

Emsley, J. (2011). Nature's building blocks: An a-z guide to the elements. Oxford University Press.

Epstein, E. (1972). Mineral nutrition of plants: Principles and perspectives. John Wiley \& Sons. Epstein, E. (1994). The anomaly of silicon in plant biology. Proceedings of the National Academy of Sciences, 91(1), 11-17. https://doi.org/10.1073/pnas.91.1.11

Epstein, E. (1999). Silicon. Annual Review of Plant Physiology and Plant Molecular Biology, 50(1), 641-664. https://doi.org/10.1146/annurev.arplant.50.1.641

Epstein, E. (2001). Chapter 1 silicon in plants: Facts vs. concepts. Silicon in Agriculture Studies in Plant Science, 1-15. https://doi.org/10.1016/s0928-3420(01)80005-7

Epstein, E. (2009). Silicon: Its manifold roles in plants. Annals of Applied Biology, 155(2), 155160. https://doi.org/10.1111/j.1744-7348.2009.00343.x

Epstein, E., \& Bloom, A. J. (2005). Mineral nutrition of plants: Principles and perspectives. Sinauer Associates.

Fernández, V., \& Eichert, T. (2009). Uptake of hydrophilic solutes through plant leaves: Current state of knowledge and perspectives of foliar fertilization. Critical Reviews in Plant Sciences, 28(1-2), 36-68. https://doi.org/10.1080/07352680902743069 
Frantz, J. M., Khandekar, S., \& Leisner, S. (2011). Silicon differentially influences copper toxicity response in silicon-accumulator and non-accumulator species. Journal of the American Society for Horticultural Science, 136(5), 329-338. https://doi.org/10.21273/jashs.136.5.329

Frantz, J. M., Pitchay, D. D., Locke, J. C., Horst, L. E., \& Krause, C. R. (2005). Silicon is deposited in leaves of New Guinea impatiens. Plant Health Progress, 6(1), 15. https://doi.org/10.1094/php-2005-0217-01-rs

Frantz*, J. M., Pitchay, D. S., Locke, J. C., \& Krause, C. (2004). Evaluating silica uptake in bedding plants. HortScience, 39(4). https://doi.org/10.21273/hortsci.39.4.776a

Frantz, J. M., Locke, J. C., Datnoff, L., Omer, M., Widrig, A., Sturtz, D., . . Krause, C. R. (2008). Detection, distribution, and quantification of silicon in floricultural crops utilizing three distinct analytical methods. Communications in Soil Science and Plant Analysis, 39(17-18), 2734-2751. https://doi.org/10.1080/00103620802358912

Frantz, J. M., Locke, J. C., Sturtz, D., \& Leisner, S. (2010). Capítulo 6 Silicon in Ornamental Crops: Detection, Delivery, and Function. In F. Rodriguez (Ed.), Silicio na agricultura: Anais do V Simpósio Brasileiro sobre silício na agricultura (pp. 111-134). Universidade Federal de Vicxosa. https://www.ars.usda.gov/ARSUserFiles/50820500/GPRG/2010PublicationsandSummarie s/SiliconinOrnamentalCrops[Article].pdf.

Grupp, S. (n.d.). Gardening with annuals. Retrieved July 03, 2020, from https://web.extension.illinois.edu/annuals/care.cfm Haghighi, M., \& Daneshmand, B. (2018). Beneficial effect of titanium on plant growth, photosynthesis and nutrient trait of tomato cv. foria. Iran Agricultural Research, 37, 83-88. 
Hall, C. R., Hodges, A. W., \& Haydu, J. J. (2006). The economic impact of the green industry in the United States. HortTechnology, 16(2), 345-353.

https://doi.org/10.21273/horttech.16.2.0345

Hamrick, D. (2003). Ball redbook: Crop production. Ball Publishing.

Hentschel, R. (2018, June 13). Landscape mulch with expectations.

https://extension.illinois.edu/blogs/down-garden-path/2018-06-13-landscape-mulchexpectations

Hessayon, D. G. (2004). The greenhouse expert. Expert Books.

Hogendorp, B. K., Cloyd, R. A., \& Swiader, J. M. (2012). Determination of silicon concentration in some horticultural plants. HortScience, 47(11), 1593-1595.

https://doi.org/10.21273/hortsci.47.11.1593

Hrubý, M., Cígler, P., \& Kuzel, S. (2002). Contribution to understanding the mechanism of titanium action in plant. Journal of Plant Nutrition, 25(3), 577-598.

https://doi.org/10.1081/pln-120003383

Illinois landscape contractors association (ILCA) Sustainable landscape maintenance annual calendar (Publication). (2016, June). https://www.ilca.net/wpcontent/uploads/2016/09/Sustainable_Landscape_Calendar_Finalv3.pdf

International Association of Horticultural Producers (AIPH) \& Union Fleurs - the International Flower Trade Association. (2018) International statistics - flowers and plants 2018.

Ingels, J. E. (1994). Ornamental horticulture: Science, operations \& management. Clifton Park, NY: Delmar/Cengage Learning. 
Irmak, S., Haman, D. Z., Irmak, A., Jones, J. W., Campbell, K. L., \& Crisman, T. L. (2004). Measurement and analyses of growth and stress parameters of viburnum odoratissimum (Ker-gawl) grown in a multi-pot box system. HortScience, 39(6), 1445-1455. https://doi.org/10.21273/hortsci.39.6.1445

Janas, R. (2009) Effect of titanium on the yield and quality of onion seeds. Zeszyty Problemowe Postępów Nauk Rolniczych, 541

Jones, J. B. (2012). Plant nutrition and soil fertility manual. CRC Press.

Kaiser, C., \& Ernst, M. (2019). Bedding plants (Rep. No. CCD-CP-56). Center for Crop Diversification, University of Kentucky College of Agriculture, Food and Environment. http://www.uky.edu/ccd/sites/www.uky.edu.ccd/files/beddingplants.pdf

Kalinowski, K., Wadas, W., \& Borysiak-Marciniak, I. (2018). Tuber quality of very early potato cultivars in response to titanium foliar application. Acta Scientiarum Polonorum Hortorum Cultus, 17(3), 17-28. https://doi.org/10.24326/asphc.2018.3.2

Kamenidou, S., \& Cavins, T. J. (2005). Silicon supplementation practices on cut flowers production. (Unpublished doctoral dissertation). Oklahoma State University.

Kamenidou, S., Cavins, T. J., \& Marek, S. (2008). Silicon supplements affect horticultural traits of greenhouse-produced ornamental sunflowers. HortScience, 43(1), 236-239. https://doi.org/10.21273/hortsci.43.1.236

Kamenidou, S., Cavins, T. J., \& Marek, S. (2009). Evaluation of silicon as a nutritional supplement for greenhouse zinnia production. Scientia Horticulturae, 119(3), 297-301. https://doi.org/10.1016/j.scienta.2008.08.012 
Kamenidou, S., Cavins, T. J., \& Marek, S. (2010). Silicon supplements affect floricultural quality traits and elemental nutrient concentrations of greenhouse produced gerbera. Scientia Horticulturae, 123(3), 390-394. https://doi.org/10.1016/j.scienta.2009.09.008

Kelemen, G.; Keresztes, A.; Bacsy, E.; Feher, M.; Fodor, P.; and Pais, I. (1993) Distribution and intracellular localization of titanium in plants after titanium treatment. Food Structure: Vol. 12 : No. 1 , Article 8. https://digitalcommons.usu.edu/foodmicrostructure/vol12/iss1/8

Kessler, J., Jr. (2004). Growing and marketing bedding plants. (Rep. No. ANR-559). Alabama Cooperative Extension System - Alabama A\&M and Auburn Universities.

Kessler, J., Jr. (2013). Annual bedding plants (Rep. No. ANR-0184). Alabama Cooperative Extension System - Alabama A\&M University and Auburn University.

Kleiber, T. (2016). Effect of titanium application on lettuce growth under Mn stress. Journal of Elementology, (1/2017). https://doi.org/10.5601/jelem.2016.21.2.1120

Kleiber, T., \& Markiewicz, B. (2013). Application of "tytanit" in greenhouse tomato growing. ACTA Scientarum Polonorum, Horturum Cultus, 12(3) 2013, 117-126. Retrieved from http://www.hortorumcultus.actapol.net/pub/12_3_117.pdf

Kováčik, P., Baran, A., Filová, A., Vician, M., \& Hudec, J. (2014). Content changes of assimilative pigments in leaves after fertilizer Mg-titanit application. Acta Fytotechnica Et Zootechnica, 17(02), 58-64. https://doi.org/10.15414/afz.2014.17.02.58-64

Kuzel, S., Hruby, M., Cígler, P., Tlustos, P., \& Van, P. N. (2003). Mechanism of physiological effects of titanium leaf sprays on plants grown on soil. Biological Trace Element Research, 91(2), 179-190. https://doi.org/10.1385/bter:91:2:179

Latimer, J. G. (1991). Growth retardants affect landscape performance of zinnia, impatiens, and marigold. HortScience, 26(5), 557-560. https://doi.org/10.21273/hortsci.26.5.557 
Leatherwood, R., \& Mattson, N. (2015). Adding silicon to the fertilizer program in poinsettia production: Benefits and facts (Publication). Cornell Greenhouse Horticulture.

Lešnik, M., Šerbinek, Ž, \& Vajs, S. (2017). The level of grapevine pathogen infection rate reduction in the application of titanium and silicon based plant strengtheners. Lectures and papers: Presented at the 13th Slovenian conference on plant protection with international participation Rimske Toplice (pp. 236-246). Retrieved from https://www.cabdirect.org/cabdirect/abstract/20183159777.

Liang, Y., Nikolic, M., Bélanger, R., Gong, H., \& Song, A. (2016). Silicon in agriculture: From theory to practice. Springer.

Link, C., \& Ross, D. (1978). Year-round gardening with a greenhouse (Publication No. YS-78 8). University of California.

Lyu, S., Wei, X., Chen, J., Wang, C., Wang, X., \& Pan, D. (2017). Titanium as a beneficial element for crop production. Frontiers in Plant Science, 8. https://doi.org/10.3389/fpls.2017.00597

Ma, J. F., \& Yamaji, N. (2006). Silicon uptake and accumulation in higher plants. Trends in Plant Science, 11(8), 392-397. https://doi.org/10.1016/j.tplants.2006.06.007

Ma, J. (1991). Studies on beneficial effects of silicon on rice plants (Doctoral dissertation, Kyoto University, 1991). University of Kyoto.

Ma, J. F. (2004). Role of silicon in enhancing the resistance of plants to biotic and abiotic stresses. Soil Science and Plant Nutrition, 50(1), 11-18. https://doi.org/10.1080/00380768.2004.10408447

Ma, J. (2007). Silicon. In A. V. Barker \& D. J. Pilbeam (Authors), Handbook of plant nutrition (pp. 681-696). CRC/Taylor \& Francis. 
Ma, J. F., \& Takahashi, E. (1993). Interaction between calcium and silicon in water-cultured rice plants. Plant and Soil, 148(1), 107-113. https://doi.org/10.1007/bf02185390

Ma, J. (2002). Soil, fertilizer, and plant silicon research in Japan. Elsevier.

Ma, J., \& Takahashi, E. (1990). Effect of silicon on the growth and phosphorus uptake of rice. Plant and Soil, 126(1), 115-119. https://doi.org/10.1007/bf00041376

Ma, J., Miyake, Y., \& Takahashi, E. (2001). Silicon as a beneficial element for crop plants. In L. E. Datnoff, G. H. Korndörfer, \& G. H. Snyder (Authors), Silicon in agriculture (pp. 1739). Elsevier Science.

Malinowska, E., \& Kalembasa, S. (2012). The yield and content of Ti, Fe, Mn, Cu in celery leaves (Apium graveolens L. var. dulce Mill. Pers.) as a result of tytanit application. Acta Sci. Pol., Hortorum Cultus, 69-80.

Marcinek, B., \& Hetman, J. (2008). The effect of foliage feeding on the structure of yield, dry weight content and macroelements in the corms of sparaxis tricolor ker-gawl. Acta Sci. Pol., Hortorum Cultus, 89-99.

Marschner, P. (1995). Mineral nutrition of higher plants. Academic Press.

Marschner, H., Oberle, H., Cakmak, I., \& Römheld, V. (1990). Growth enhancement by silicon in cucumber (Cucumis sativus) plants depends on imbalance in phosphorus and zinc supply. Plant Nutrition - Physiology and Applications, 241-249. https://doi.org/10.1007/978-94-009-0585-6_41

Marschner, P. (2012). Marschner's mineral nutrition of higher plants. Academic Press.

Mattson, M. P. (2008). Hormesis defined. Ageing Research Reviews, 7(1), 1-7. https://doi.org/10.1016/j.arr.2007.08.007

Mengel, K., \& Kirkby, E. (1987). Principles of plant nutrition. International Potash Institute. 
Mills, H. A., \& Jones, J. B. (1996). Plant analysis handbook II: A practical sampling, preparation, analysis, and interpretation guide. Micro-Macro Publishing.

Morgan, L. (2016, September 01). The full menu: Beneficial elements for plant growth. https://www.maximumyield.com/the-full-menu/2/977

Morrow, R. C. (2008). LED lighting in horticulture. HortScience, 43(7), 1947-1950. https://doi.org/10.21273/hortsci.43.7.1947

National Agricultural Statistics Service - NASS (2018) Floriculture Crops 2018 Summary. USDA

Nelson, P. V. (2012). Greenhouse operation and management. Pearson Education Limited.

Neto, A. E., Boldrin, K. V., \& Mattson, N. S. (2015). Nutrition and quality in ornamental plants. Ornamental Horticulture, 21(2), 139. https://doi.org/10.14295/aohl.v21i2.809

Niu, G., Rodriguez, D. S., \& Aguiniga, L. (2007). Growth and landscape performance of ten herbaceous species in response to saline water irrigation. Journal of Environmental Horticulture, 204-210.

Njue, G. (2018, December 18). Scheduling bedding plants. https://extension.sdstate.edu/scheduling-bedding-plants

Norman, D. J., \& Chen, J. (2011). Effect of foliar application of titanium dioxide on bacterial blight of geranium and xanthomonas leaf spot of poinsettia. HortScience, 46(3), 426-428. https://doi.org/10.21273/hortsci.46.3.426

Olberg, M. W., \& Lopez, R. G. (2016). High tunnel and outdoor production of containerized annual bedding plants in the midwestern United States. HortTechnology, 26(5), 651-656. https://doi.org/10.21273/horttech03454-16 
Owolade, O., \& Ogunleti, D. (2008). Effects of titanium dioxide on the diseases, development and yield of edible cowpea. Journal of Plant Protection Research, 48(3), 329-336. https://doi.org/10.2478/v10045-008-0042-5

Pais, I. (1983). The biological importance of titanium. Journal of Plant Nutrition, 6(1), 3-131. https://doi.org/10.1080/01904168309363075

Pemberton, H. B., \& Roberson, W. E. (2001). The east Texas bedding plant pack and garden performance trials. HortTechnology, 11(3), 392-396. https://doi.org/10.21273/horttech.11.3.392

Pilon-Smits, E. A., Quinn, C. F., Tapken, W., Malagoli, M., \& Schiavon, M. (2009). Physiological functions of beneficial elements. Current Opinion in Plant Biology, 12(3), 267-274. https://doi.org/10.1016/j.pbi.2009.04.009

Prasad, S., \& Kumar, U. (2005). Greenhouse management for horticultural crops. Agrobios (India).

Prusiński, J., \& Kaszkowiak, E. (2005). Effect of titanium on yellow lupin yielding (Lupinus luteus L.). Electronic Journal of Polish Agricultural Universities (EJPAU), 8. http://www.ejpau.media.pl/volume8/issue2/art-36.html

Radkowski, A. (2013). Leaf greenness (SPAD) index in timothy-grass seed plantation at different doses of titanium foliar fertilization. Ecological Chemistry and Engineering, 167174.

Radkowski, A., \& Radkowska, I. (2013). Effect of foliar application of growth biostimulant on quality and nutritive value of meadow sward. Ecological Chemistry and Engineering, 20, 1205-1211. https://doi.org/10.2428/ecea.2013.20(10)110 
Radkowski, A., Radkowska, I., \& Lemek, T. (2015). Effects of foliar application of titanium on seed yield in timothy (Phleum pratense L.). Ecological Chemistry and Engineering S, 22(4), 691-701. https://doi.org/10.1515/eces-2015-0042

Rangwala, T., Bafna, A., Vyas, N., \& Gupta, R. (2019). Beneficial role of soluble silica in enhancing chlorophyll content in onion leaves. Current Agriculture Research Journal, 7(3), 358-367. https://doi.org/10.12944/carj.7.3.12

Raviv, M., Lieth, J. H., \& Bar-Tal, A. (2019). Soilless culture: Theory and practice. Academic Press.

Reed, D. W. (1996). Water, media, and nutrition for greenhouse crops. Ball Publishing.

Sargent, J. A., \& Blackman, G. E. (1962). Studies on foliar penetration: I. Factors controlling the entry of 2, 4 - dichlorophenoxyacetic acid. Journal of Experimental Botany, 13(3), 348368. https://doi.org/10.1093/jxb/13.3.348

Sivanesan, I., Son, M. S., Soundararajan, P., \& Jeong, B. R. (2014). Effect of silicon on growth and temperature stress tolerance of nephrolepis exaltata 'corditas'. Korean Journal of Horticultural Science and Technology, 32(2), 142-148.

https://doi.org/10.7235/hort.2014.13080

Skocaj, M., Filipic, M., Petkovic, J., \& Novak, S. (2011). Titanium dioxide in our everyday life; is it safe? Radiology and Oncology, 45(4). https://doi.org/10.2478/v10019-011-0037-0

Sommer, M., Kaczorek, D., Kuzyakov, Y., \& Breuer, J. (2006). Silicon pools and fluxes in soils and landscapes-a review. Journal of Plant Nutrition and Soil Science, 169(4), 582-582. https://doi.org/10.1002/jpln.200690016

Synder, E. (2015). Silicon. In A. V. Barker \& D. J. Pilbeam (Authors), Handbook of plant nutrition (pp. 551-562). CRC Press. 
Technavio (November 2018) Global floriculture market 2018-2022. Retrieved from https://www.technavio.com/report/global-floriculture-market-analysis-share-2018?tnplus

The National Gardening Association [NGA] (2019). National Gardening Survey 2019.

Tlustoš, P., Cígler, P., Hrubý, M., Kužel, S., Száková, J., \& Balík, J. (2011). The role of titanium in biomass production and its influence on essential elements' contents in field growing crops. Plant, Soil and Environment, 51(No. 1), 19-25. https://doi.org/10.17221/3551-pse

Van Horen, L. (2017, December). Flourishing flowers, promising plants: Changes in consumer behavior. https://research.rabobank.com/far/en/sectors/regional-foodagri/Flourishing_flowers_promising_plants_Changes_in_consumer_behaviour.html Van Rijswick, C. (2016, November). World floriculture map 2016: Equator countries gathering speed. https://research.rabobank.com/far/en/sectors/regional-foodagri/world_floriculture_map_2016.html

Veatch-Blohm, M. E., Malinowski, M., \& Keefer, D. (2012). Leaf water status, osmotic adjustment and carbon assimilation in colored calla lilies in response to saline irrigation. Scientia Horticulturae, 144, 65-73. https://doi.org/10.1016/j.scienta.2012.06.036

Wadas, W., \& Kalinowski, K. (2017). Effect of titanium on growth of very early-maturing potato cultivars. Acta Scientiarum Polonorum Hortorum Cultus, 16(6), 125-138. https://doi.org/10.24326/asphc.2017.6.11

Wade, G., \& Sparks, B. (2016). Care of ornamental plants in the landscape (Publication No. UGA Cooperative Extension Bulletin 1065). University of Georgia Extension.

Watanabe, T., Broadley, M. R., Jansen, S., White, P. J., Takada, J., Satake, K., . . Osaki, M. (2007). Evolutionary control of leaf element composition in plants. New Phytologist, 174(3), 516-523. https://doi.org/10.1111/j.1469-8137.2007.02078.x 
Whitted-Haag, B., Kopsell, D. E., Kopsell, D. A., \& Rhykerd, R. L. (2014). Foliar silicon and titanium applications influence growth and quality characteristics of annual bedding plants. The Open Horticulture Journal, 7(1), 6-15. https://doi.org/10.2174/1874840601407010006

Wik, R. M., Fisher, P. R., Kopsell, D. A., \& Argo, W. R. (2006). Iron form and concentration affect nutrition of container-grown pelargonium and calibrachoa. HortScience, 41(1), 244251. https://doi.org/10.21273/hortsci.41.1.244

Williams, D. E., \& Vlamis, J. (1957). The effect of silicon on yield and manganese-54 uptake and distribution in the leaves of barley plants grown in culture solutions. Plant Physiology, 32(5), 404-409. https://doi.org/10.1104/pp.32.5.404

Wojcik, P., \& Wojcik, M. (2001). Growth and nutrition of M.26 emla apple rootstock as influenced by titanium fertilization. Journal of Plant Nutrition, 24(10), 1575-1588. https://doi.org/10.1081/pln-100106022

Wróblewska, K., \& Dębicz, R. (2012). The effect of silicon foliar application on the development of season ornamental plants. part II: Argyranthemum frutescens 'blazer rose', xerochrysum bracteatum 'gold', osteospermum ecklonis 'grande pink blush' and gaura lindheimeri 'corinas choice'. Acta Agrobotanica, 64(4), 107-114. https://doi.org/10.5586/aa.2011.052

Zhang, W., Zhu, Z., \& Cheng, C. Y. (2011). A literature review of titanium metallurgical processes. Hydrometallurgy, 108(3-4), 177-188. https://doi.org/10.1016/j.hydromet.2011.04.005 